\title{
تطوير منهاج التربية الرياضية في ضوء متغيرات تكنولوجيا التعليم بمحافظة شمال سيناء
}

\section{أحمد سالم سليمان سليم}

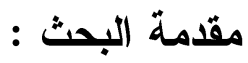

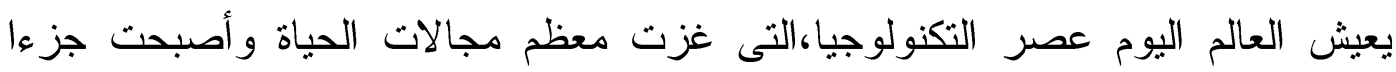

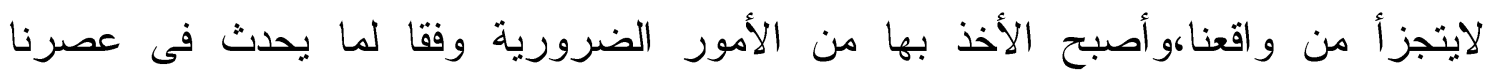

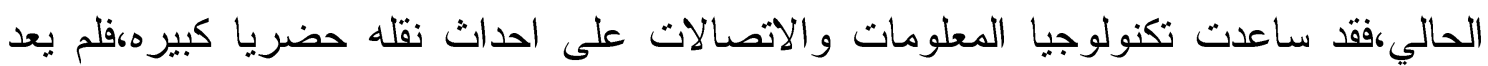
هناك حواجز مكانيه أو زمانيه بين أفراد المجتمع الواحد أو بين أفراد مجتمع وأخر ،وأصبح

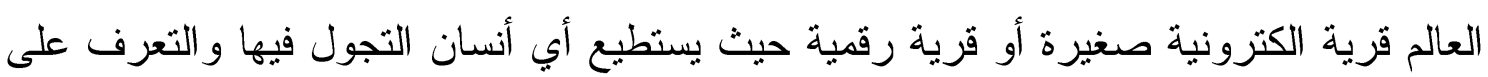
كل مافيها.( (

إن تطوير المناهج من حيث هو نظرة مستقبلية للسياسة العامة إنما يستهدف خلق صورة

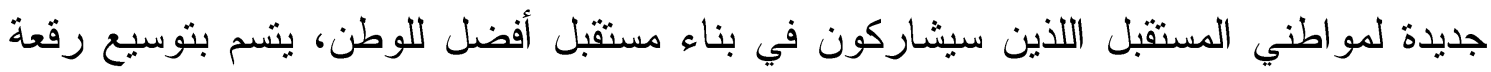
الإنجازات العلمية والتكنولوجية المطلوبة، فلم يعد من المقبول أن تتخلف المناهج عن مجريات

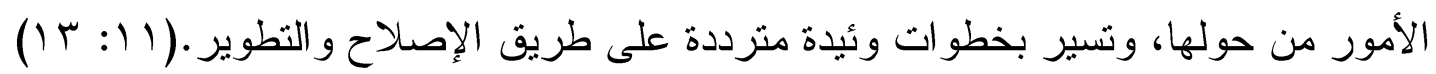
المنهاج هو العمود الفقري للمؤسسة التعليمية ويتوقف نجاح المعلم فى توصيل المادة للطلاب

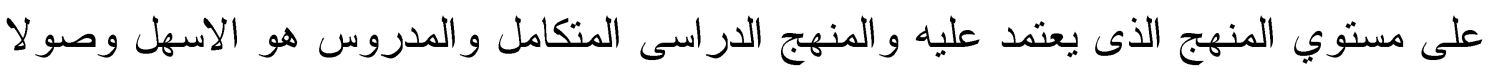

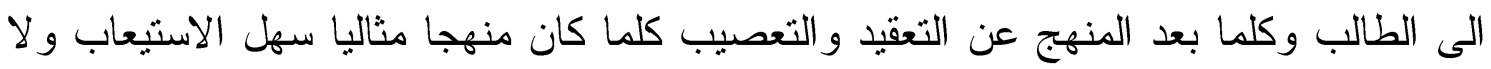

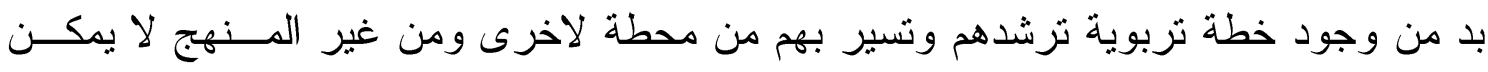

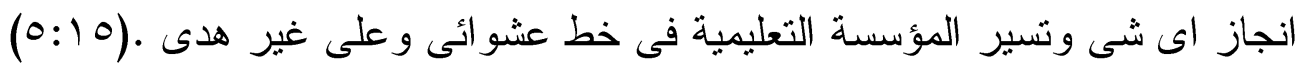

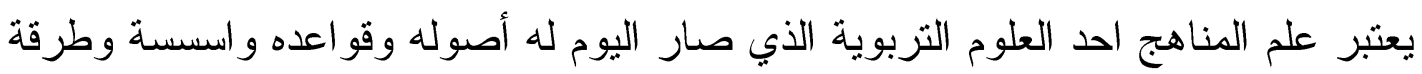
ووسائله ومؤلفاته المتخصصة غير انه من الضروري إعادة النظر والبحث في الأسس النظرية

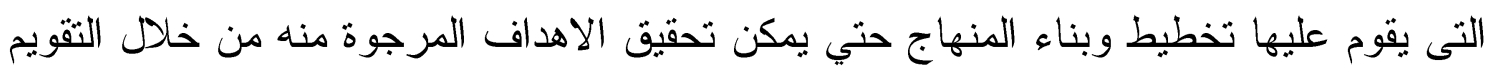

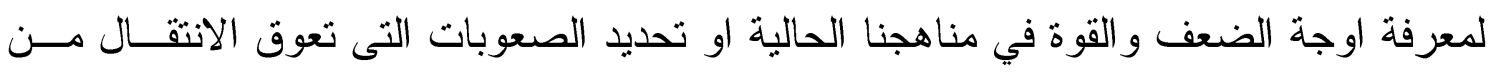
النظرية الى النطبيق.(1: 9 (1)

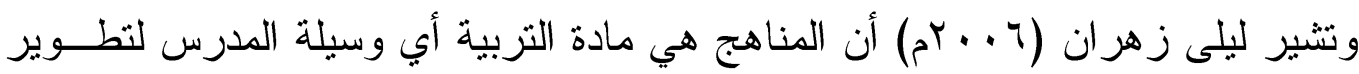

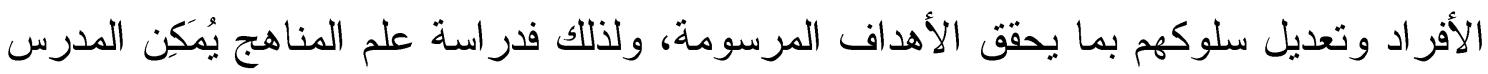
و الددرب من فهم فلسفة التغيير و التطوير الحادث في المتمع و أساليبه و العمليات التي يقتضيها 
تطوير المناهج ومر اجعتها وتغييرها، وبالتالي يستطيع من خلال تطوير مادة التربية الرياضــية

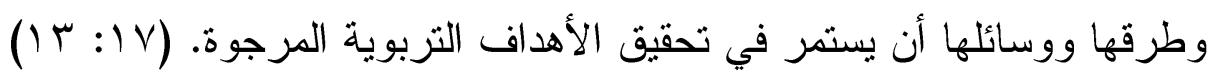

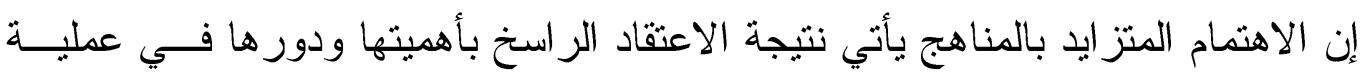

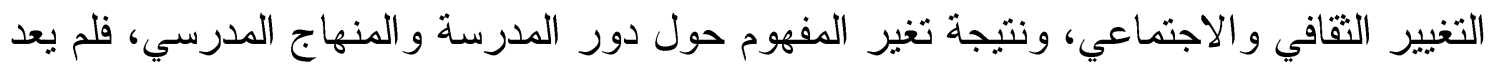

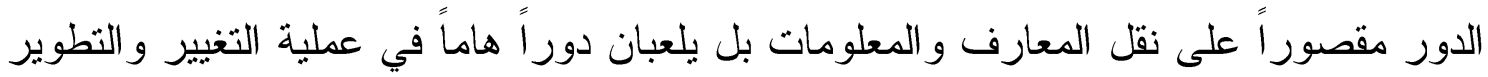

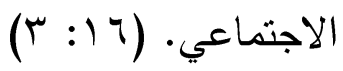

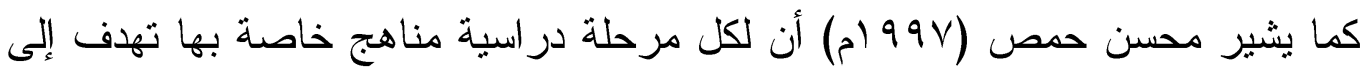
تحقيق النمو الثامل المتكامل لتلاميذ هذه المرحلة من جميع النواحى المعرفية والنفسية وغيرها

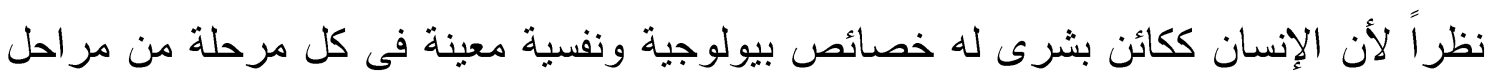

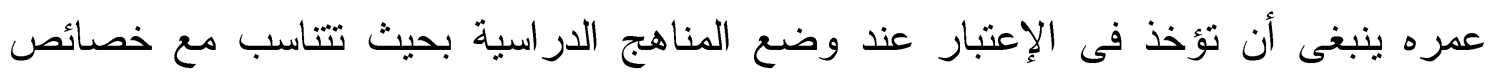

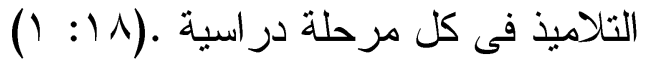

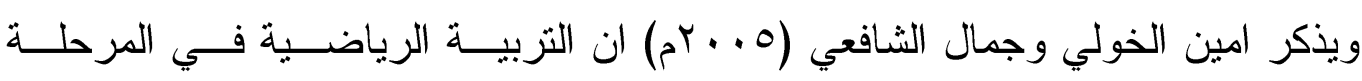

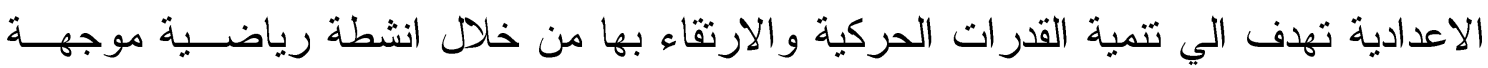

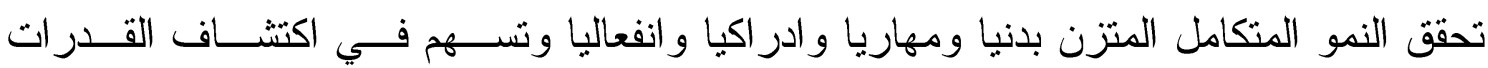

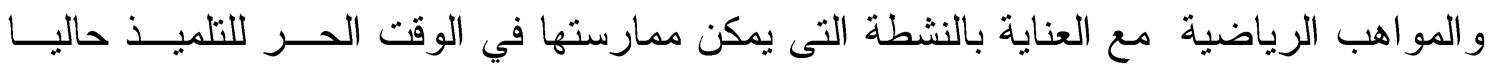

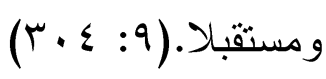

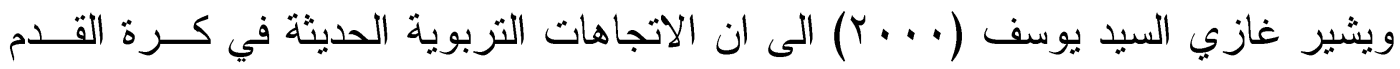

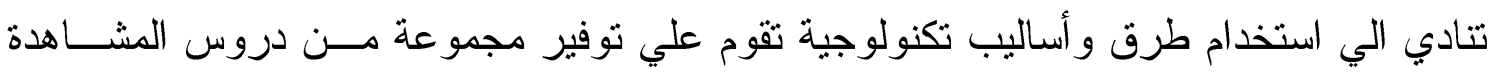

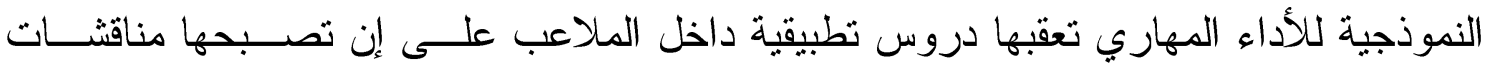

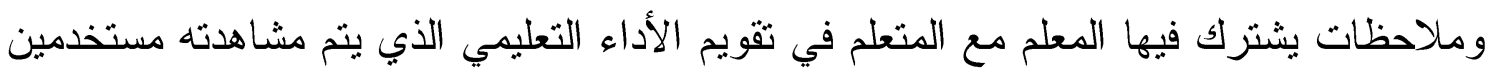
في ذللك كل ما تو افر من وسائل تعليمية كالأفلام و الثر ائح و الأشرطة السينمائية وائية وأجززة التسجيل

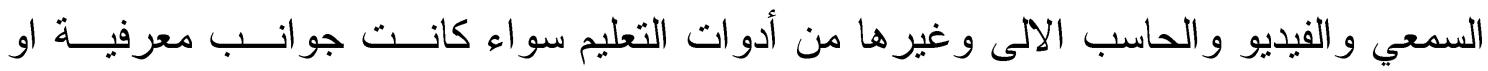

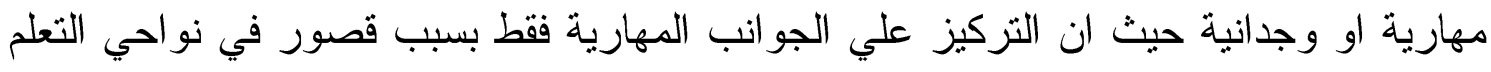

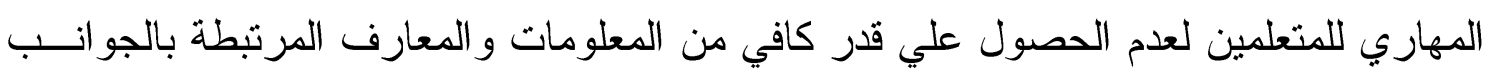

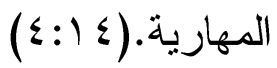

وتعتبر تكنولوجيا التعليم جزء من العملية التعليمية بمعناها الثامل وترتبط بأهداف وطرق

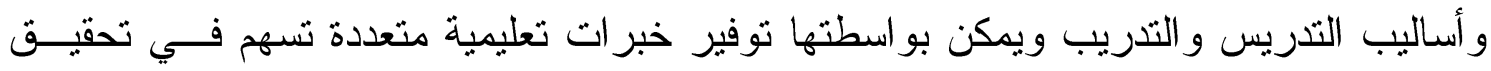

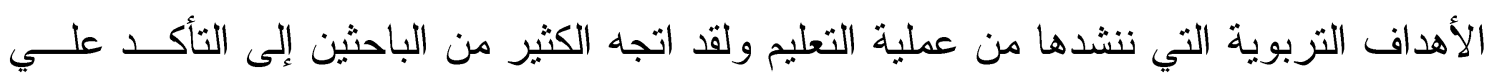


أهمية تكنولوجيا التعليم حتى تحقق العملية التعليمية أهدافها الفعالة ويسود التعلم كل أنو اع النشاط البشرى تقريبا حتى انه لا يكاد يخلو نمط من أنماط السلوك من نوع ما من التعليم و عملية التعليم

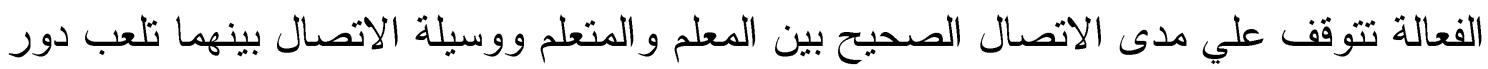

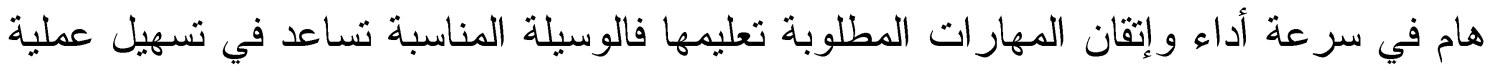

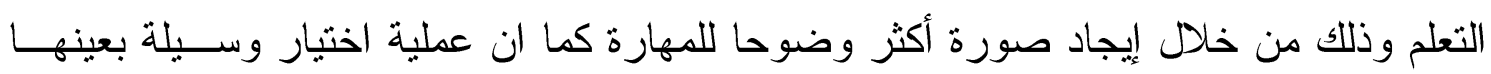

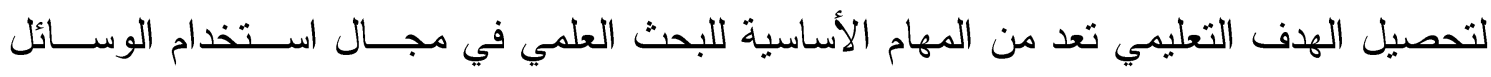

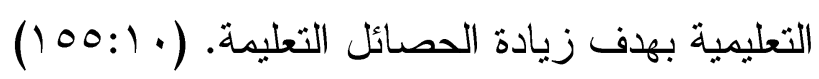
ثنانياً: مشكلة البحث وأهميته:

ويضيف مصطفي حسن عبد الرحمن (1991) انه عند تطبيق تكنولوجيا التعليم نختار التقنيات

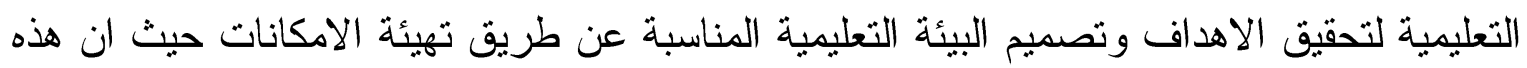
التكنولوجيا ساعدت المتعلم في تكوين مفاهيم جديدة وجعلتة قادر على التعبير عند استيعابة للمادة

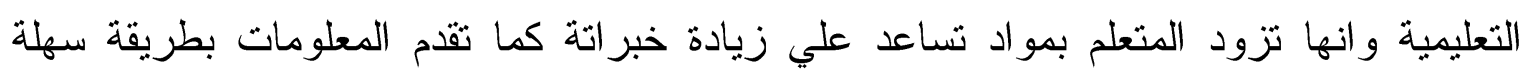

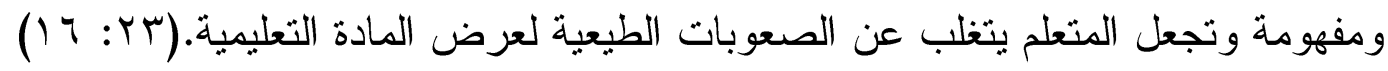
ويرى الباحث أن التربية الرياضية إحدى الأركان الرئيسية لعملية التربية للمرحلة

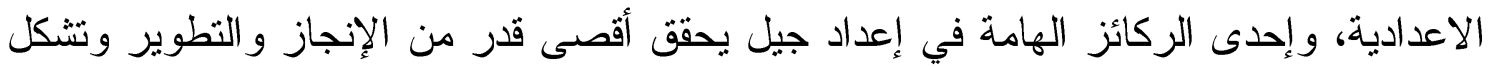

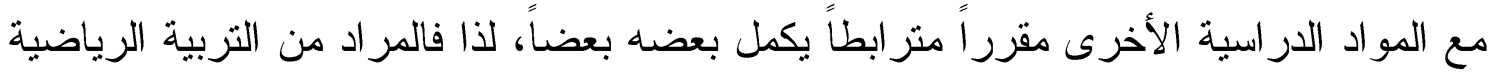

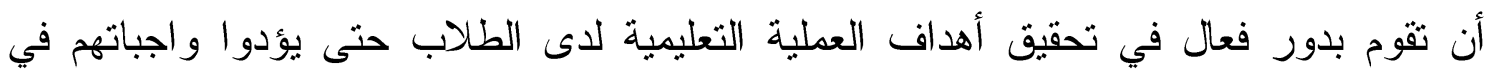
خدمة مجتمعهم.

وتركز التزبية الرياضية في المدارس التعليم الاساسى على التربية عن طريق اللعب

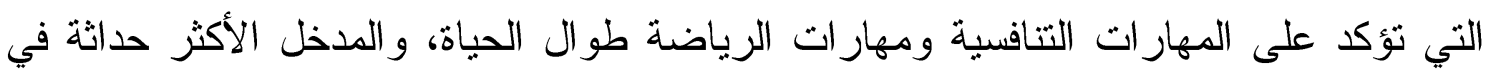

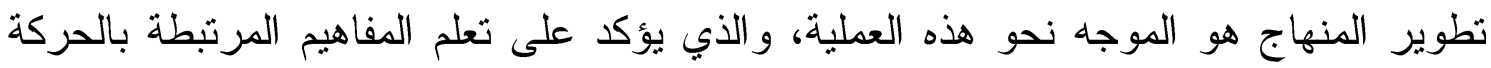
وكذلك تعلم مهار ات الحركة المنوعة، ويؤكد المدخل الإنساني في التربية الرياضية على الهي استخدام

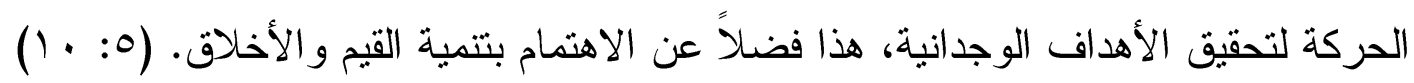
ونظراً لعمل الباحث مدرساً للتربية الرياضية ، و إطلاعه على المقررات الدراسية

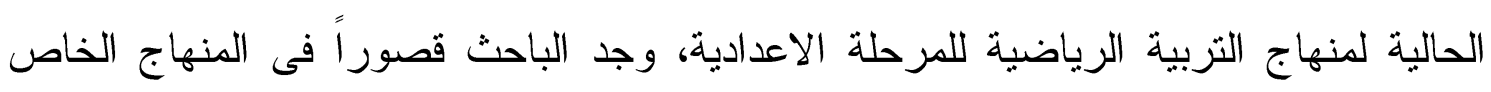

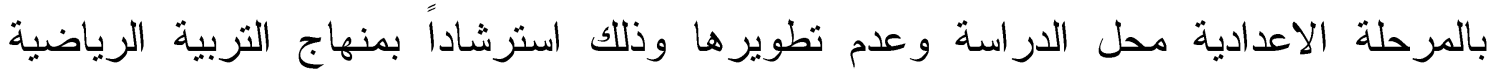

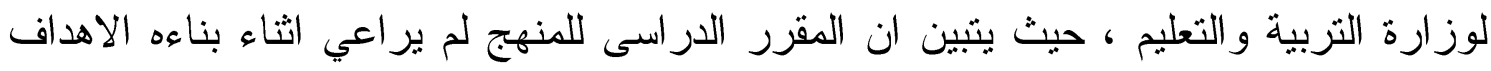

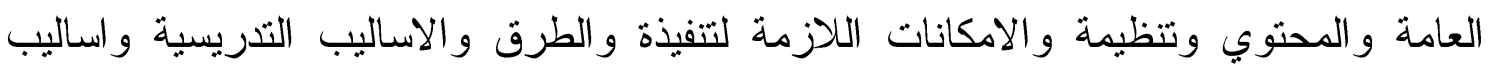


التقويم كل هذه الاسباب ادت الي محاولة القاء الضوء علي هذه الدراسة ومحاولة تطوير منهاج

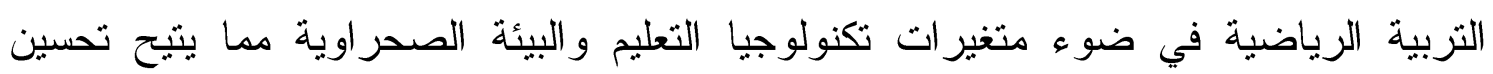

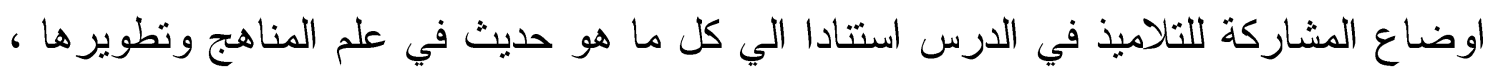
حيث يتطلع التلاميذ في هذه المرحلة إلى رسم خطط مستقبلية فكرية وحسية، ونظراً للنطور الذي طرأ على المجتمع المصري من نطورفي مجال تكنولوجيا التعليم والانفتاح على العالم بطريقة بها تأثير ات سلبية.

فقد وجد الباحث أنه من الأهمية أن يتم تطوير منهاج التربية الرياضية للمراحل الاعدادية بما يتو افق مع متطلبات العصر .

\section{حيث تبرز أهمية هذا البحث فيما يلي:}

1- تطوير منهاج التربية الرياضية للمرحلة الاعدادية بما يناسب التلاميذ و احتياجاتهم.

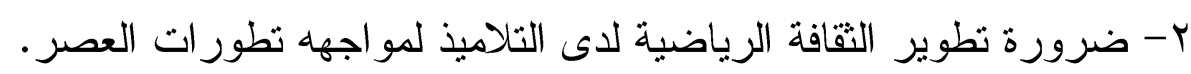

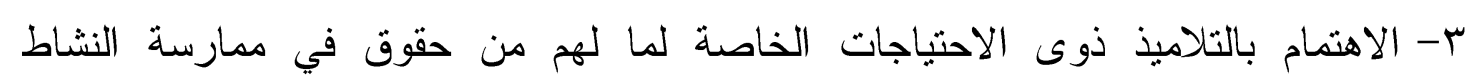
الرياضي. ع - تو عية البيئة المحيطة بأهمية التربية الرياضية. 0- ربط التربية الرياضية بالمو اد الدراسية الأخرى.

ثالثاً: هدف البحث : مبط

يهذف هذا البحث إلى تطوير منهاج التربية الرياضية فى ضوء متغيرات تكنولوجيا

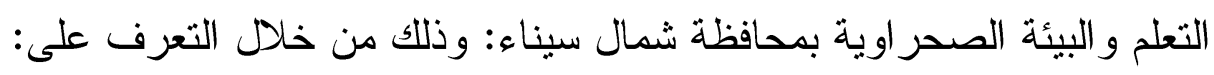

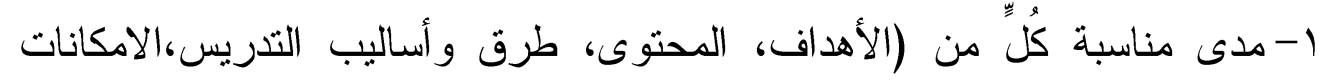
المتاحة وأساليب التقويم) لمنهاج المرحلة الاعدادية قيد الدراسة.

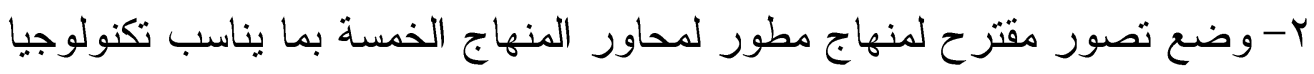

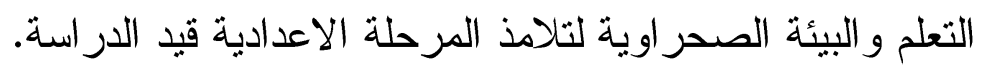

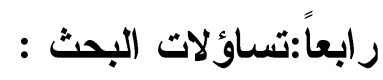
يحاول هذا البحث الاجابة عن هذه التساؤلات :

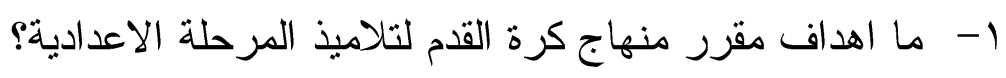

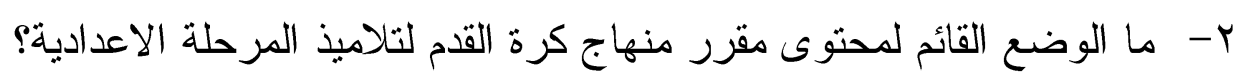

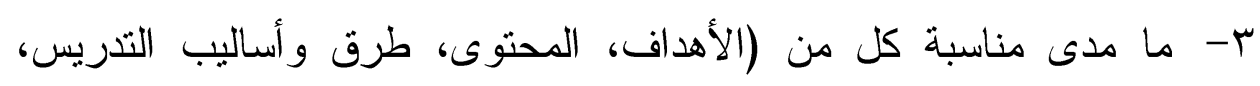

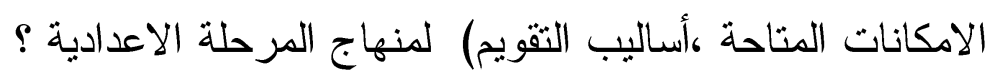


ع- ما التصور المقترح لنظوير المحاور الخمسة لمنهاج المرحلة الاعدادية ؟

خامسا: مصطلحات البحث

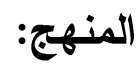

"هو خبرات و أنشطة تربوية و التي تتيحها الدولة للمتعلمين داخل وخارج الددرسة بهدف

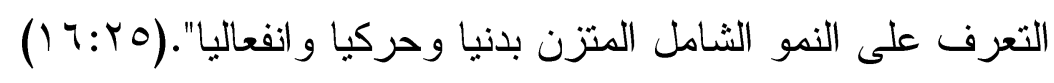

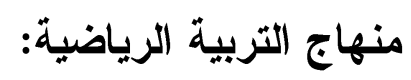

يعرف أبو النجا أحمد عز الدين (.... آم) بأنه هو "جميع المعارف والخبرات والأنشطة

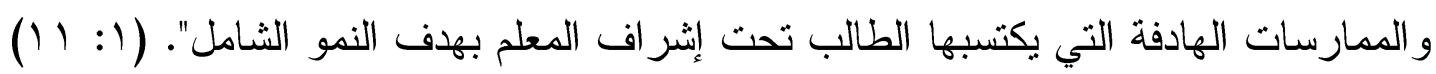

\section{تكنولوجيا التعلم:}

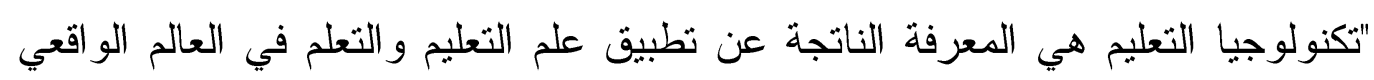

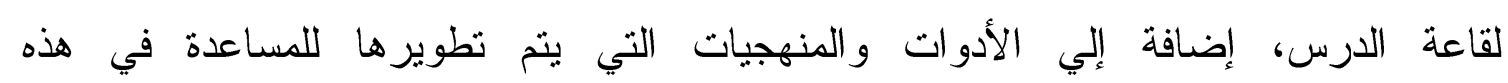

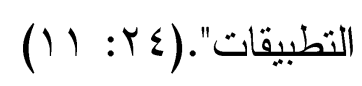

\section{التطوير :}

هو الوصول بالثى المطور او النظام المطور الي احسن صورة من الصور حتي يؤدى

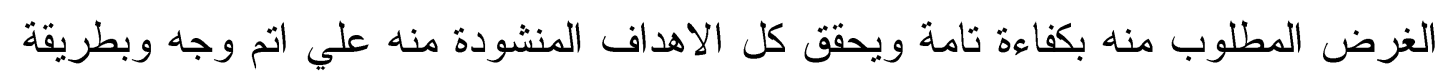

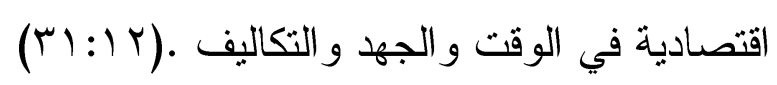

الاراسات السابقة :-

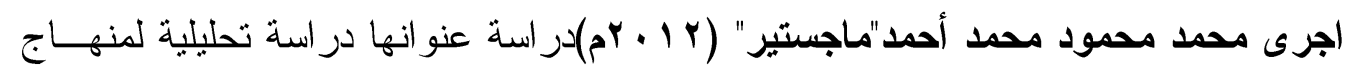

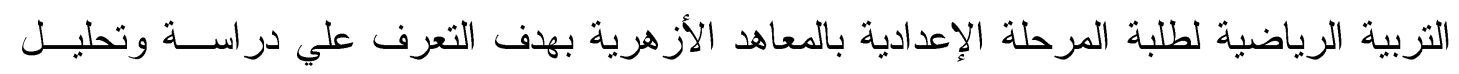

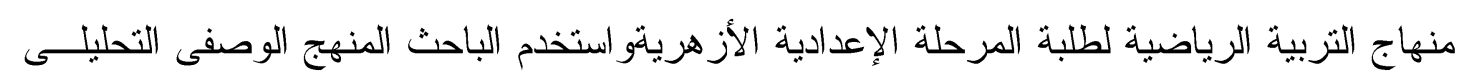

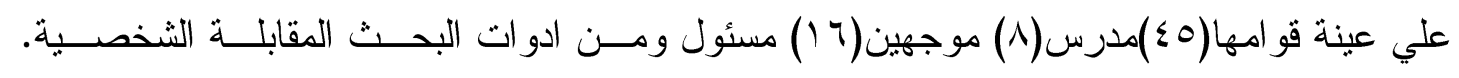

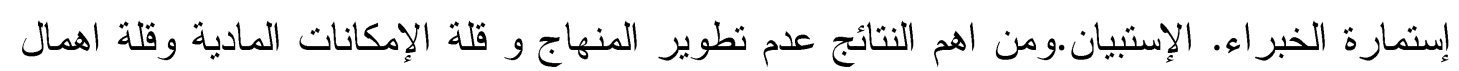
ذوى الإحتياجات الخاصة و المساحات اللازمة للممارسة.

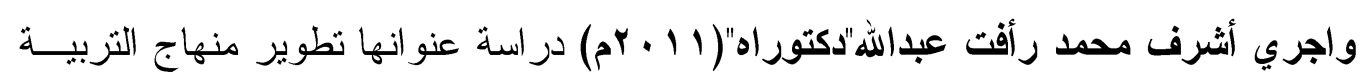

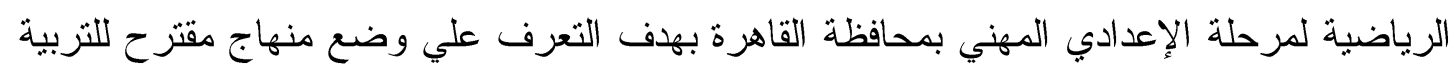

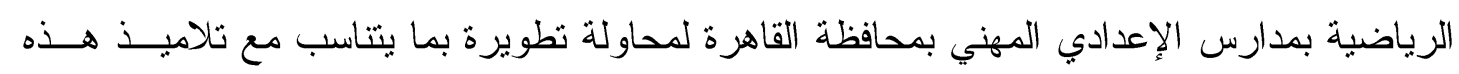

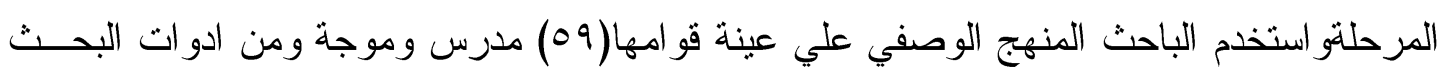

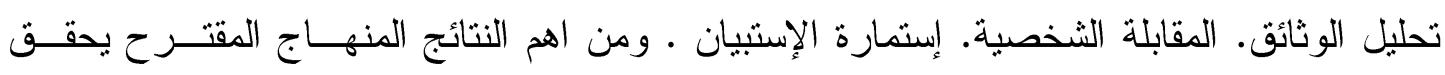


الأهداف الثي وضع من أجلها. وجود نقص فى الإمكانيــات. عـــم الهتـــام المســؤلين بالأنثـــة

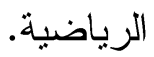

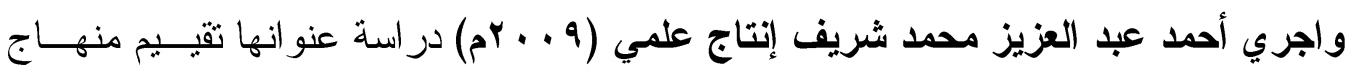

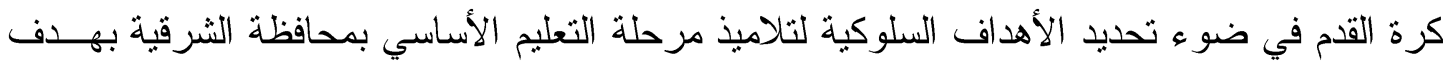

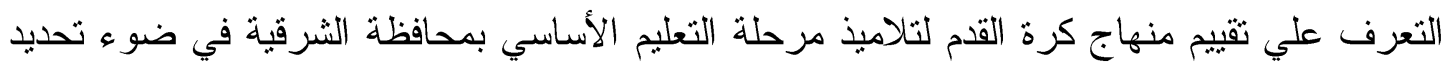

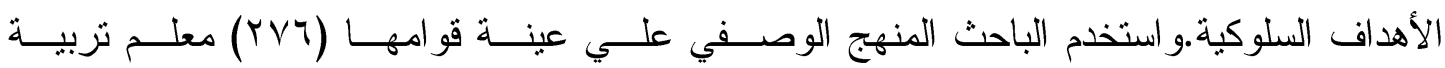

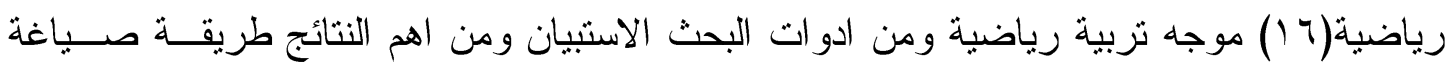

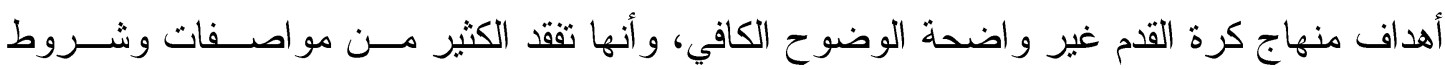

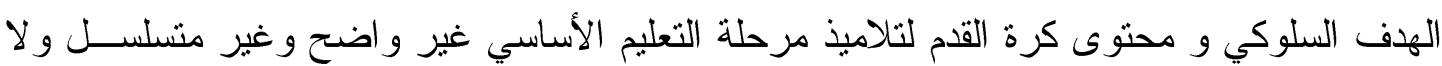
براعى المرحلة السنية.

واجري محمد عبدالنبى توفيق محمد ناصف"ماجستير" (؟ · . rم)در اسة عنو انها دور محتوى مناهج التربية الرياضية ومعلميها فى إكساب بعض القيم الخلقية و الإجتماعية و الجمالية لتلاميذ مرحلة الثانوي العام بجمهورية مصر العربية بهدف التعرف علي القيم الخلقية و الإجنماعية والجمالية التـي يمكن اكسابها لتلاميذ مرحلة الثانوي العام ومدى تو افرها فى محتوى المنهاج ومدى إسهام المعلم فى

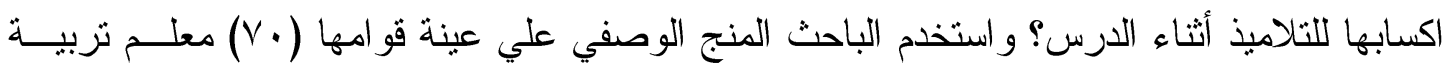
رياضية ومن ادوات البحث الاستبيان وتحليل المحتوى وبطاقة الملاحظة ومن اهم النتــائج طريقـــة

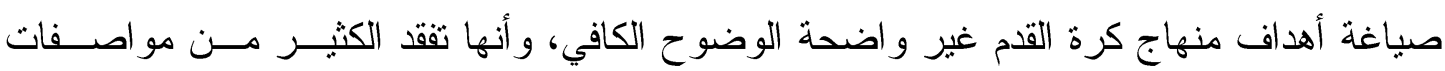
وشروط الهدف السلوكي ومحتوى كرة القدم لتلاميذ مرحلة التعليم الأساسي غيــر و اضــــح وغيــر متسلسل و لا بر اعى المرحلة السنية.

واجري محمد عبدالعاطى عباس"دكتوراه" (ه . . بم) در اسة عنو انها بناء نموذج فلسفى لمنهج التربية البدنية و الرياضة للتعليم ما قبل الجامعى فى سياق النقافة العربية الإسلامية بهدف التعرف علي بناء نموذج فلسفى لمنهج التربية الرياضية للتعليم ما قبل الجامعى فى سياقات الثقافة العربية الإسلامية. و استخدم الباحث المنهج التاريخي علي عينة قو امها(ع) خبر اء ومن ادوات البحث الإستقز اءو و المقابلة الشخصية والإستبيان ومن اهم النتائج نم التوصل إلى بناء نموذج فلسفى لمنهج التربية الرياضية للنعليم ما قبل الجامعى فى سياقات الثقافة العربية الإسلامية. واجريت إيمان محمد عبدالله ربيع (ع ـ . rم) دراسة عنو انها دراسة تحليلية لأهداف مناهج التربية الرياضية بمرحلة التعليم الأساسي بجمهورية مصر العربية بهدف التعرف علي الحالة الراهنة لأهداف مناهج التربية الرياضية بمرحلة التعليم الأساسي. واستخدم الباحث المنهج الوصفي علي عينة

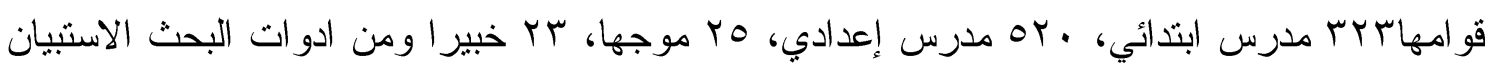
و التحليل الوثائي ومن أهم النتائج ضرورة إعادة صياغة الأهداف العامة و الخاصة لمناهج التربية الرياضية بمرحلة التعليم الأساسي. 
استخدم الباحث المنهج الوصفي بالأسلوب المسحي وذلك لمناسبته لطبيعة البحث وتحقيقا لأهداف.

ثناتياً: مجتمع البحث: قام الباحث باختبار مجتمع البحث من جميع معلمي التربية الرياضية بالمرحلة الإعدادية

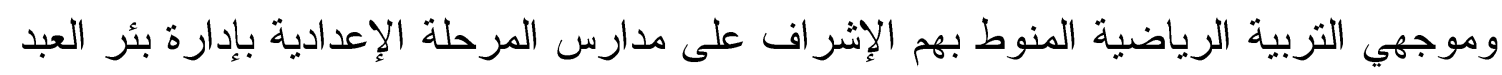

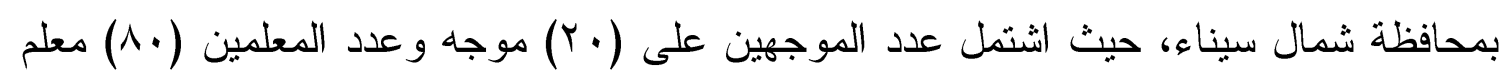
للتربية الرياضية، ليصبح مجتمع البحث ( . (1). ثالثاً: عينة البحث: البث:

اشتملت عينة البحث الأساسية على ( •0) معلم للتربية الرياضية بالمرحلة الإعدادية من بين

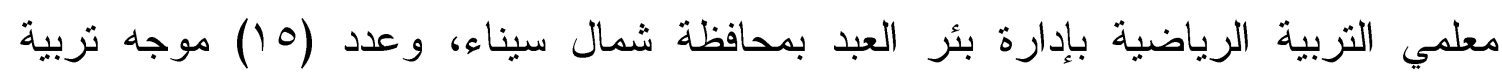
رياضية من المنوط بهم الإشراف و التوجيه على مدارس المرحلة الإعدادية بإدارة بئر العبد بمحافظة شمال سيناء

و لإجر اء الدراسات الاستطلاعية قام الباحث بالسحب العشو ائي من مجتمع البحث لعدد (r) موجه ومن بين معلمي التربية الرياضية وعدد (Y Y) معلم للتربية الرياضية بالمرحلة الإعدادية

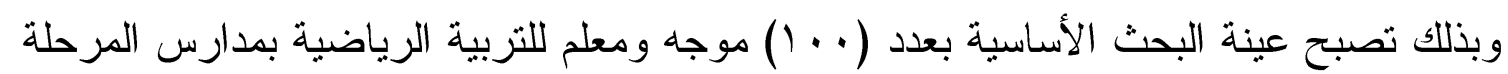

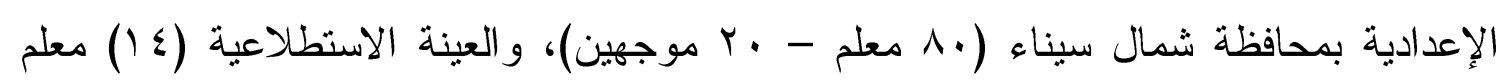
وموجه (r ا معلم - r موجه)، و الجدول التالي يوضح نوصيف مجتمع و عينة البحث.

جدول (1)

توصيف عينة البحث

\begin{tabular}{|c|c|c|c|c|}
\hline مستبعدون & عينة أساسية & عينة استطلاعية & مجتمع البحث & البيـــــــان \\
\hline$r$ & 10 & r & $r$ r. & الموجهين \\
\hline 11 & o. & ir & $\Lambda$. & المعلمين \\
\hline ri & 70 & $1 \varepsilon$ & $1 \ldots$ & الإجمالي \\
\hline
\end{tabular}

يوضح جدول (1) (توصيف العينة ) ان اجمالي مجتمع البحث ( · ل ( معلم وموجه) ثم اختيار

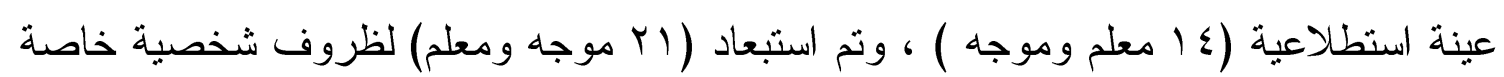

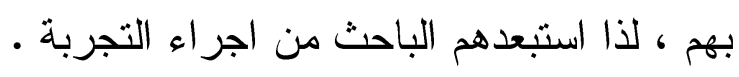


ـ يكون عضو هيئة تدريس لاتقل عن • ا سنوات . ـ يكون من المتخصصين في مجال المناهج وطرق التدريس بكليات التربية الرياضة ذون ذوبن خبرة لا نقل عن · ا سنوات وكذلك في مجال رياضة كرة القدم .

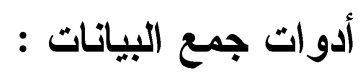
ـ الملاحظة . ــ المقابلة الثخصية . ـ المسح المرجعي الأطر النظرية و الدراسات السابقة وتحليل المحتوى وفحص الوثائق . -

\section{خطو ات بناء الاستبيان :}

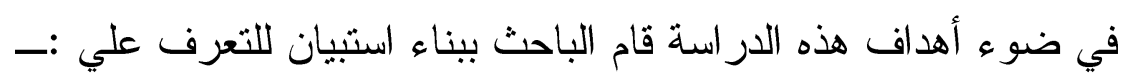

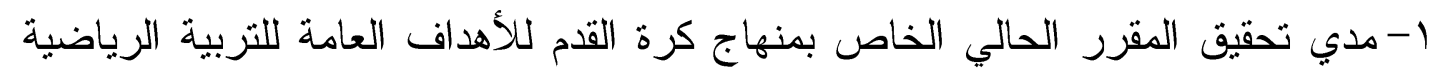

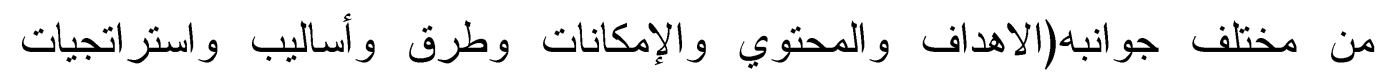

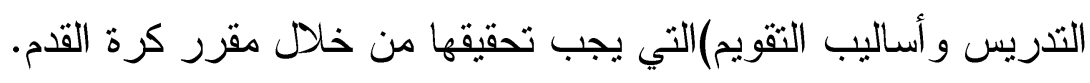
r-ر أب القائمين بالتدريس لدقرر كرة القدم للمرحلة الإعدادية. r-رأى الخبراء في المناهج وطرق التدريس للتعرف علي مدي تحقيق الأهداف العامة للتزبية الرياضية وكذللك جوانب الأهداف( المعرفية ـ النفس حركية ــ الوجدانية )

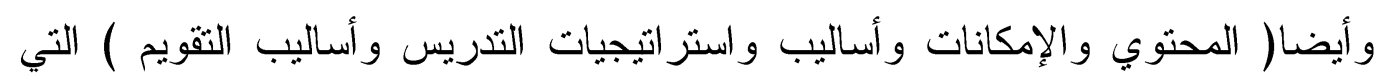
يجب تحقيقها من خلال مقرر كرة القدم.

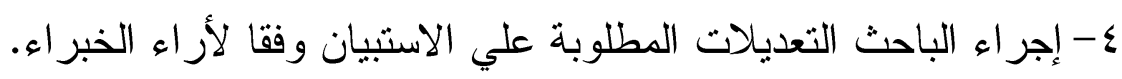

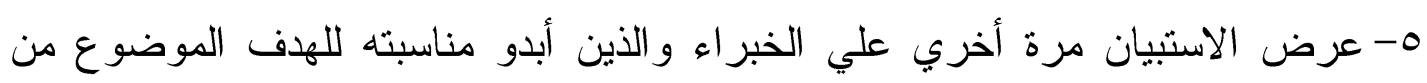
اجله. צ- حدد الباحث ميزان ثلاثي التقدير لاستجابات العينة عليه ( مناسب ـ إلي حدا ما ـ غير

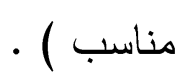

V- إجراء الباحث المعاملات العلمية للاستبيان (الصدق - الثبات ) علي عينة البحث الاستطلاعية للتأكد من مدي قدرته علي تحليل الواقع الحالي لمقرر كرة القدم و إمكانية تطويره . 
بعد المسح المرجعي وتحليل المحتوي و الوثائق والمقابلات الثخصية مع المتخصصين ومر اجعة الاطر النظرية والدراسات السابقة توصل الباحث الي تحديد محاور الاستبيان ( خبراء

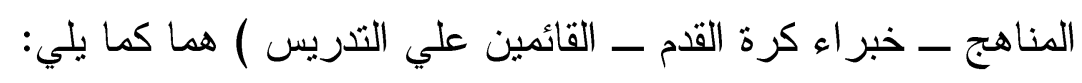

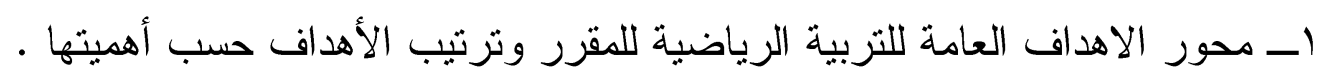

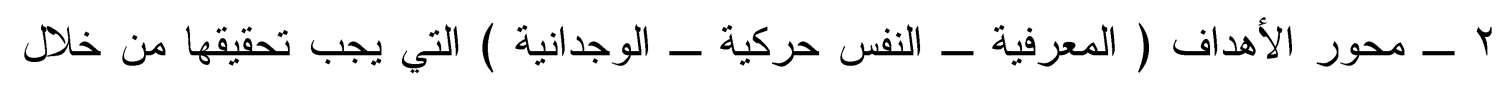
مقرر كرة القدم وترتيبها حسب أهميتها . بــ محور محتوي مقرر كرة القدم لتلاميذ المرحلة الإعدادية .

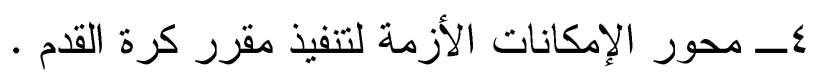

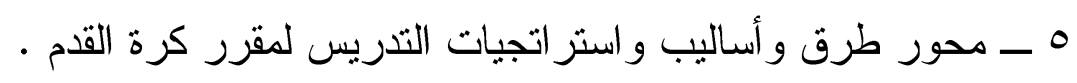
1 - ـ محور اساليب التقويم لمقرر كرة القدم . راي الخبر اء حول مناسبة محاور الاستبيان .

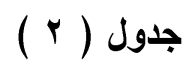

النسبية المئوية لاتفاق أراء الخبراء لتحديد المحاور الأساسية لإستبيان لإستبيان منهاج التربية الرياضية في ن

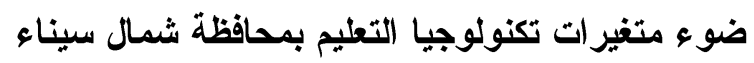

\begin{tabular}{|c|c|c|c|c|c|c|c|}
\hline النسبية المئوية\%\% & غيرمناسب & 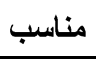 & \multicolumn{2}{|c|}{ عدد العبارات } & \multicolumn{2}{|l|}{ المحاور المقترحة } & b \\
\hline vo... & r... & $7 . .$. & \multirow{4}{*}{$\leqslant 1$} & ir & الاهداف العامة & \multirow{4}{*}{ الأهداف } & \multirow{4}{*}{1} \\
\hline vo... & r... & 7... & & $\wedge$ & الاهداف السلوكية & & \\
\hline Av.०. & $1 \ldots$ & V... & & 1. & النفس حركية & & \\
\hline vo... & r... & 7... & & 1. & الوجداتية & & \\
\hline $1 \ldots$ & $\cdots$ & ^... & \multirow{4}{*}{$r$} & 7 & الجاتب البدني & \multirow{4}{*}{ المحتوى } & \multirow{4}{*}{ r } \\
\hline vo... & r... & $7 .$. & & $\checkmark$ & الجاتب المعرفي & & \\
\hline AV.०. & $1 \ldots$ & v... & & $1 \varepsilon$ & الجاتب المهاري & & \\
\hline $1 \ldots$ & $\cdots$ & А... & & 9 & الجانب الوجداني & & \\
\hline AV.०. & $1 \ldots$ & v... & \multicolumn{2}{|c|}{ rr } & \multicolumn{2}{|c|}{ الإمكانات اللازمة لتففيذ المحتوي } & $r$ \\
\hline vo... & r... & 7... & \multicolumn{2}{|c|}{17} & \multicolumn{2}{|c|}{ الطرق والأساليب والاستر اتيجيات التدريسية } & $\varepsilon$ \\
\hline AV.०. & $1 \ldots$ & v... & \multicolumn{2}{|c|}{17} & \multicolumn{2}{|c|}{ أساليب التقويم } & 0 \\
\hline$\Lambda \varepsilon \ldots q$ & $1 . r v$ & T.VY & \multicolumn{2}{|c|}{ IrA } & \multicolumn{3}{|l|}{ الإجمالي } \\
\hline
\end{tabular}

يوضح جدول(r) النسبة المئوية لإتفاق أراء الخبراء فى المحاور الخمسة الأساسية لإستبيان منهاج التربية الرياضية في ضوء منغير ات تكنولوجيا التعليم و البيئة الصحر اوية بمحافظة شمال

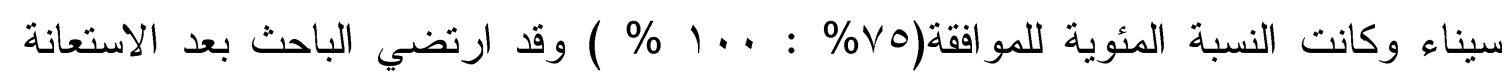

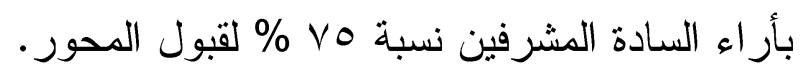


المعاملات العلمية للإستمارة لاستمارة منهاج التربية الرياضية في ضوء متغير اتتكنولوجيا التعليم والبيئة الصحر اوية بمحافظة شمال سيناء. - صدق المحكمين: لقد قام الباحث بعرض إستبيان منهاج التربية الرياضية في ضوء متغير تكنولوجيا التعلــيم

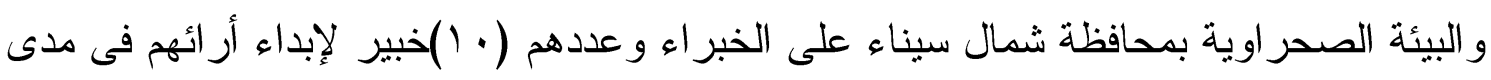

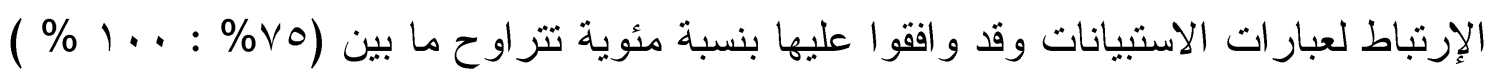
و إعتبر ذلك مؤشر الصدق المحكمين. إعداد عبارات الاستبيان :-

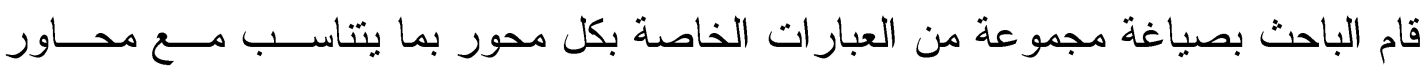

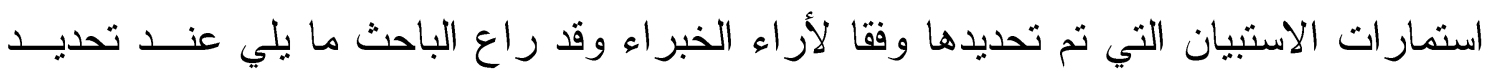

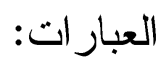

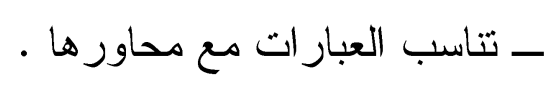

- وضوح صياغة العبار ات لإفراد العينة .

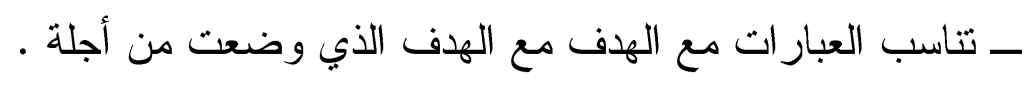
عرض الاستمارة في صورتها المبائية : قام الباحث بعرض الاستمارة في صورتها المبدئية متضمنا المحاور و العبارات التي تمنلها

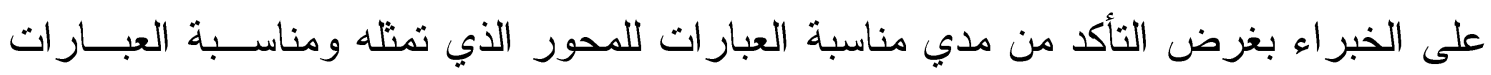

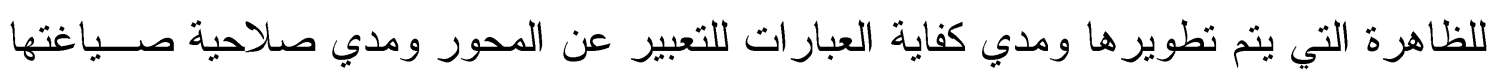

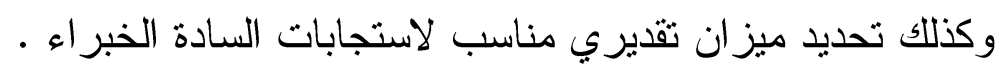

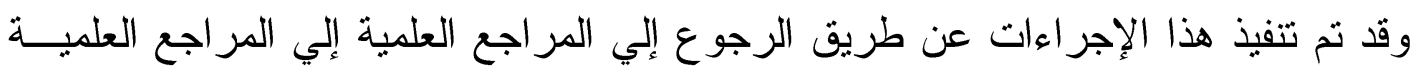

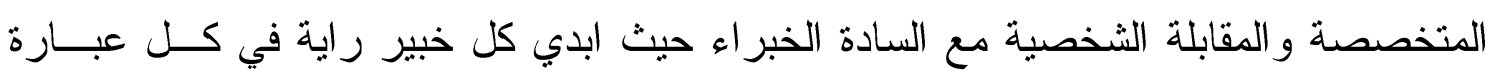

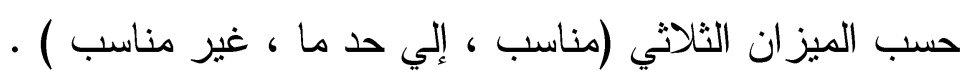
وكذلك رأي الخبر اء في صلاحية محاور الاستبيان و المفردات التي يحتويها هذا الاســنبيان

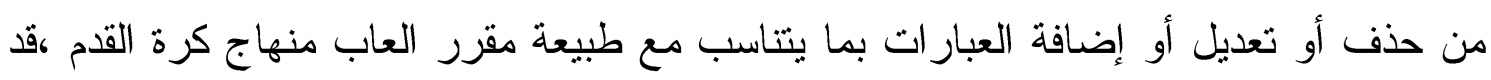

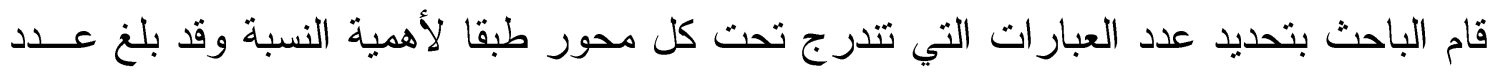

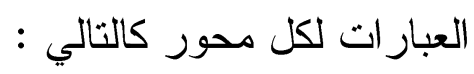




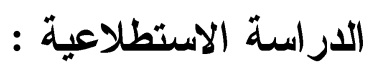

قام الباحث بتطبيق استمارة الاستبيان علي العينة الإستطلاعية وعددها (ع () من الموجهين

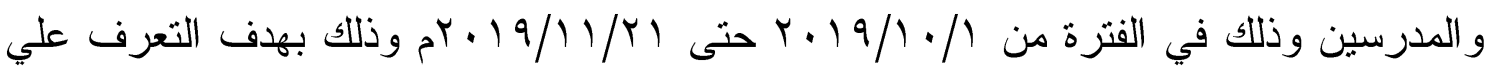

ـ تحديد الصعوبات التي قد تو اجه العينة الأساسية . ـ التأكد من سهولة الاختيار من الاستجابات .

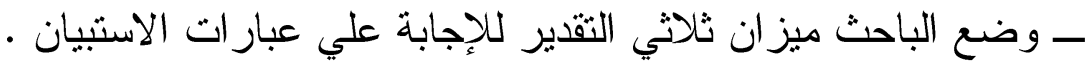

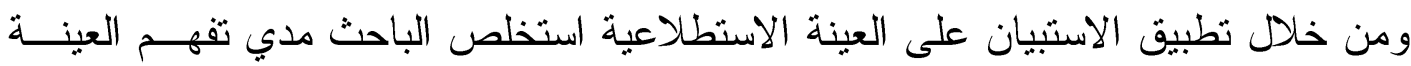
الاستطلاعية لعبار ات الاستبيان من خلال إجابتهم حيث وجدت انهه لا توجد عبار ات تحمل أكثر الانر من تفسير واحد اوعبار ات غامضة في معناها ومفهومها ومن ثم إجر اء المعلومات العلمية للعينة

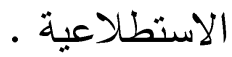

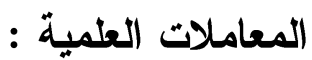

قام الباحث بإجر اء صدق وثبات الاستبيان بالطريقة العلمية .

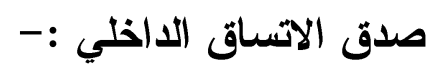

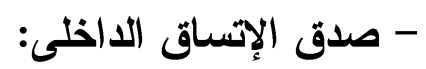
تم إستخدام صدق الإتساق الإخلى بين درجات كل عبارة و الارجة الكلية للمحور الخـاص بالعبارة وقد تم تطبيق الإستمارة على العينة الإستطلاعية وعددها (ع ()من الموجهين و والمدرسين

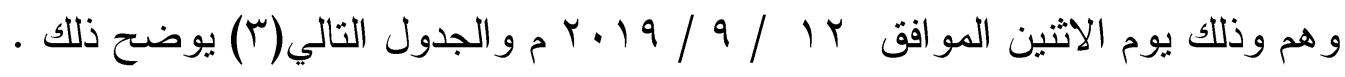

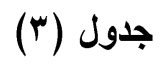

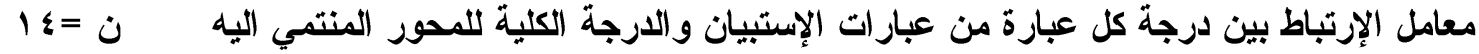

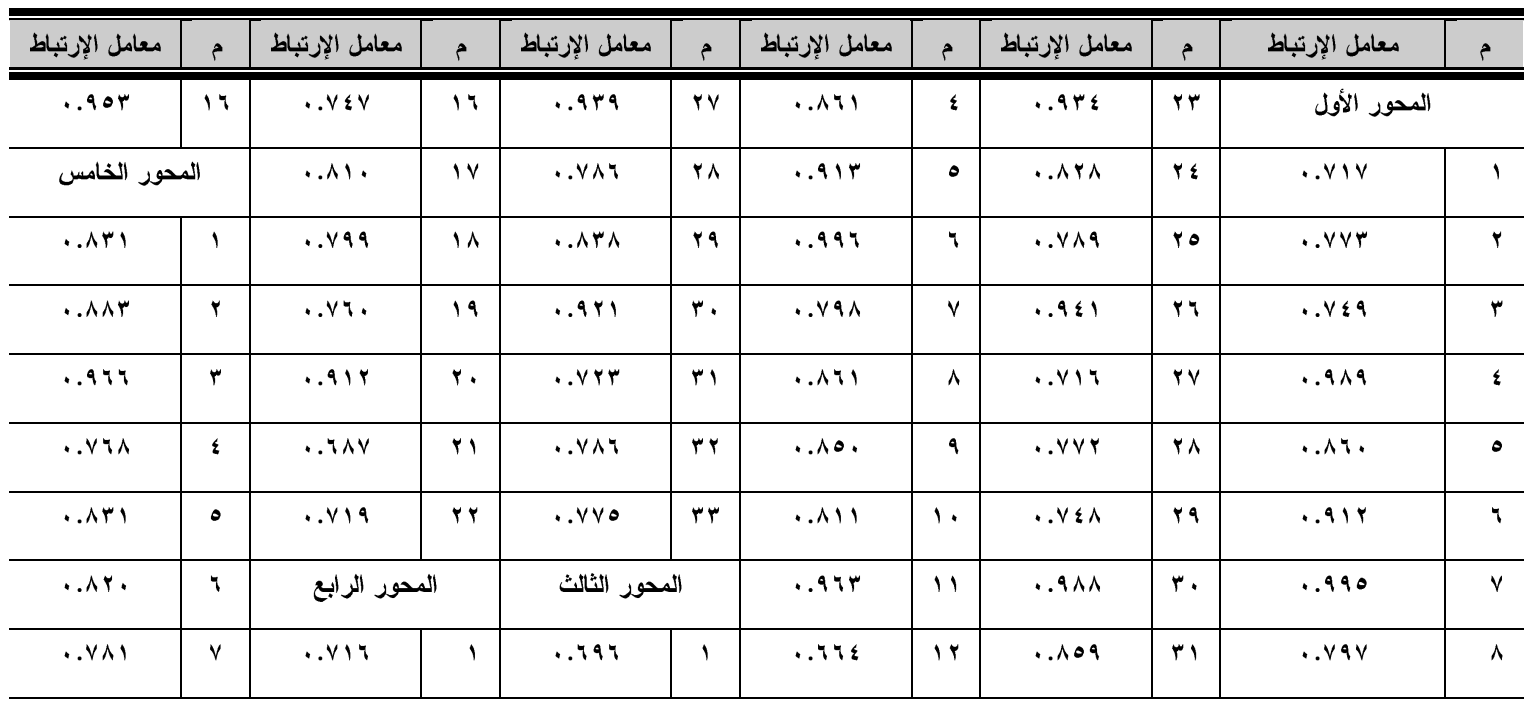




\begin{tabular}{|c|c|c|c|c|c|c|c|c|c|c|c|}
\hline r & $\wedge$ & .904 & $r$ & & $r$ & .vr. & ir & .9911 & rr &.$\wedge 4$. & 9 \\
\hline$\cdot v \cdot 1$ & 9 & . Arv & $r$ & $\cdots A \cdot V$ & $r$ & .790 & $1 \varepsilon$ & . ११६ & r & $\therefore \wedge \leqslant q$ & 1. \\
\hline$\because v \varepsilon$. & 1. & . Av 9 & $\varepsilon$ & .109 & $\varepsilon$ & .940 & 10 & . . १९५ & $r \varepsilon$ &.$\wedge 1$. & 11 \\
\hline .91 & 11 & .94 & 。 & $.9 \leq r$ & 。 &. $.1 \cdot 4$ & 14 &. .109 & ro & .974 & ir \\
\hline. .101 & Ir & 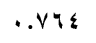 & 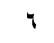 & $\because v \varepsilon \varepsilon$ & 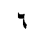 &.$\wedge \bullet \wedge$ & IV & $. \wedge \leqslant \wedge$ & rq & .vrv & ir \\
\hline .9 .4 & ir & . ArV & v & $\cdot \cdot \cdot \cdot v$ & v & $.9 \leqslant 1$ & 11 & $\cdot .1 \cdot 9$ & rv & . . & $1 \varepsilon$ \\
\hline . .914 & $1 \varepsilon$ & . & $\wedge$ & .V१ & $\wedge$ & $\therefore V \leqslant r$ & 19 & 1.971 & rA & . VOr & 10 \\
\hline.$\vee \vee \wedge \wedge$ & 10 & $\because \vee \vee \vee$ & 9 & $\because v \circ v$ & 9 &. $.1 \cdot 4$ & r. & . & rq & .VrA & 17 \\
\hline . 101 & 19 & .949 & 1. & .9 .9 & 1. & $\because \vee q 0$ & rI &..$v \backslash A$ & $\varepsilon$. & $.9 \div \wedge$ & IV \\
\hline & & $\because \backslash \wedge \wedge$ & 11 &.$\top \wedge \varepsilon$ & 11 & . vor & Yr & $.79 \varepsilon$ & \&1 & .Arq & 11 \\
\hline & & $\because V \varepsilon \varepsilon$ & ir & $\because \vee v \varepsilon$. & ir & $\cdot 9 \cdot 1$ & rr & \multicolumn{2}{|c|}{ المحور الثاني } & $\because \wedge 91$ & 19 \\
\hline & & .VY. & ir &.$\wedge 1$ & ir & . & r & . .var & 1 & $.9 \vee \leqslant$ & r. \\
\hline & & .97 & $1 \varepsilon$ & - A & $1 \varepsilon$ & .VRTY & ro &. .879 & $r$ & $\because \vee \vee 4$ & ri \\
\hline & & . & 10 & $.9 \leqslant 0$ & 10 & .7999 & rq & $.90 \varepsilon$ & $r$ &. $.1 r q$ & rY \\
\hline
\end{tabular}

* قيمة " ر " الجدولية عند مستوي معنوية ( 0. . ) ودرجات حرية 1^= ؟ ؟ . .

يتضح من الجدول (ب) أن جميع معاملات الإزتباطات لكل عبارة بالدرجة الكلية دالة إحصائياً عند

جدول (乏)

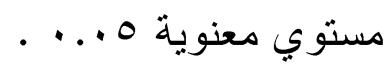

معامل الإرتباط بين درجة كل محور من محاور الإستبيان والارجة الكلية لإستبيان

\begin{tabular}{|c|c|c|}
\hline معامل الإرتباط & المحاور & م \\
\hline$\because V Y q$ & المحور الأول & 1 \\
\hline .979 & المحور الثاني & $r$ \\
\hline$\cdot . \wedge r v$ & المحور الثالث & $r$ \\
\hline$\cdot . \wedge \wedge q$ & المحور الرابع & $\varepsilon$ \\
\hline. $.9 \vee r$ & المحور الخامس & 0 \\
\hline
\end{tabular}

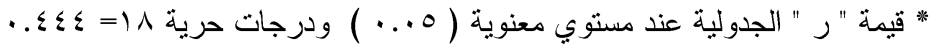

يتضح من الجدول (ع) أن جميع معاملات الإرتباطات لكل محور مرتبط بالدرجة الكلية

للإستبيان دالة إحصائياً عند مستوي معنوية ه م. . . . 
حيث قام الباحث بتطبيق الإستمارة على العينة الاســنطلاعية وعـددها . أمـن أسـاتذة

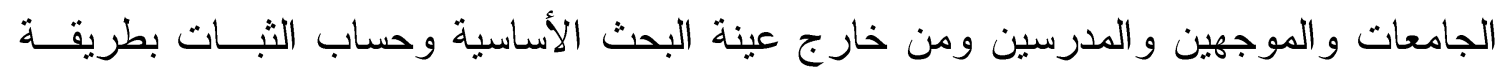

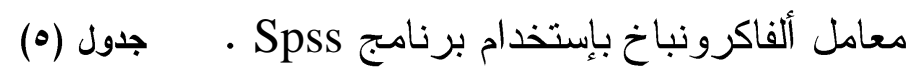

\begin{tabular}{|c|c|c|c|c|c|c|c|}
\hline ن & & جية للإستب & ت ت الفردية & إنباخ بين (ا) & ومعامل ألف و و & ع عامل الإرتب & \\
\hline \multirow{2}{*}{ كرونباخ } & \multirow[b]{2}{*}{ بين الجزئين } & \multicolumn{2}{|c|}{ العبارات الزوجية } & \multicolumn{2}{|c|}{ العبارات الفردية } & \multirow[b]{2}{*}{ العبارات } & \multirow[b]{2}{*}{ البيان } \\
\hline & & المعياري & الحستب المسط & المعباري & الحسابي & & \\
\hline..$\wedge r \wedge$ & "..vor &. .10 & T.1\& &. .14 & r.. 9 & IrA & الإنتشيان \\
\hline
\end{tabular}

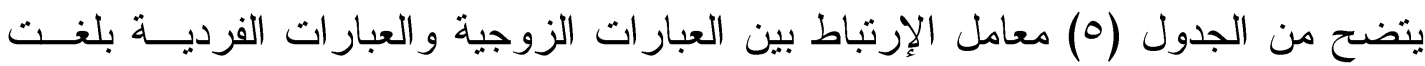

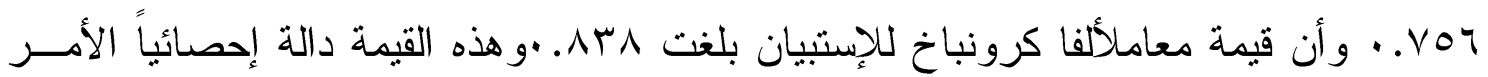
الذى يؤكد أن الإستبيان ذو معامل ثبات عالى. الار اسدة الاساسبة : الاسية قام الباحث بتطبيق الاستبيان عل معلمي التربية الرياضية بالمرحلة الإعداديــة ومــوجهي لإيـي

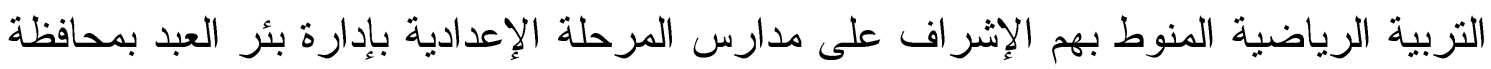

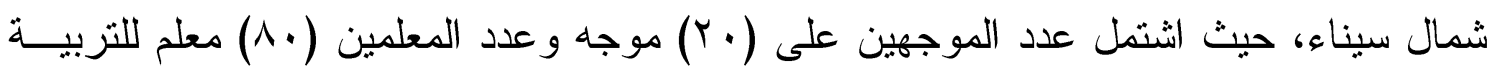

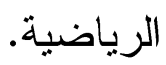

وبعد الانتهاء من تطبيق الاستبيان ثم تفريغها في الكشوف المعدة لذلك تمهيـــا لمعالجتهـــا

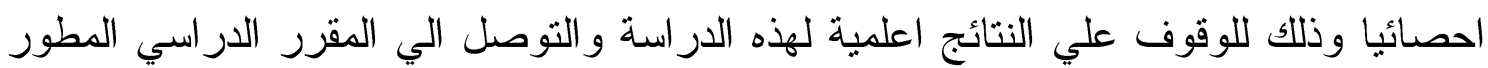
الخاص بكرة القدم لطلاب المرحلة الاعدادية . المعالجات الإحصائية|المستخدمة:بعد الإنتهاء من التطبيق قام الباحث بجدولة البيانات الخاصة بالبحث ومعالجتها إحصائياً،

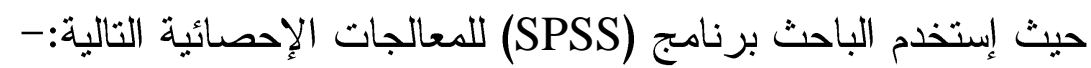

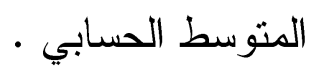

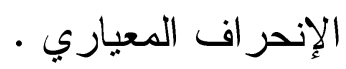

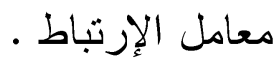


معامل ألفا كرونباخ - (ختار

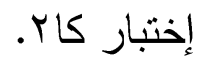

النسبة المئوية.

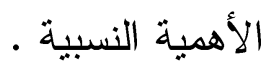

مرض ومناقشية النتائج:

(7) (7)

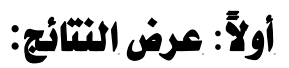

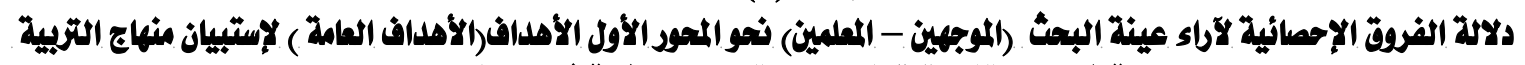

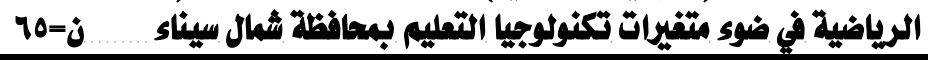

\begin{tabular}{|c|c|c|c|c|c|c|c|c|c|c|}
\hline \multirow{3}{*}{$\begin{array}{l}E_{i} \\
E:\end{array}$} & \multirow{3}{*}{ 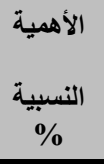 } & \multirow{3}{*}{ كLا } & \multicolumn{6}{|c|}{ الإســتجابات } & \multirow{3}{*}{ العبـــارات } & \multirow{3}{*}{ b } \\
\hline & & & \multicolumn{2}{|c|}{ غير مناسب } & \multicolumn{2}{|c|}{ الى حـ ما } & \multicolumn{2}{|c|}{ مناسب } & & \\
\hline & & & $\%$ & ك & $\%$ & ك & $\%$ & ك & & \\
\hline 9 & $1 \cdot .07$ & $* v_{.} \ldots$ & $17.7 \mathrm{~V}$ & $\varepsilon$ & ro... & $7 . \cdots$ & O^.r & $1 \leq . \cdots$ & والانحرابات النواحي القوامية والمعرفية الهامة لبعضية الوقائية & 1 \\
\hline 9 & $1 . .07$ & $* 4 . Y_{0}$ & $1 Y .0$. & r... & rr.rr & $\Lambda_{.} .$. & $0 \leqslant .1 V$ & $1 r .$. & القوام السليم. التلميذ الوعي الصحي وشروط & $r$ \\
\hline$r$ & $\wedge \vee .0$. & $* 1 \wedge . \vee 0$ & 14.0. & r... & $1 Y .0$. & r... & vo... & $1 \Lambda_{.} \ldots$ & 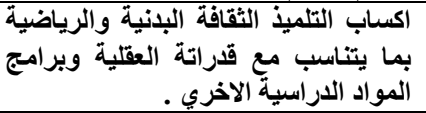 & $r$ \\
\hline$r$ & $\Lambda \varepsilon . V Y$ & $* 10.40$ & $17.7 \mathrm{~V}$ & $\varepsilon .$. & $1 Y .0$. & r... & $v \cdot . \wedge r$ & $1 v_{.} \ldots$ & والمقانونية التيذاصة المعارف والقنطة الرياضية الفنية & $\varepsilon$ \\
\hline$r$ & $\Lambda \varepsilon . V Y$ & $* 1 . . v 0$ & N.rr & r... & rq.1V & $v_{.} .$. & $7 Y .0$. & $10 .$. & التلاميذ . وتنمية الصفات البلنية للي & 0 \\
\hline$r$ & $\Lambda \varepsilon . V Y$ & $* 1 \cdot . v 0$ & $\varepsilon .1 V$ & $1 . \cdots$ & $r v .0$. & $9 . \cdots$ & O^.r & $1 \leq .$. & تاسليمية لبعض التلميذ المهنارات الرياضية. الرياضية & 7 \\
\hline 1 & $q \cdot . r \wedge$ & *Y.VD & N.r & r... & Ir.0. & r... & Vq.IV & $19 . \ldots$ & 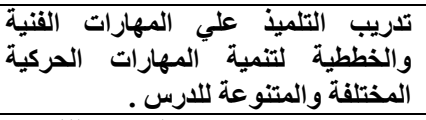 & v \\
\hline ir & V५.rq & r.ro & $r \cdot . \wedge r$ & $0 .$. & rq.1V & $v_{.} .$. & $\bullet \cdot \cdots$ & $1 \% .$. & رياضيا . الارتقاء بمستوى الاداء المهارى للفائقين & $\wedge$ \\
\hline 11 & $\vee \vee . \vee \wedge$ & $* v_{.}$. & N.rr & r... & $\bullet \cdot . \cdots$ & Ir... & $\leqslant 1.7 \mathrm{~V}$ & $1 \cdot \cdots$ & 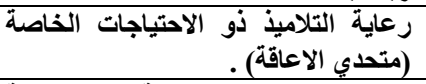 & 9 \\
\hline$r$ & $\Lambda \varepsilon . V Y$ & $* 1 \cdot . v 0$ & $\varepsilon .1 V$ & $1 . \cdots$ & $r v .0$. & $9 .$. & O^.rr & $1 \leq .$. & 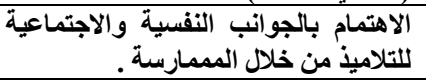 & 1. \\
\hline$\wedge$ & & $* q . \vee 0$ & 14.0. & r... & ro... & $7 . \cdots$ & Tr.o. & $10 .$. & تدعيم روح الابتكار والابداع لدي التلاميذ & 11 \\
\hline$r$ & $\Lambda \varepsilon . V Y$ & $* 1 \cdot . v_{0}$ & $\varepsilon .1 V$ & $1 . \cdots$ & $r v .0$. & $9 . \cdots$ & $0 \wedge . r r$ & $1 \leq .$. & تدي التلاميذي . الرياضية والروحية المرجوة & ir \\
\hline ir & $79 . \leqslant \leq$ & $1 . \cdots$ & ro... & ४. & $\leqslant 1.7 \mathrm{~V}$ & $1 \cdot \cdots$ & 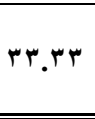 & ^... & 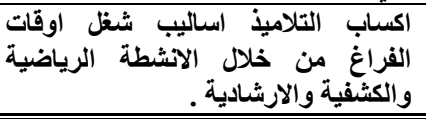 & ir \\
\hline
\end{tabular}

$0.99=0$ =.

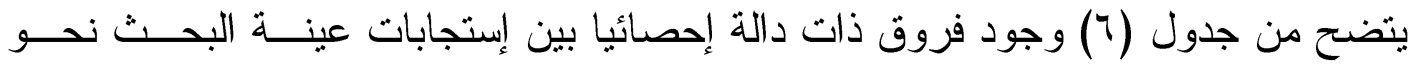

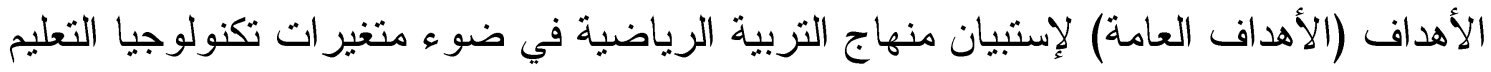


و البيئة الصحر اوية بمحافظة شمال سيناء، حيث كانت قيمة كاب المحسوبة تتر اوح مابين (....

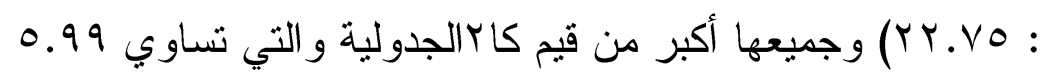

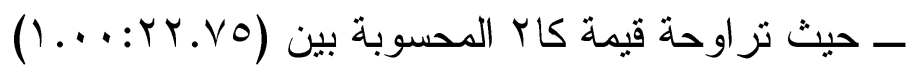

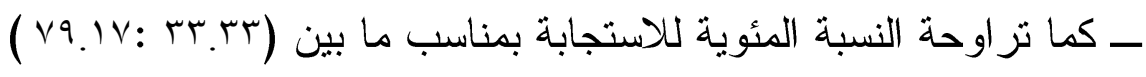

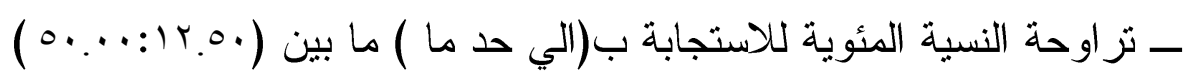

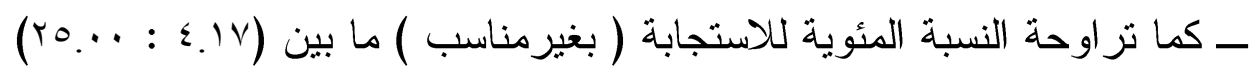

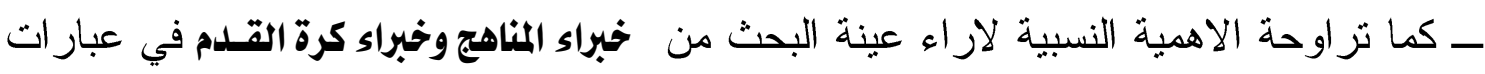

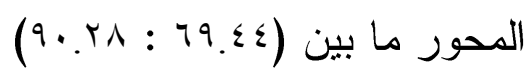

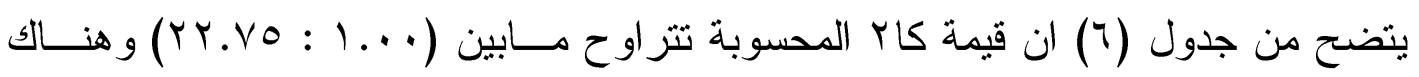

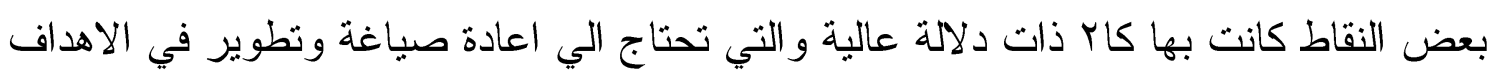

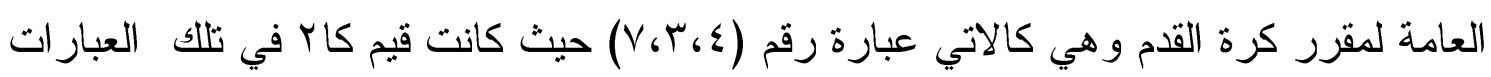

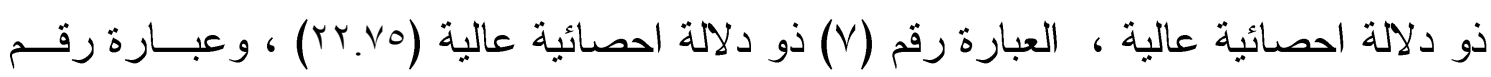

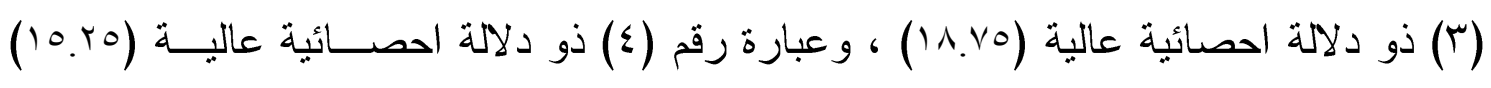

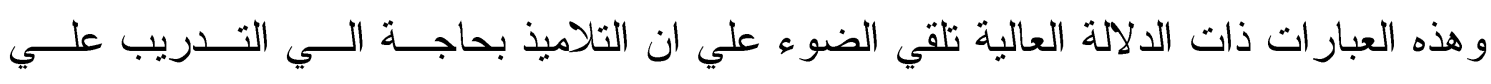

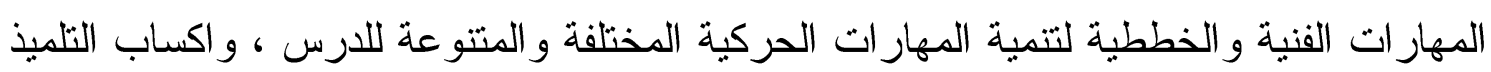

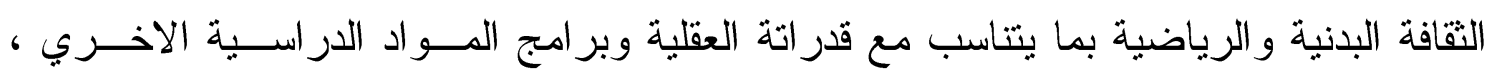

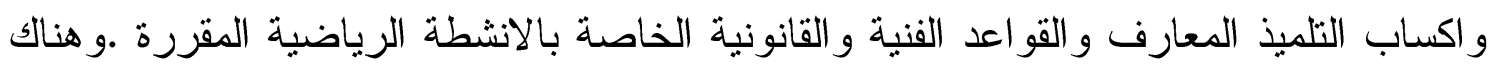

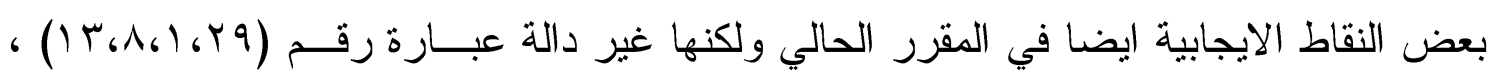

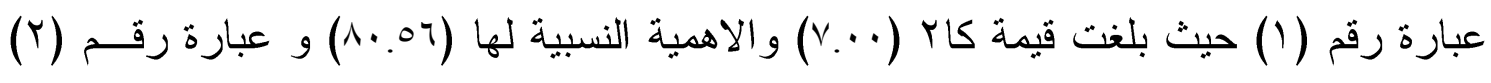

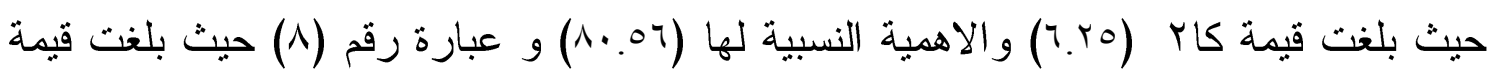

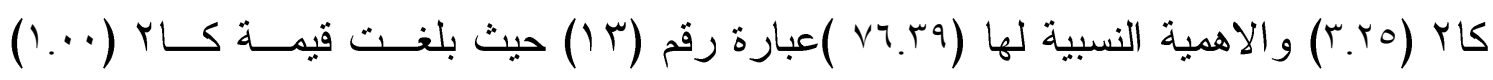
و الاهمية النسبية لها (ع §.97) مما يدل على ان مقرر كرة القدم يكتسب النواحي المعرفية الهامة

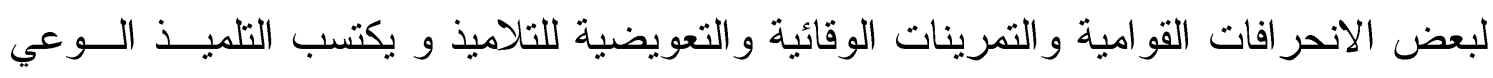

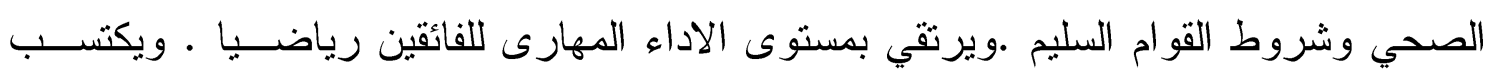

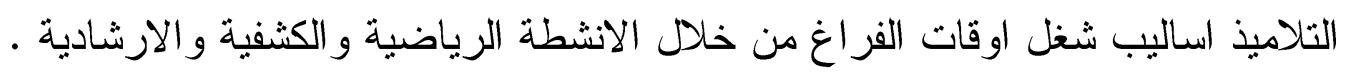

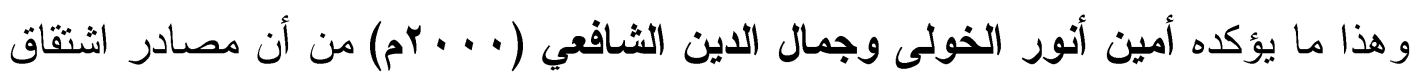
الأهداف العامة للتربية البدنية تتمثل في التالي: 
• المجتمع: حيث يجب أن تشتق من و اقع الإطار الفلسفي الاجتماعي التزبوي الذي ارتضاه

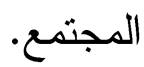

•المتعلم: يجب أن نر اعى طبيعة المتعلم وحاجاته الفردية و الاجتماعية، كـذلك الحاجــات المتعلقة بالإطار الاجتماعي. المادة الار اسية: البيئة المعرفية للتربية البدنية زاخرة بما تحويه المــو اد المختلفــة مــن

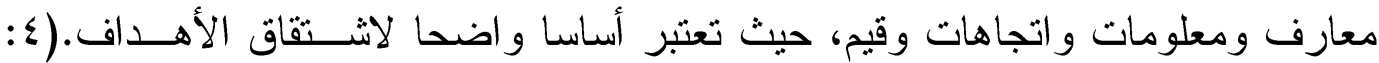
(ro0 ، YOS

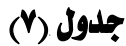

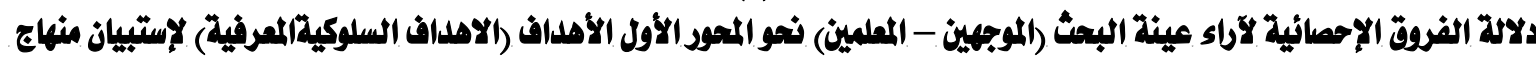
ن 10

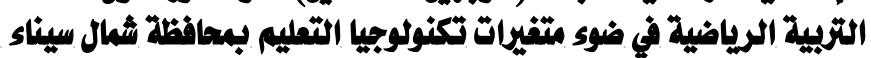

\begin{tabular}{|c|c|c|c|c|c|c|c|c|c|c|}
\hline \multirow{3}{*}{$\begin{array}{l}E: \\
E:\end{array}$} & \multirow{3}{*}{ الأهبية } & \multirow{3}{*}{ SL } & \multicolumn{6}{|c|}{ الإســتجابات } & \multirow{3}{*}{ العبـــار ات } & \multirow{3}{*}{ 5 } \\
\hline & & & \multicolumn{2}{|c|}{ غير مناسب } & \multicolumn{2}{|c|}{ الى حد ما } & \multicolumn{2}{|c|}{ مناسب } & & \\
\hline & & & $\%$ & ك & $\%$ & ك5 & $\%$ & 5 & & \\
\hline$\varepsilon$ & $11.9 \leq$ & *q. ro & $17.7 \mathrm{~V}$ & $\varepsilon .$. & $r \cdot . \wedge r$ & $0 .$. & Tr.o. & $10 . \cdots$ & والمعارف التعرف التلميذ بالأداء الفنى. المعلومات & $1 \leq$ \\
\hline 1 & 94.7 & *YY,YO & $\varepsilon .1 V$ & $1 . \cdots$ & ir.o. & $r .$. & Tr.r. & $r \cdot .$. & والن يلمة بلعبادىء الإسعافات الأولية & 10 \\
\hline$\varepsilon$ & $11.9 \leq$ & $* \vee$. ${ }^{\circ}$ & A.r & $r_{.} .$. & rv.o. & $9 .$. & $0 \leqslant .1 V$ & $1 \pi .$. & 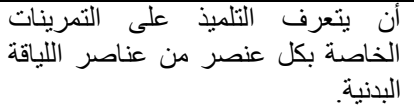 & 17 \\
\hline$\wedge$ & VT.TI & 1.20 & $r \cdot \Delta r$ & $0 .$. & rv.o. & $9 .$. & \&1.TV & $1 \cdot \cdots$ & فيى الدرس. أندرك التلميذ أهمية الأمن و السلامة & IV \\
\hline$r$ & זיזה & $* 9$. $\vee 0$ & Ir.o. & r... & ro... & ร. $\cdots$ & Tr.o. & $10 . \cdots$ & 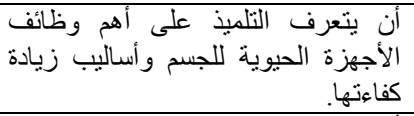 & 11 \\
\hline 7 & $\checkmark \vee . \vee \wedge$ & $* v_{.}$. & $\Lambda . \mu \mu$ & $r .$. & $0 . \cdots$ & Ir... & $\{1.7 \mathrm{~V}$ & $1 \cdot \cdots$ & 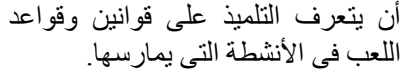 & 19 \\
\hline v & $v 7 . r q$ & $* \vee$. $\vee 0$ & rq. IV & $v_{.}$. & IT.O. & $r .$. & ON.rT & $1 \leq \ldots$ & ألنيم وكيفعرف التلميذ على موافظة علية ووقايته من القوات & $r$. \\
\hline r & $\Lambda \varepsilon . Y Y$ & *Ir. ro & ir.o. & $r .$. & $r \cdot . \wedge r$ & $0 .$. & $74.7 \mathrm{~V}$ & $17 . \ldots$ & 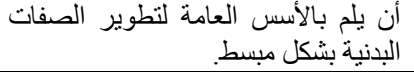 & YI \\
\hline
\end{tabular}

$0.99=0$ = قيمة كاب عند مستوى دلالة 0.

يتضح من جدول (V) وجود فروق ذات دالة إحصائيا بين إستجابات عينة البحـث نحسـو

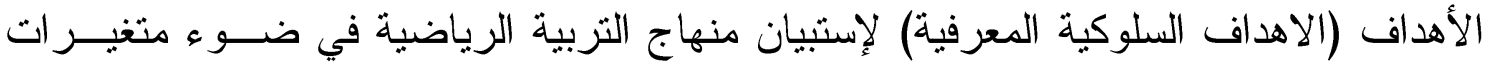

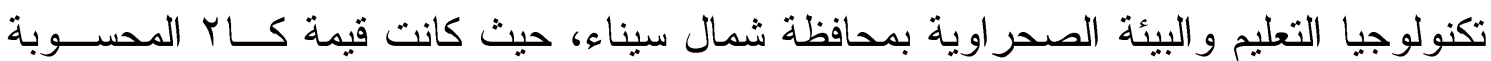

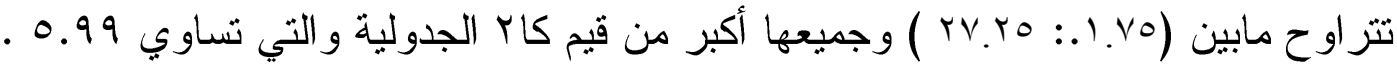

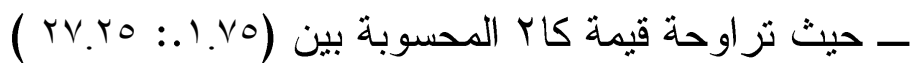

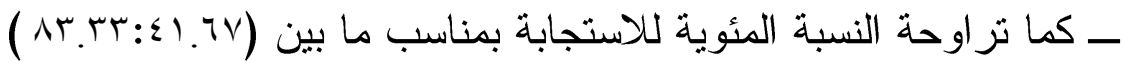
ــ تراوحة النسية المئوية للاستجابة ب(الي حد ما ) ما بين (.0.r ا:....0 )

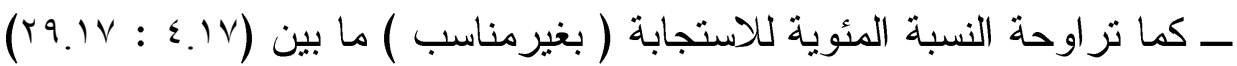


ــ كما تر اوحة الاهمية النسبية لار اء عينة البحث من خبراء المناهج وخبراء كرة القدم في عبار ات

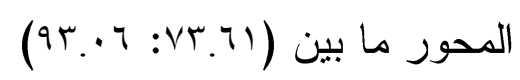

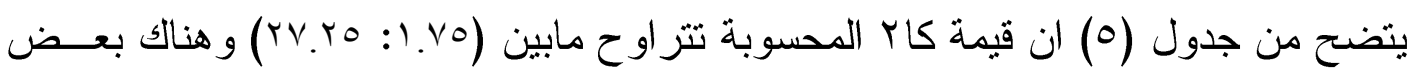

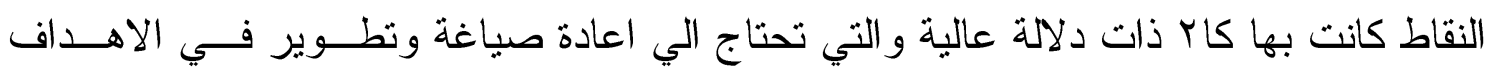

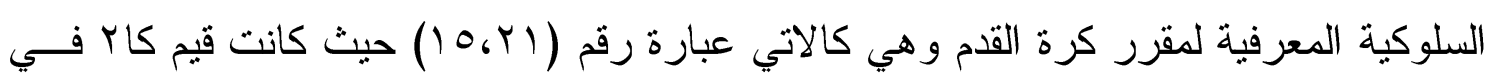

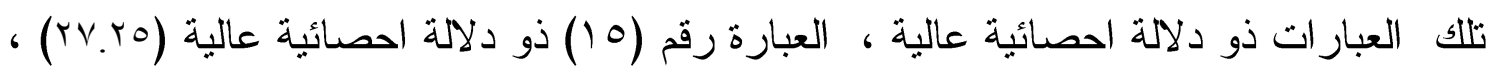

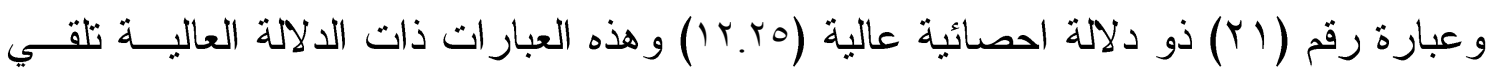

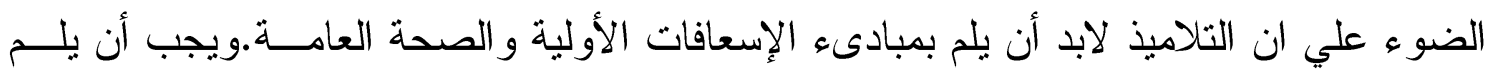

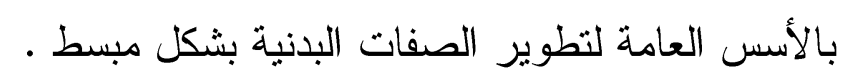

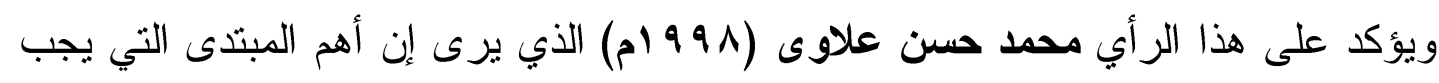
مر اعاتها عند وضع الأهداف تتمثل في النقاط التالية: - أن تكون الأهداف محددة بدقة.

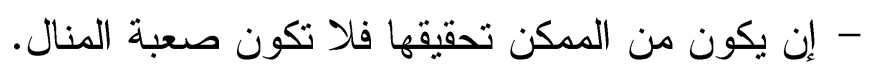

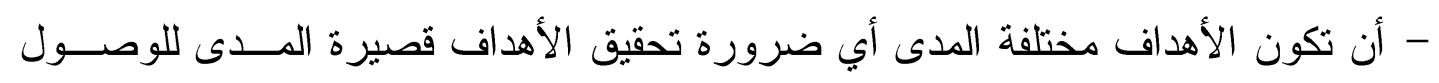
للهدف بعيد المدى وتحقبقه. - أن تكون الأهداف فاعلة ومؤثرة وحيوية. - يجب إن تثميز الأهداف بالمرونة.

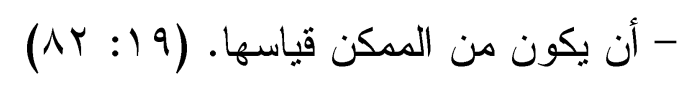

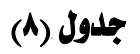

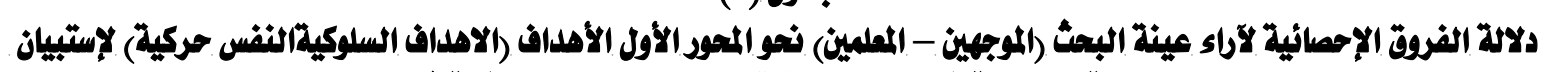

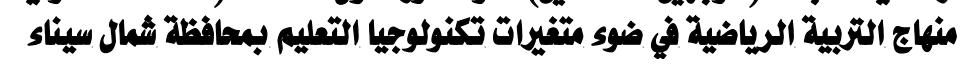

\begin{tabular}{|c|c|c|c|c|c|c|c|c|c|c|}
\hline \multirow{3}{*}{$\begin{array}{l}E_{i} \\
\underline{E} \\
\underline{E}\end{array}$} & \multirow{3}{*}{ الأهمية } & \multirow{3}{*}{ كاr } & \multicolumn{6}{|c|}{ الإســتجابات } & \multirow{3}{*}{ العبــارات } & \multirow{3}{*}{ s } \\
\hline & & & \multicolumn{2}{|c|}{ غير مناسب } & \multicolumn{2}{|c|}{ الى حـ مـا } & \multicolumn{2}{|c|}{ مناسب } & & \\
\hline & & & $\%$ & s & $\%$ & s & $\%$ & كs & & \\
\hline v & $v 9.17$ & $* 4 . \vee 0$ & A.rr & $r_{.} . \cdot$ & $\varepsilon 0 . \wedge r$ & $11 . \cdots$ & $\varepsilon 0 . \wedge r$ & $11 .$. & خلال القياس الدورى للمستواهة البانية من & rr \\
\hline$r$ & $\Lambda v_{.} \circ$. & $* 1 \leqslant . \varphi_{0}$ & $\varepsilon .1 V$ & $1 . \cdots$ & rq. IV & $v_{.} .$. & $77.7 \mathrm{~V}$ & $17 .$. & وأنفسية. & rr \\
\hline r & $\wedge \wedge . \wedge q$ & $* 19 .$. & A.r & $r_{.} .$. & $17.7 \mathrm{~V}$ & $\varepsilon .$. & $v_{0} . .$. & $1 \Lambda_{.}$. & خلال المشبق قوكة الإيجابية. فلى النشاط من & $r \varepsilon$ \\
\hline$\varepsilon$ & r.r. & $* q . \vee 0$ & Ir.o. & $r . .$. & ro... & ч.. & Tr.o. & $10 .$. & 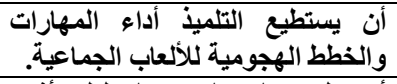 & ro \\
\hline ! & OQ.Vr & r. ro & $0 \cdot . \cdots$ & lr... & $r \cdot . \wedge r$ & $0 . \cdots$ & r9.1V & $v_{.}$. & أن أنظاء. عليه الوعى الخططى أثناء & rT \\
\hline 0 & $11.9 \leq$ & $* q$. ro & $17.7 \mathrm{~V}$ & $\varepsilon . \cdots$ & $r \cdot . \wedge r$ & $\bullet .$. & T.O. & $10 .$. & 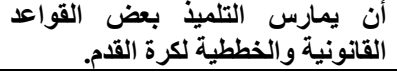 & rv \\
\hline$\Lambda$ & $\vee V . \vee \wedge$ & $* v .$. & $\Lambda . r r$ & Y... & $0 . . \cdots$ & IT... & $\approx 1.7 \mathrm{~V}$ & $1 .$. & أن يطور مستواه المهارى بما تسمح & $r \wedge$ \\
\hline
\end{tabular}




\begin{tabular}{l|l|l|l|l|l|l|l|l|l|l}
\hline & & & & & & & & \\
\hline & & & & & & & & \\
\hline
\end{tabular}

$0.99=0.0$.

يتضح من جدول (^)وجود فروق ذات دالة إحصائيا بين إستجابات عينــة البحــث نحــو

الأهداف (الاهداف السلوكيةالنفس حركية) لإستبيان منهاج التربية الرياضية في ضوء متغيرات تكنولوجيا التعليم و البيئة الصحر اوية بمحافظة شمال سيناء، حيث كانت قيمة كــاب المحســوبة

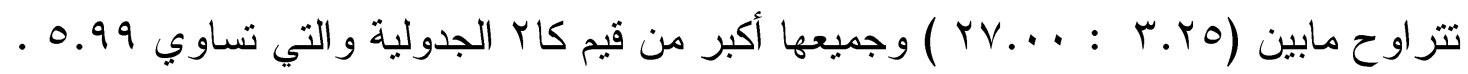

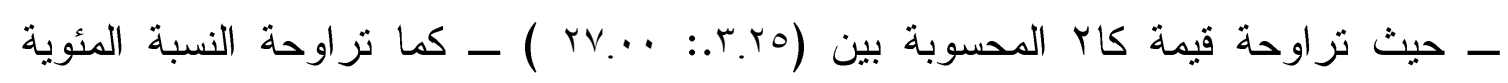

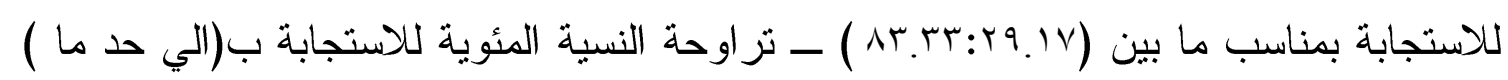

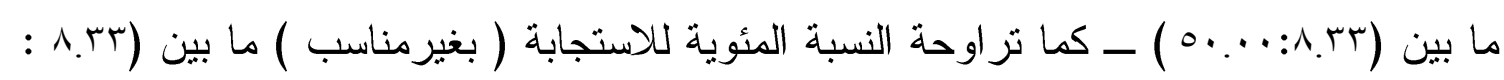
$(0 \cdot \ldots$

ـ كما تر اوحة الاهمية النسبية لار اء عينة البحث من خبراء المناهج وخبراء كرة القلدم في عبار ات

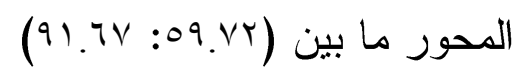

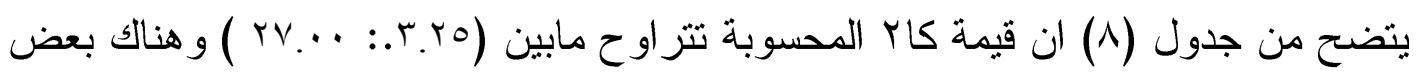

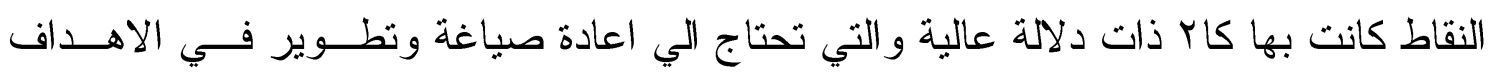

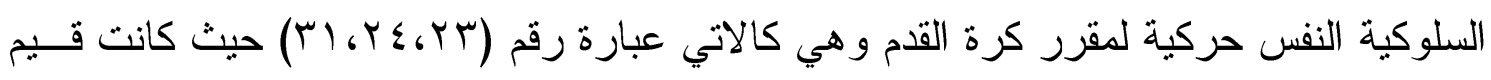
كاب في تلك العبار ات ذو دلالة احصائية عالية ، العبارة رقم (ع ب) ذو دلالة احصائية عاليــة

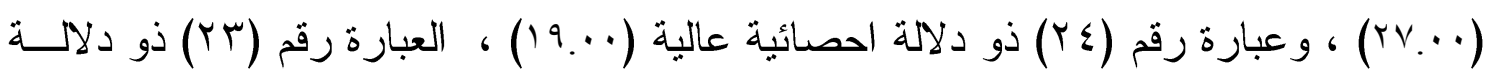
احصائية عالية (0..؟ ()) وهذه العبار ات ذات الدلالة العالية تلقي الضوء علي ان التلامبذ لابد أن يميزو بين الفراغ الثخصى و الفراغ العام أثناء ممارسة النشاط الرياضي أن يطبق قو اعد اللعب فى النشاط من خلال المشاركة الإيجابية و أن ينمى التلميذ طاقاته البدنية و النفسية.

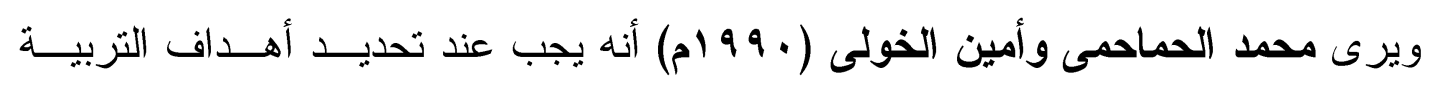
الرياضية در اعاة ان يكون تحديدها في إطار من المعايير العلمية، ومن أهم المعايير التي يجب تو افر ها في أهداف التزبية الرياضية هي: - أن تتبع من حاجات المجتمع. - مناسبة للمرحلة السنية وثز اعى خصائص النمو. 


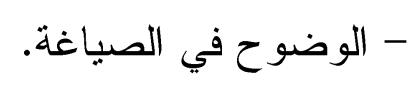

- يمكن تحقيقها بالموارد البشرية و المادية المتاحة.

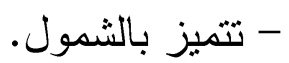

- يمكن تحليل الأهداف المركبة إلى أهداف خاصة.

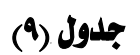

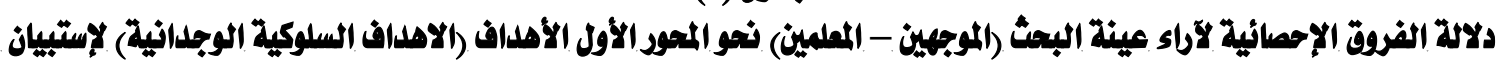

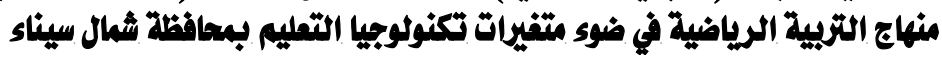

$10=\dot{0}$

\begin{tabular}{|c|c|c|c|c|c|c|c|c|c|c|}
\hline \multirow{3}{*}{$\begin{array}{l}E_{i} \\
\underline{E} \\
\underline{E}\end{array}$} & \multirow{3}{*}{ الأهمبة } & \multirow{3}{*}{ كاr } & \multicolumn{6}{|c|}{ الإســتجابات } & \multirow{3}{*}{ العبــارات } & \multirow{3}{*}{ p } \\
\hline & & & \multicolumn{2}{|c|}{ غير مناسب } & \multicolumn{2}{|c|}{ الى حد ما } & \multicolumn{2}{|c|}{ مناسب } & & \\
\hline & & & $\%$ & s & $\%$ & ك & $\%$ & ث & & \\
\hline r & $\Lambda \leq . \vee r$ & $* 1$ r. Y & Ir.o. & r... & $r \cdot . \wedge r$ & $0 . \cdots$ & $77.7 \mathrm{~V}$ & $17 . \cdots$ & سلوكيا. & rr \\
\hline$\varepsilon$ & $\Lambda \cdot .07$ & $* 4.10$ & $1 T .0$. & r... & rr.ru & ^... & $0 \leqslant .1 \mathrm{~V}$ & ir... & يمارسيها. & rr \\
\hline 9 & $79 . \leqslant \leq$ & $1 . \cdots$ & ro... & ร.. & $\leqslant 1.7 \mathrm{~V}$ & $1 \cdot \ldots$ & rr.ru & А... & أن يكتسب التلميذ الشجاعة والجراءة. & $r \varepsilon$ \\
\hline$\varepsilon$ & $1 . .07$ & $* q$. ro & $r \cdot . \wedge r$ & $\bullet . \cdots$ & $17.7 \mathrm{~V}$ & 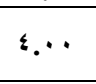 & Tr.O. & $10 .$. & الممارسة الرياضية. التلميذ. & ro \\
\hline$\varepsilon$ & $\Lambda \cdot .07$ & $* 4$. Yo & 1T.0. & r... & rr.ru & ^... & $0 \leqslant .1 \mathrm{~V}$ & Ir... & بالنزوق الفردية. التلميذ القدات والميول ويؤمن & r \\
\hline$\wedge$ & $\vee \vee . \vee \wedge$ & $* v_{.} .$. & N.r & $r_{.} .$. & $0 \cdot . \cdots$ & Ir... & $\approx 1.7 \mathrm{~V}$ & $1, \ldots$ & أن تنمي لاي التلميذ الإتجاهات الإيجابية & $r v$ \\
\hline $\begin{array}{l}1 \\
\end{array}$ & $79 . \leqslant \leq$ & $\cdot r^{\circ}$ & rq. $1 \mathrm{~V}$ & $v_{.}$. & rr.rr & ^... & $r v .0$. & 9... & أن يلتزئم. التلميذ بالنظام و وتحمل & r \\
\hline v & V9.1V & $* 4 . \vee 0$ & A.rr & $r_{.} .$. & $\varepsilon 0 . \wedge r$ & $11 . \cdots$ & $\varepsilon 0 . \wedge r$ & $11 .$. & والن ينمى لاي التكار الذيذ الروح الرياضية & $r q$ \\
\hline 1 & 17.11 & $* \|$ Ir... & N.rr & r... & ro... & $7 .$. & $77.7 \mathrm{~V}$ & $17 .$. & 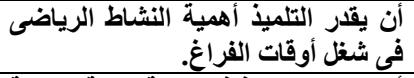 & $\varepsilon$. \\
\hline$r$ & $11.9 \leq$ & $* q$. Y & $17.7 \mathrm{~V}$ & $\varepsilon$. & $r \cdot . \wedge r$ & $0 . \cdots$ & . & $10 .$. & أن يستاهم التلميذ فى تنمية البيئة وخلمة & $\leq 1$ \\
\hline
\end{tabular}

قيمة كاب عند مستوى دلالة 0. . .

يتضح من جدول (9) وجود فروق ذات دالة إحصائيا بين إستجابات عينة البحــث نحسو

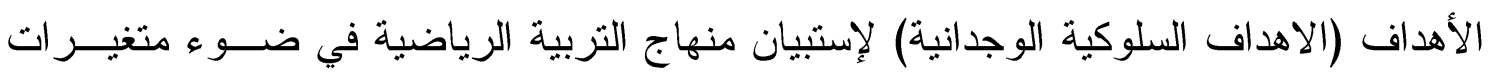

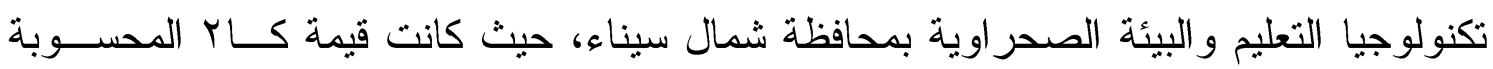

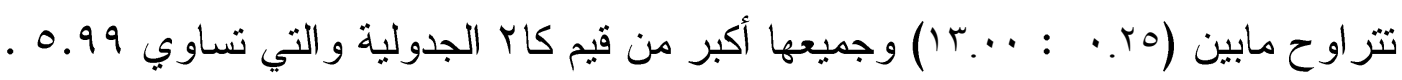

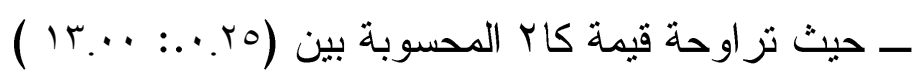

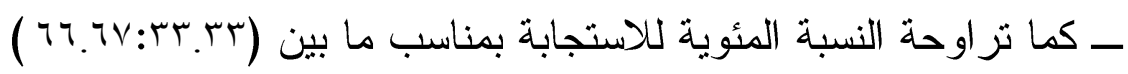

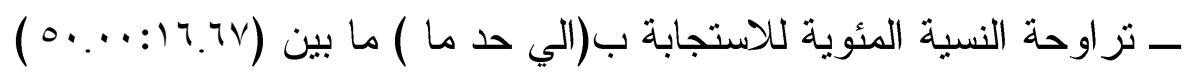

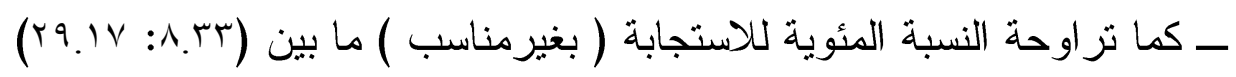


ــ كما تر اوحة الاهمية النسبية لار اء عينة البحث من خبراء المناهج وخبراء كرة القدم في عبار ات

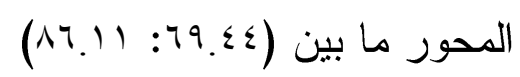

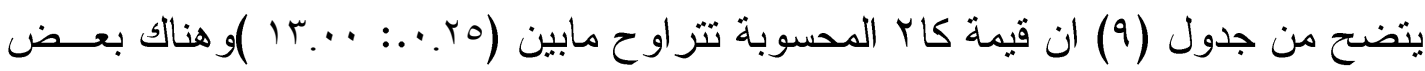

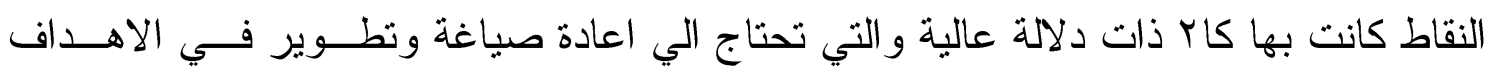

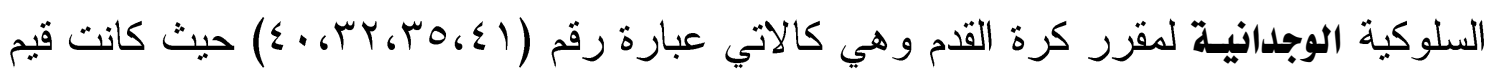

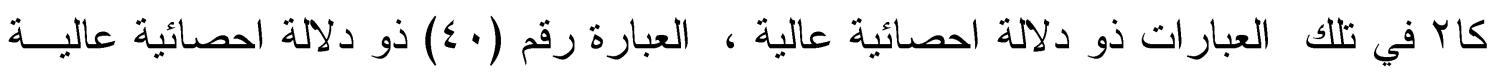

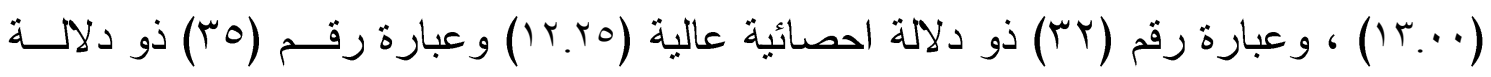

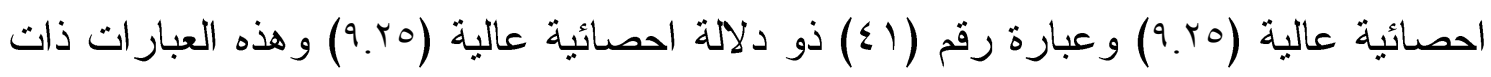

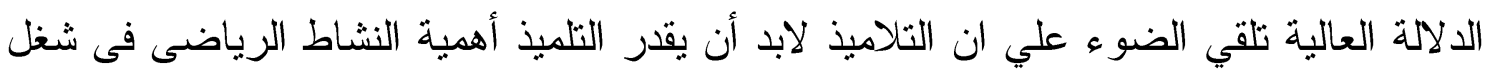

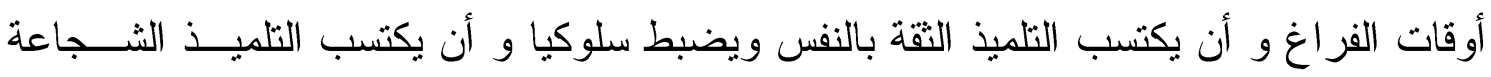
و الجر اءة و أن يساهم التلميذ فى تتمية البيئة وخدمة المجتمع.

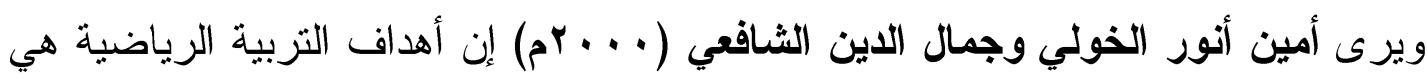

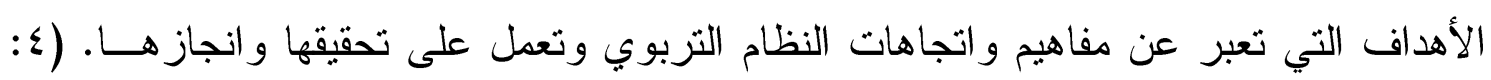

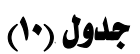

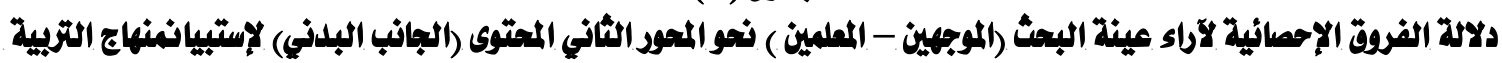

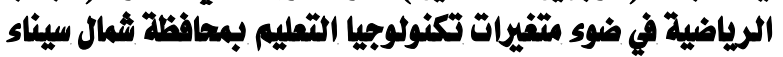

\begin{tabular}{|c|c|c|c|c|c|c|c|c|c|c|}
\hline \multirow{3}{*}{$\begin{array}{l}\mathbb{E}_{2} \\
\underline{\underline{E}}\end{array}$} & \multirow{3}{*}{ الألهبية } & \multirow{3}{*}{ كاr } & \multicolumn{6}{|c|}{ الإســتجابات } & \multirow{3}{*}{ العبــارات } & \multirow{3}{*}{ P } \\
\hline & & & \multicolumn{2}{|c|}{ غير مناسب } & \multicolumn{2}{|c|}{ الى حـ ما } & \multicolumn{2}{|c|}{ مناسب } & & \\
\hline & & & $\%$ & s & $\%$ & s & $\%$ & s & & \\
\hline $\bar{r}$ & Aq.Yr & $* 0 Y .04$ & 8.79 & $0 .$. & 18.94 & $11 . .$. & $\overline{V 0 . r \Lambda}$ & $\varepsilon 9 .$. & القوة & 1 \\
\hline 1 & $q \cdot . v V$ & $* \Delta \vee . \leqslant \theta$ & $\varepsilon .7 \%$ & $r . .$. & $11 . \leqslant 7$ & $1 \mu_{.} .$. & $V Y .9 Y$ & $\theta . .$. & السرعة & $r$ \\
\hline$r$ & VY.AD & $* 1 . .00$ & $10.4 \Lambda$ & $1, \ldots$ & $\varepsilon V .79$ & ri... & $r 4.94$ & $r \leqslant .$. & الرشاقة & $r$ \\
\hline 0 & VY.YI & $* 1 T . r Y$ & $10.4 \mathrm{~N}$ & $1, \ldots$ & OY.YI & $r \leqslant \ldots$ & TY.TI & $r 1 . .$. & المرونة & $\varepsilon$ \\
\hline$r$ & $V T$ VTo & $* 4 . \leqslant 9$ & 11.87 & $1 Y . .$. & $\leqslant 1.0 \leqslant$ & $r V_{.} .$. & $\varepsilon . .$. & r... & التحمل & 0 \\
\hline 7 & 7 Tะ. &. .01 & r..9Y & $Y \varepsilon .$. & rr.Ao & YY.. & YQ.YY & $19 . .$. & التوازن & 7 \\
\hline
\end{tabular}

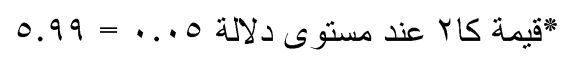

يتضح من جدول (· () وجود فروق ذات دالة إحصائيا بين إستجابات عينة البحث نحسو

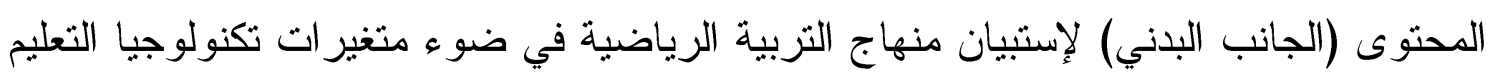

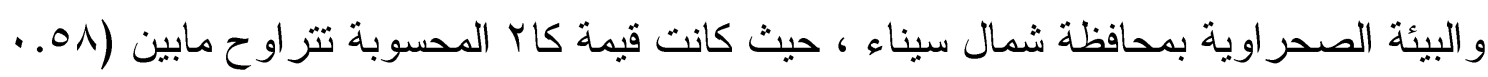

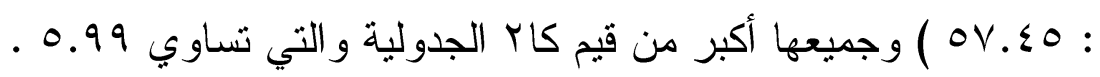

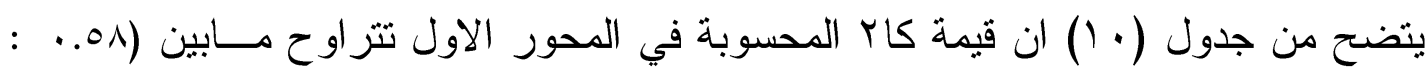

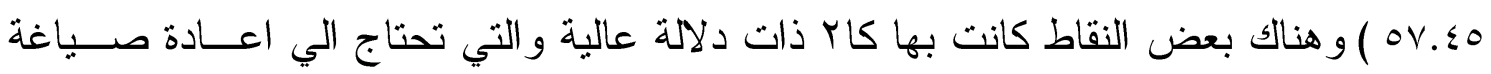




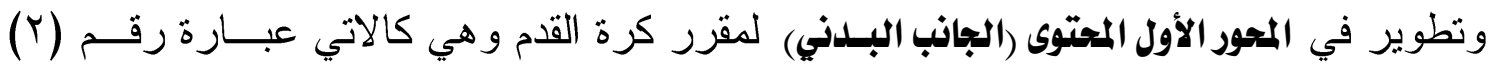

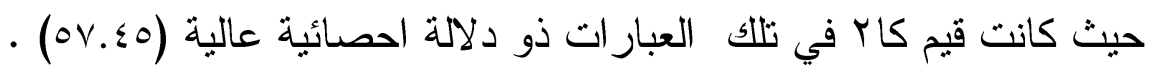

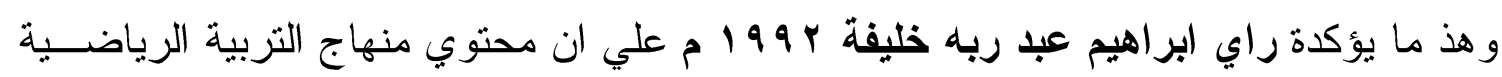

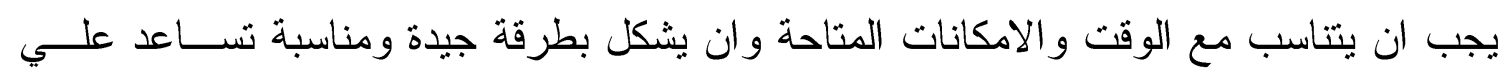

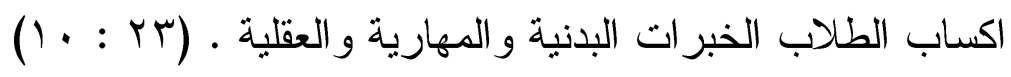

\section{(II) جدول}

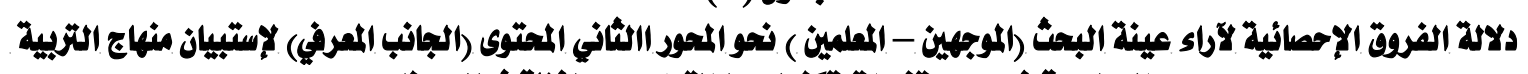

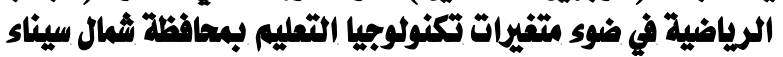

\begin{tabular}{|c|c|c|c|c|c|c|c|c|c|c|}
\hline \multirow{3}{*}{$\begin{array}{l}E_{i} \\
E_{2}\end{array}$} & \multirow{3}{*}{ الأهمبية } & \multirow{3}{*}{ كاr } & \multicolumn{6}{|c|}{ الإســتجابات } & \multirow{3}{*}{ العبــارات } & \multirow{3}{*}{ s } \\
\hline & & & \multicolumn{2}{|c|}{ غير مناسب } & \multicolumn{2}{|c|}{ الى حـ ما } & \multicolumn{2}{|c|}{ مناسب } & & \\
\hline & & & $\%$ & s & $\%$ & ك & $\%$ & ك & & \\
\hline 1 & A..10 & $* r \leqslant . \wedge r$ & V.79 & $0 . \cdots$ & r..10 & $1 \mathrm{IV}_{.}$. & 74.10 & \&ץ... & نبذة تاريخية عن قانون كرة القدم . & $\mathrm{v}$ \\
\hline$\varepsilon$ & $\vee \wedge .9 \vee$ & $* 1 V_{.} . r$ & $9.4 \mathrm{r}$ & ร.. & $\varepsilon \varepsilon .74$ & rq... & $\leqslant 7.10$ & $r \cdot . \cdots$ & قو انين وقو اعد رياضة كرة القدم. & $\wedge$ \\
\hline$\bullet$ & $V \vee .90$ & $* 11 . r$. & 17.94 & $11 . \cdots$ & rutru & r... & $0 \cdot . V V$ & rr... & المعارف رياضة كرة القدم في اكتساب & 9 \\
\hline r & $\Lambda \leq .7 Y$ & $* \nvdash \wedge . \curlyvee \wedge$ & 7.10 & $\varepsilon . \cdot$ & rr.Ao & rr... & $\because \ldots$ & rq... & كرة القدات & 1. \\
\hline 7 & VY.Ar & $\varepsilon .9$ & Y1.0 & $1 \leqslant .$. & $r \wedge . \leqslant 7$ & ro... & $\varepsilon \cdot \ldots$ & rq... & الاسس الميكانيكية للاعب كرة القدم . & 11 \\
\hline$v$ & १^.VY & $\cdot \wedge \uparrow$ & rr.ru & r... & rq. rr & $19 . \cdots$ & $r \wedge . \leqslant 7$ & ro... & لاي التلاميذ. مفسابقات الاتحاد لكرة القدم & Ir \\
\hline$r$ & Ar..o & $* r \cdot . \wedge$. & $1 . . v V$ & $v_{.}$. & Ir.r. & r... & 07.94 & $r v_{.} .$. & التلامتذي . اهداف بطولات كرة القام لاي & ir \\
\hline
\end{tabular}

"قيمة كاr عند مستوى دلالة 0.

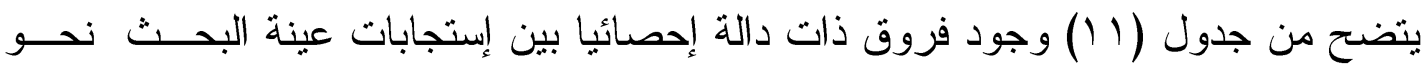

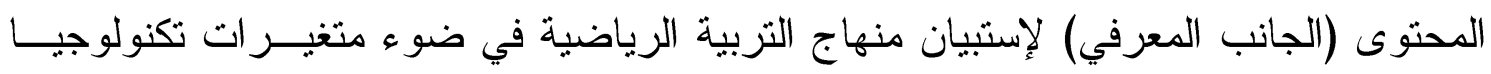

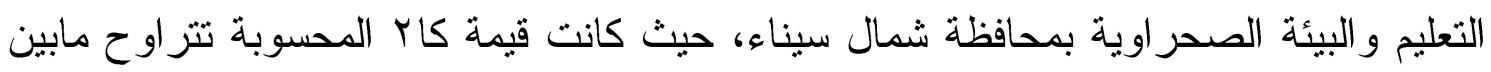

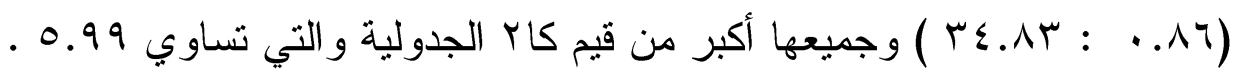

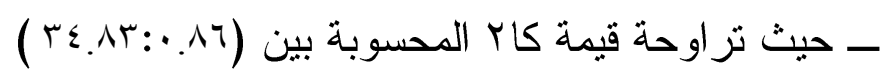

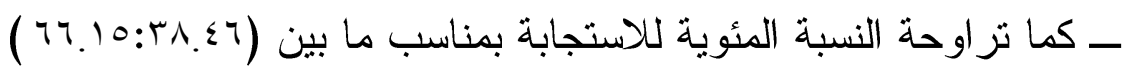

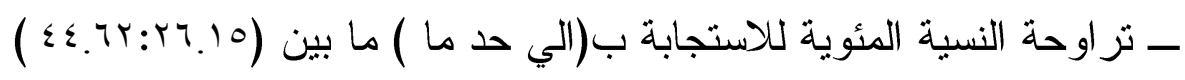

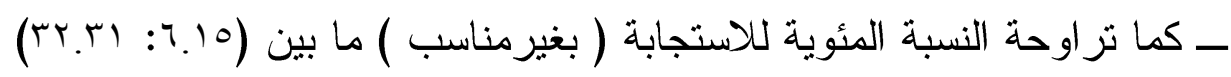

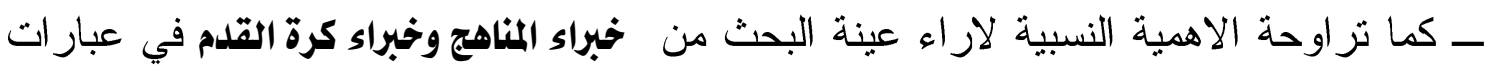

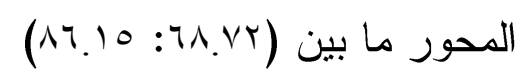

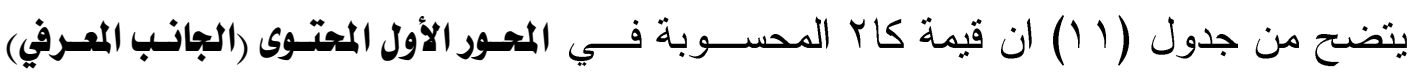

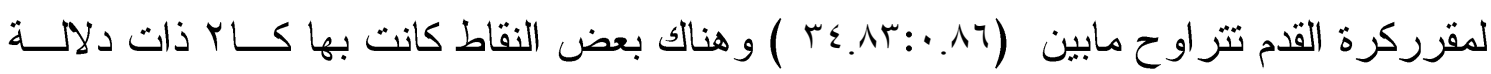




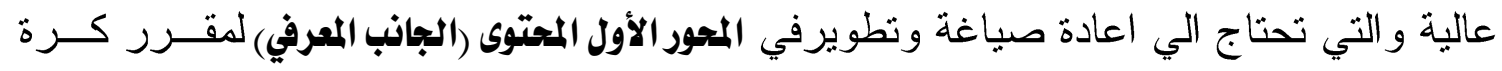

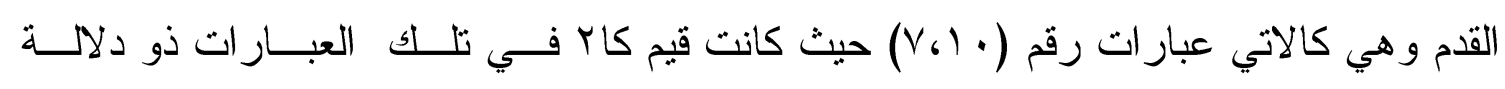

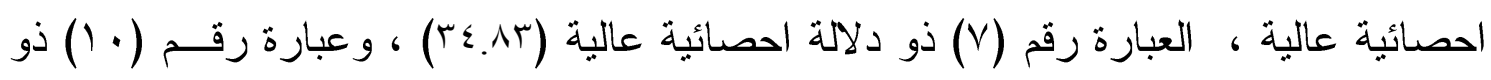

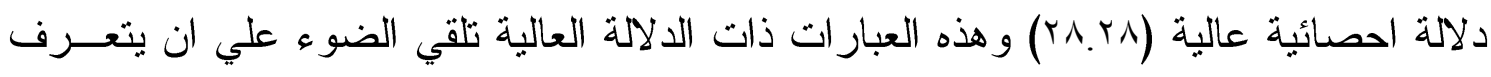

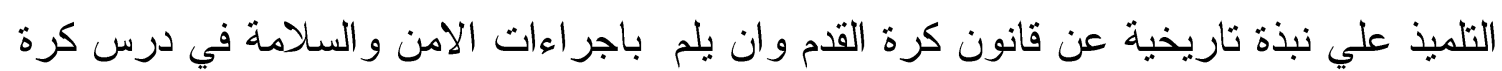
القد . القع

ويؤكد كلا من حلمي احمد الوكيل وحسن السيد بثير ل .. بام و ايضا عبد العـال بــدوي

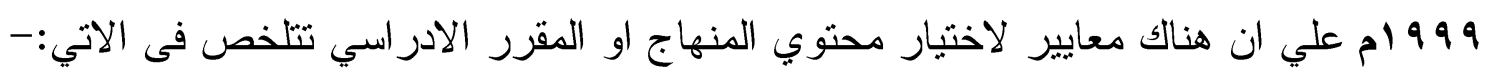

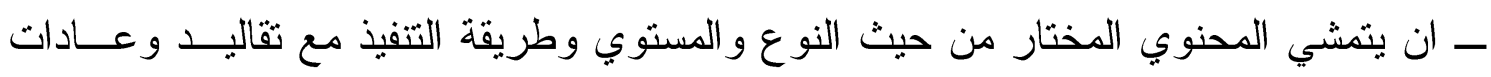
المجنمع ــ ان يتتاسب المحتوي مع ميول الافر اد الذين يعد لهم المنهاج وان تثبع حاجتهم وتتمشى مـــع

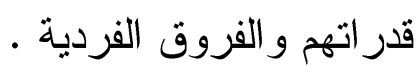
ــ ان تحقق المهار ات المختارة النمو المتزن للفرد في كلفة جو انبة البدنبة و المهاريـــة و العقليـــة

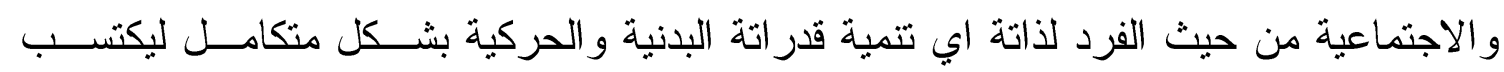

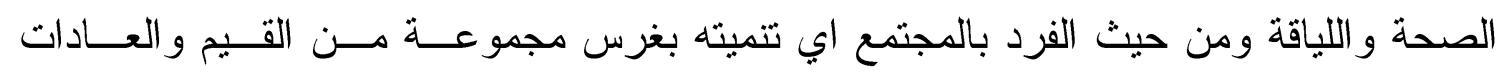
الاجتماعية . - المحه

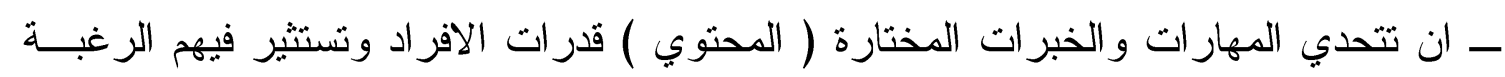

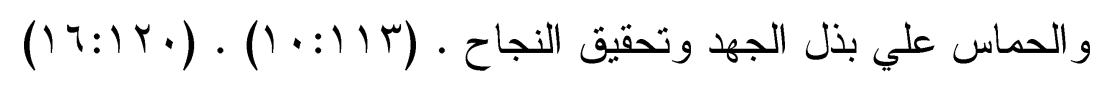

$$
\text { جدان (ir) }
$$

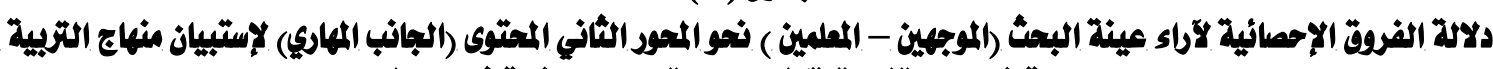

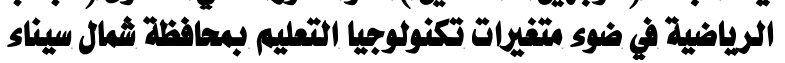

\begin{tabular}{|c|c|c|c|c|c|c|c|c|c|c|}
\hline \multirow{3}{*}{$E_{E:}^{E:}$} & \multirow{3}{*}{$\begin{array}{l}\text { الأهمية } \\
\text { النسبية }\end{array}$} & \multirow{3}{*}{ SLY } & \multicolumn{6}{|c|}{ الإســتجابات } & \multirow{3}{*}{ العبـــارات } & \multirow{3}{*}{ م } \\
\hline & & & \multicolumn{2}{|c|}{ غير مناسب } & \multicolumn{2}{|c|}{ الى حد ما } & \multicolumn{2}{|c|}{ مناسب } & & \\
\hline & & & $\%$ & ك5 & $\%$ & ك & $\%$ & s & & \\
\hline$r$ & $\wedge 9 . \vee \leq$ & $* 0, . \Lambda$. & \&.TY & r... & Y1.0 & $1 \leq .$. & Vr.^o & $\varepsilon \wedge . \cdots$ & 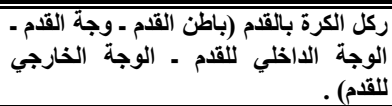 & $1 \varepsilon$ \\
\hline 0 & $V V . \leq \varepsilon$ & $* Y \leq . \leq$ & 7.10 & $£$. & $00 . \mathrm{r}$ & r... & $r \wedge . \leqslant 7$ & ro... & 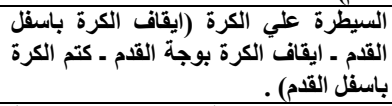 & 10 \\
\hline$\varepsilon$ & $\vee \wedge .9 \vee$ & $* 1 r . v q$ & 17.94 & $11 .$. & Yq.rT & $19 .$. & or.Ao & ro... & 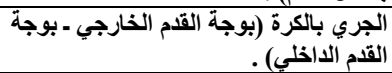 & 17 \\
\hline 7 & vo.rA & *Y १.१ & 7.10 & $\varepsilon$. & $71.0 \leq$ & $\varepsilon . \cdots$ & וr.ru & ri... & ضرب الكرة بالرأس (من الثبات - من & iv \\
\hline $\mathrm{V}$ & $V \varepsilon . \wedge V$ & $* 9.74$ & $10 . \mathrm{r}$ & $1 \cdot \ldots$ & $\leq \leqslant .7 Y$ & rq... & $\varepsilon \cdot \ldots$ & ry... & ضرب الكرة بالر أس من الوثب . & 11 \\
\hline $1 \leq$ & Or.ru & $* 18.11$ & 07.94 & $r v . .$. & $r 7.10$ & $1 V_{.} .$. & 17.94 & $11 . \cdots$ & السيطرة علي الكرة بالصدر . & 19 \\
\hline Ir & $0 \wedge . \leqslant 7$ & $* V . \leqslant Y$ & $\varepsilon q . r^{r}$ & rr... & $r 7.10$ & $1 V_{.}$. & $r \leq .7 Y$ & $17 . \cdots$ & الخداع بتغير السرعة خلال الجري بالكرة . & $r$ r. \\
\hline r & QY.Ar & *VY.97 & $\varepsilon .7 Y$ & r... & $\mid Y . M$ & ^... & $\Lambda r . \wedge$ & $0 \leq .$. & رمية التماس . . & YI \\
\hline
\end{tabular}




\begin{tabular}{|c|c|c|c|c|c|c|c|c|c|c|}
\hline 1. & $v \cdot . T^{\top}$ & $0.9 \leqslant$ & Y 1.0$\}$ & $1 \varepsilon .$. & $\$ 7.10$ & $r \cdot . \cdot$ & rY.r & rI... & الجري بالكرة و الركلات بانواعها . & YY \\
\hline iT & 04.94 & $* 1 \leqslant . \wedge$. & $00.4 \Lambda$ & rч... & $11 . \leqslant 4$ & $1 T_{.} \cdot$ & 49.10 & $1 V_{.} .$. & السيطرة علي الكرة بالفذذ. . & $\overline{r T}$ \\
\hline 1. & $V \cdot . Y 4$ & $1.1 \leqslant$ & YV.79 & $11_{.} .$. & rr.Ao & YY... & $r \wedge . \leqslant 4$ & ro... & الذذاع بتصويب الكرة . & $r \leq$ \\
\hline $\mathrm{v}$ & $V \leftleftarrows . \wedge V$ & $* 1 \leqslant . \wedge$. & $\mid r . r 1$ & $\Lambda_{.} .$. & $0 . . \mathrm{VV}$ & rr... & $r 9.94$ & $r \leqslant .$. & بعض الخطط الهجومية والدفاعية. & ro \\
\hline 9 & VT.RT & $* 1 \leqslant . \leqslant \Gamma$ & $1 \% . \wedge 0$ & $9 .$. & 0 Or.rI & $r \varepsilon \ldots$ & $r r . \wedge 0$ & YY... & ممارسة اللعبة . . & ז \\
\hline 1 & $94 . r 4$ & $* V V_{.} Y q$ & ¿.Tr & r... & $1 \cdot . \mathrm{VV}$ & $v_{.} \cdot$. & $\Lambda \leq . T Y$ & $00 .$. & التقويم والقياس ـ & TV \\
\hline
\end{tabular}

$0.99=\ldots .0$ =. قيمة كاب عند مستوى دلالة

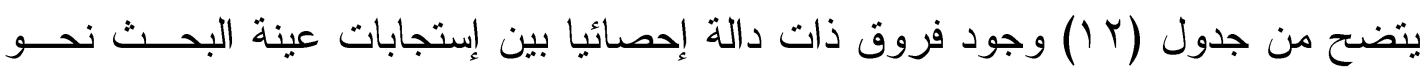

المحتوى (الجانب المهاري) لإستبيان منهاج التربية الرياضية في ضوء منغيـر ات تكنولوجيــا التعليم و البيئة الصحر اوية بمحافظة شمال سيناء، حيث كانت قيمة كاب المحسوبة تتراوح مابين

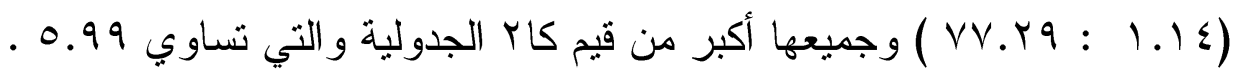

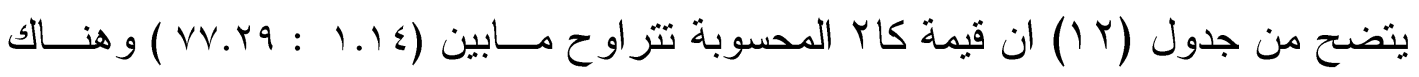
بعض النقاط كانت بها كاب ذات دلالة عالية و التي تحتاج الي اعادة صياغة وتطوير فـي المحسور

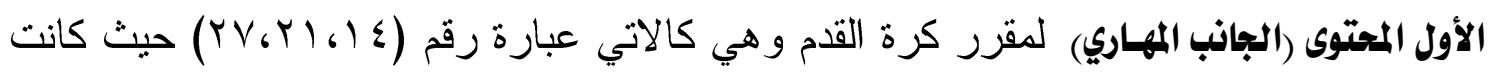
قيم كاب في تلكك العبار ات ذو دلالة احصائية عالية ، العبارة رقم (YV) ذو دلالـــة احصــائية

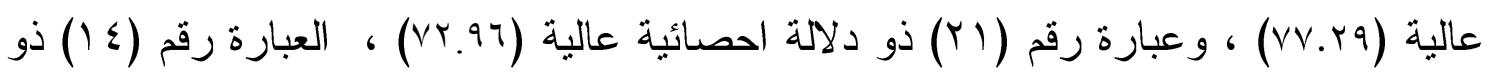
دلالة احصائية عالية (•^.••م) وهذه العبار ات ذات الدلالة العالية تلقي الضوء علي ان التلاميــذ لابد أن يلمو ا بمهار ات ركل الكرة بالقدم (باطن القدم ـ وجة القدم ـ الوجة الــداخلي للقـدم ـ الوجة الخارجي للقدم) ومهارة رمية التماس ويتم عمل تقويم وقياس في نهاية كل وحدة در اسية لكي تساعد التلاميذ علي اتقان مهار ات مقرر كرة القدم • ويؤكد علي ذلك محمد عبده صالح ومفتح إبراهيم ( 99 ام) على إن المهار ات الأساســية في كرة القدم هي العامل المهم وبدون إتقان المتعلمين لها بصورة جيدة يكون من الصعب عليهم تتفيذ الأداء السليم بصورة فعالة وفى هذا الصدد يذكر كلا من محمد على ومصطفى الجيلانسـي (r ( . r م) إن المهار ات الأساسية ليسه هي كل شي في كرة القدم فهناك بلا شك الخطط و اللباقة البدنية لكن تبقى المهار ات الأساسية هي العامل المهر فيه اللعبة فبدون إجادة ألاعب للمهار ات لا

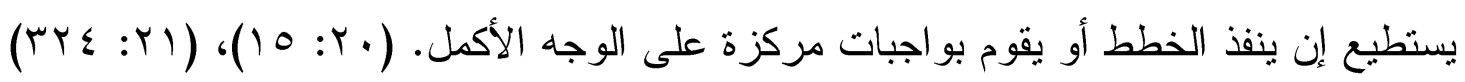

\section{(ir) جلدول)}

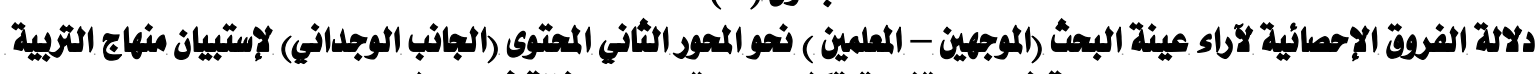

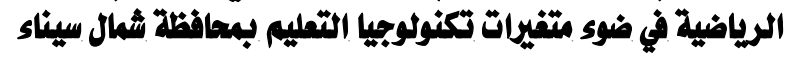

\begin{tabular}{|c|c|c|c|c|c|c|c|c|c|c|}
\hline \multirow{3}{*}{ E: } & \multirow{3}{*}{ الأهمية } & \multirow{3}{*}{ كاr } & \multicolumn{6}{|c|}{ الإســتجابات } & \multirow{3}{*}{ العبـــارات } & \multirow{3}{*}{ s } \\
\hline & & & \multicolumn{2}{|c|}{ غير مناسب } & \multicolumn{2}{|c|}{ الى حـ مـا } & \multicolumn{2}{|c|}{ مناسب } & & \\
\hline & & & $\%$ & ك & $\%$ & s & $\%$ & s & & \\
\hline$\varepsilon$ & $V V .90$ & $* I V . r$. & Q.rr & १... & $\varepsilon V .79$ & r... & $\varepsilon r . \wedge$ & $r \wedge .$. & 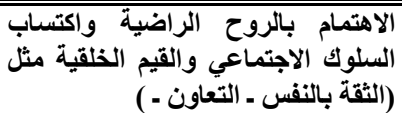 & $r \wedge$ \\
\hline
\end{tabular}




\begin{tabular}{|c|c|c|c|c|c|c|c|c|c|c|}
\hline$r$ & AV. IA & $* Y V_{.} \leqslant Y$ & \&.Tr & r... & rq.rr & $19 . \cdots$ & 79.10 & $\varepsilon r . \cdots$ & كرة القدم الاتجاهات نحو ممارسة نشاط & rq \\
\hline 1 & $\wedge \wedge.)^{\prime}$ & $* \varepsilon r . \vee q$ & 7.10 & $\varepsilon .$. & $r r . \cdot A$ & $10 .$. & $v \cdot . v v$ & $\leqslant ५ .$. & التوجباع الميول والاحتياجات في اطار من & $r$. \\
\hline 7 & $07.9 \mathrm{r}$ & $* q . Y 4$ & $0 . . V V$ & $r r . .$. & rv. 79 & $11 .$. & M $1.0 \leq$ & $1 \varepsilon \ldots$ & كرة القدام . الاوقات المفضلة لممارسة نشاط & r \\
\hline$r$ & $\vee \wedge . \leqslant 7$ & $* 1 r .01$ & $|r . r|$ & ^... & $\varepsilon \cdot \cdots$ & r... & $\leqslant V .79$ & r... & تنشاطية روة القدم التعاون من خلال ممارسة & $r r$ \\
\hline 0 & $\Upsilon \wedge .{ }^{\prime}$ & *Yr. $\leqslant 1$ & 18.94 & $11 . \ldots$ & $71.0 \leq$ & $\varepsilon \cdot \ldots$ & M. $1.0 \leq$ & $1 \leq \ldots$ & خلال ممارسة النشية الجمالية للاداء من & $r r$ \\
\hline
\end{tabular}

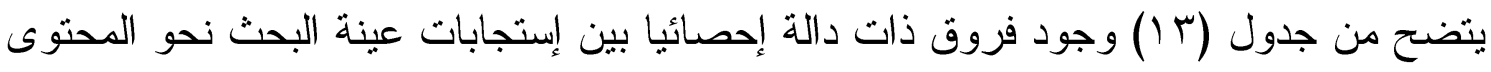

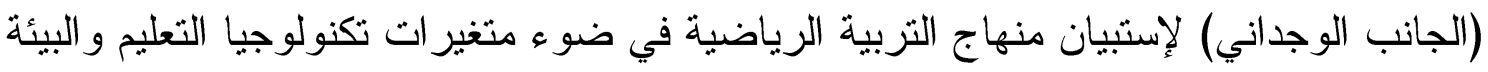

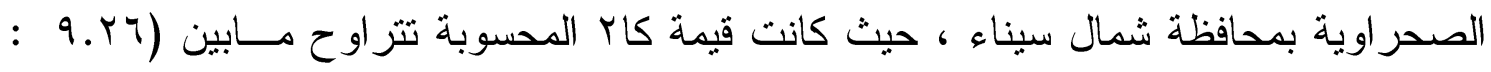

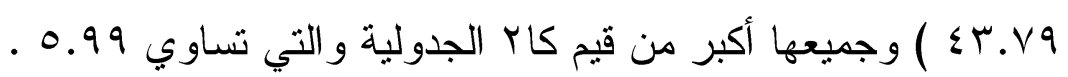

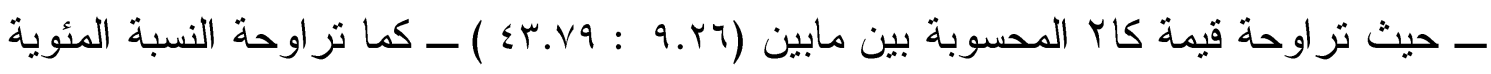
للاستجابة بمناسب ما بين ( (

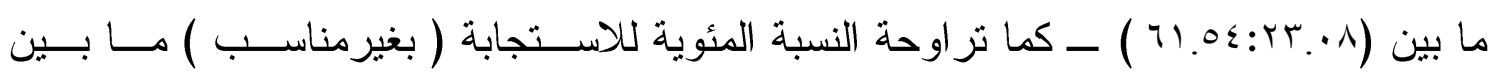

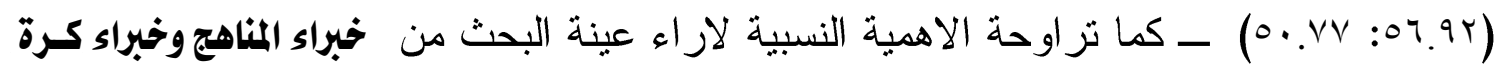

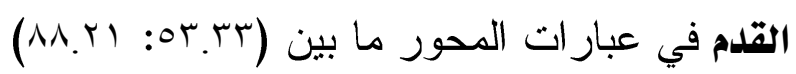

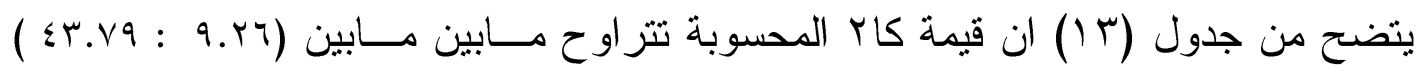

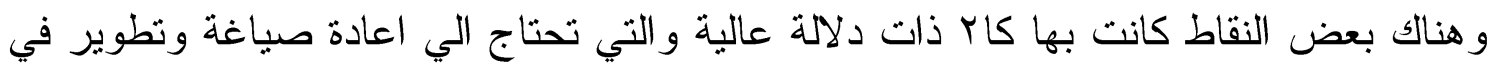

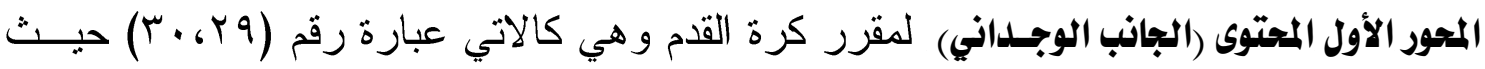

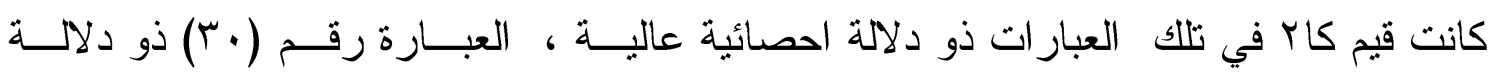

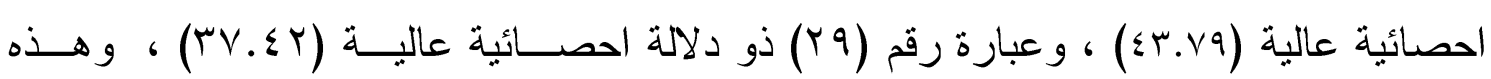

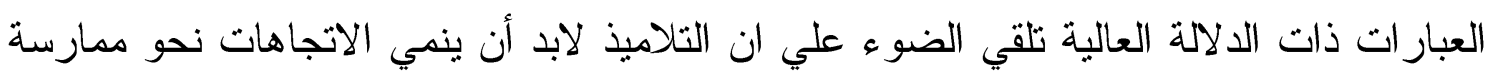

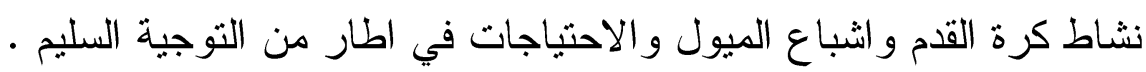

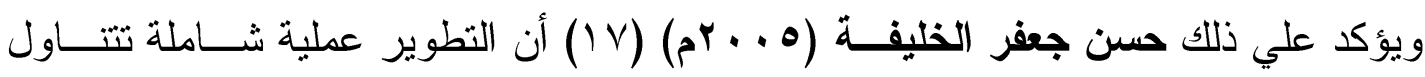

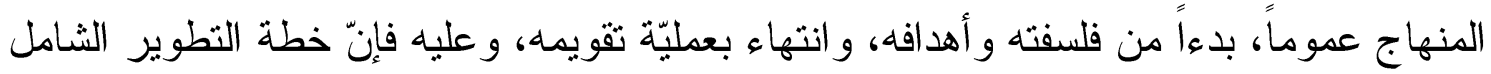

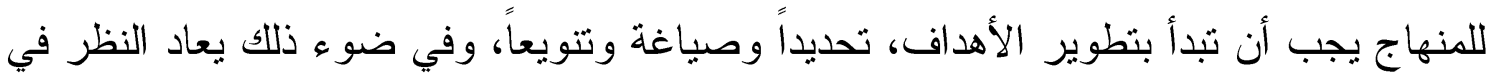
اختبار المحتوى، وأساليب تنظيمه. 


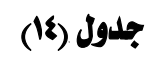

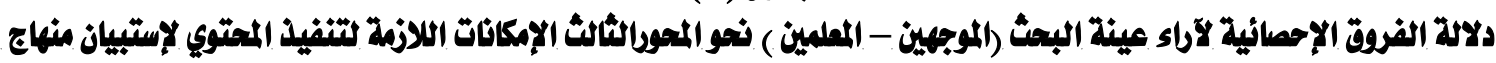

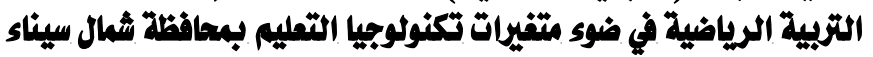

$70=\dot{j}$

\begin{tabular}{|c|c|c|c|c|c|c|c|c|c|c|}
\hline \multirow{3}{*}{ E: } & \multirow{3}{*}{ الأهمية } & \multirow{3}{*}{ SLr } & \multicolumn{6}{|c|}{ الإســتجابات } & \multirow{3}{*}{ العبـــارات } & \multirow{3}{*}{ p } \\
\hline & & & \multicolumn{2}{|c|}{ غير مناسب } & \multicolumn{2}{|c|}{ الى حـ ما } & \multicolumn{2}{|c|}{ مناسب } & & \\
\hline & & & $\%$ & ك & $\%$ & s & $\%$ & s & & \\
\hline$\varepsilon$ & $10.1 \mathrm{r}$ & $* r \cdot . \varepsilon$. & $v .79$ & o... & $r q . r r$ & $19 . \ldots$ & A... & $\leqslant 1 . \ldots$ & تناسب عدد الاجهزة والادوات مع عدد & 1 \\
\hline$r$ & $10.7 \varepsilon$ & $* r r . \wedge r$ & $9 . r T$ & $\neg . \cdots$ & $r \leqslant .7 r$ & $17 . \cdots$ & 77.10 & $\varepsilon r . \cdots$ & تتاسب مساحة الملعب مع كثافة الطلاب & $r$ \\
\hline 10 & $v \cdot . v v$ & *r.rA & $1 r . \wedge 0$ & $9 .$. & $9 .$. & rq... & $r 7.10$ & $1 V_{.}$. & 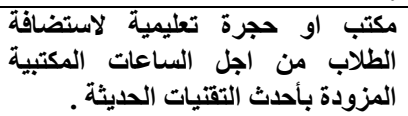 & $r$ \\
\hline 11 & $v 0.9$. & $* 1 . .00$ & $r \leqslant .7 r$ & $17 . \ldots$ & $r r . \wedge$ & $10 .$. & OY.r. & $r \varepsilon .$. & 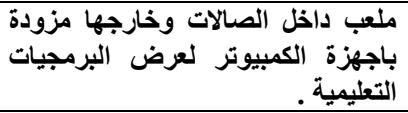 & $\varepsilon$ \\
\hline 17 & $\checkmark \Lambda . V r$ &.$\leqslant 9$ & rq.rr & $19 . \ldots$ & ro.ru & rr... & ro.ru & $r r . .$. & مكان مناسب لتنغييز الملابس تتوفر فيها & 。 \\
\hline 19 & $0 \wedge .9 \vee$ & $* V . \leqslant Y$ & $\varepsilon q . r r$ & rr... & $r \varepsilon .7 r$ & $17 .$. & $r 7.10$ & IV... & والاجهزة . مناسبة $\quad$ لتخزين الادوات & 7 \\
\hline 11 & $7 . . \cdots$ & $* 4.1 \mathrm{r}$ & $5 V .79$ & r... & $r \varepsilon .7 r$ & $17 . \cdots$ & $r v .79$ & $11 .$. & الملاعب المجززة . & $\mathrm{V}$ \\
\hline 1. & VV. 90 & $* 1 \leq . \wedge 9$ & $1 \cdot . v V$ & $v_{.}$. & $\varepsilon \varepsilon .7 r$ & rq... & $\varepsilon \varepsilon .7 r$ & rq... & توافر في المكتبة مراجع في منهاج كرة & $\wedge$ \\
\hline 0 & Ar.0q & *YO.rY & Q.rT & 7. $\cdots$ & $r \cdot . V V$ & $r \cdot . \cdot$ & $7 . . \cdots$ & rq... & عدد كافي من الادوات البديلة . . & 9 \\
\hline r & ง . . & $* \Delta r_{.} \cdot 9$ & $10 . r \mu$ & $1 \cdot \cdots$ & $9 . r r$ & ४. $\cdots$ & vo.rs & $\leqslant 9 . \cdots$ & التعليم . التوسائل السمعية والبصرية في & 1. \\
\hline 9 & $\vee \wedge . \leqslant 7$ & $* 1 r .4$. & 17.94 & $11 . \cdots$ & $r \cdot . v V$ & $r \cdot . \cdot$ & OY.ru & $r \varepsilon .$. & يراحلّ النمو ــ استخدام الوسائل التعليمية & 11 \\
\hline ir & $V \leq . r 4$ & $* 4.89$ & 11.57 & Ir... & $\varepsilon \cdot . \cdots$ & rч... & $\leqslant 1.0 \leqslant$ & $r v_{.} .$. & يربدأعي عند الفتخدام الوسائل التعليمية & ir \\
\hline
\end{tabular}

\section{تابع جدول (18)}

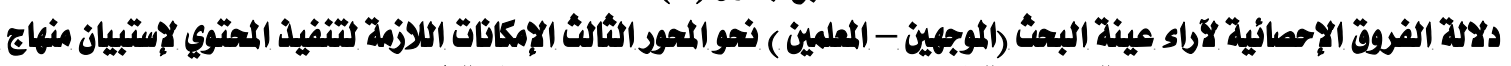

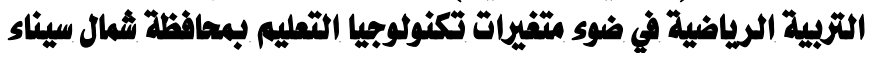

\begin{tabular}{|c|c|c|c|c|c|c|c|c|c|c|}
\hline \multirow{3}{*}{ E: } & \multirow{3}{*}{ الأهمية } & \multirow{3}{*}{ كاr } & \multicolumn{6}{|c|}{ الإســتجابات } & \multirow{3}{*}{ العبــارات } & \multirow{3}{*}{ s } \\
\hline & & & \multicolumn{2}{|c|}{ غير مناسب } & \multicolumn{2}{|c|}{ الى حـ ما } & \multicolumn{2}{|c|}{ مناسب } & & \\
\hline & & & $\%$ & s & $\%$ & s & $\%$ & ك & & \\
\hline$r \cdot$ & $0 \wedge . \leqslant 7$ & $* 4 . \varepsilon$ & $\leqslant V .79$ & $\mu_{1} . .$. & rq.r r & $19 .$. & $r r . \cdot \Lambda$ & $10 .$. & تلتاسب استخدام الوسائل التعليمية مع & ir \\
\hline 1 & $\wedge \wedge . \vee \mathrm{r}$ & $* \leqslant 9.1 \leqslant$ & $\vee .79$ & $0 . \cdots$ & 11.87 & $1 r_{.} \cdot$ & $\vee r . \wedge 0$ & $\varepsilon \wedge . \cdots$ & يتناسب عدد المعلمين مع اعداد الطلاب & $1 \leqslant$ \\
\hline $1 \varepsilon$ & VI. rA & $* r \cdot . r \varepsilon$ & ir.so & 9.. & $0 \wedge . \leqslant 4$ & rı... & rv. 79 & $1 \wedge . \cdots$ & وتوافر مدريس كرة متخصصين في المناهج & 10 \\
\hline$\bullet$ & $\wedge r . \Delta q$ & *Y५. 4 & $1 \cdot . v V$ & $v_{.} .$. & $r v .79$ & $1 \wedge . \cdots$ & $71.0 \leq$ & $\varepsilon \cdot \cdots$ & توافر معلمين متخصصين في كرة القدم & 17 \\
\hline ir & $v \leq . r q$ & *rr.Ar & 7.10 & $\{. \cdots$ & Tะ.ד & $\varepsilon r . \cdots$ & rq. rr & $19 . \ldots$ & وتوافز عمال وفنيين لصياتة الملعب & iv \\
\hline iv & $71.0 \leq$ & $\varepsilon . \iota_{\Lambda}$ & r..9r & $r \leqslant . \cdots$ & $\leqslant 1.0 \leqslant$ & $r v_{.} \ldots$ & Y1.0 & $1 \varepsilon \ldots$ & تصلحة ارضية الملاعب لممارسة & 11 \\
\hline YI & 07.94 & $* \Lambda . \Delta r$ & $\varepsilon q . r r$ & r.... & $r \cdot . v V$ & $r \cdot .$. & $r \cdot$. & ir... & تنفيذاجد لجناهج الدراسية متخصصة لمتابعة & 19 \\
\hline$v$ & $\vee \wedge . q \vee$ & $* 1 r . r r$ & $10 . \mathrm{r}$ & $1, \cdots$ & r.r.ri & r... & Or.r. & $r \varepsilon .$. & 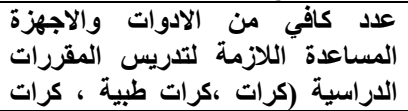 & $r$. \\
\hline
\end{tabular}




\begin{tabular}{|c|c|c|c|c|c|c|c|c|c|c|}
\hline & & & & & & & & & ناعمة) & \\
\hline $\mathrm{V}$ & $\vee \wedge .9 \vee$ & $* 1 Y . \leqslant Y$ & $1 \pi . \wedge 0$ & $9 . \cdots$ & $r 0 . r \Lambda$ & rT... & $0 . . \mathrm{VV}$ & rr... & افلام تعليميةٌ للمهارات الاساسيةٌ . & rI \\
\hline YI & 07.94 & $* 9.49$ & $0 . . V V$ & rr... & PV.79 & $1 \Lambda_{.} .$. & Y.0 & $1 \leqslant .$. & والمحلية للمباريات والبطولات الدولية & rY \\
\hline
\end{tabular}

يتضح من جدول (ع () وجود فروق ذات دالة إحصائيا بين إستجابات عينة البحث نحسو

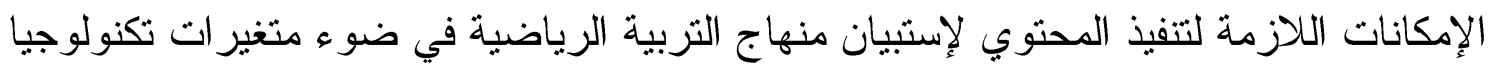

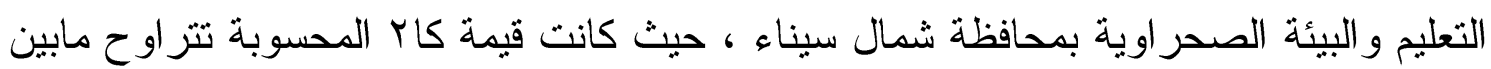

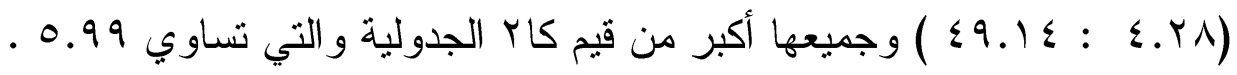

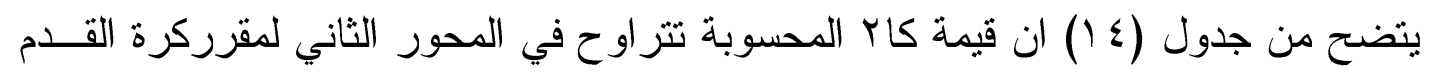

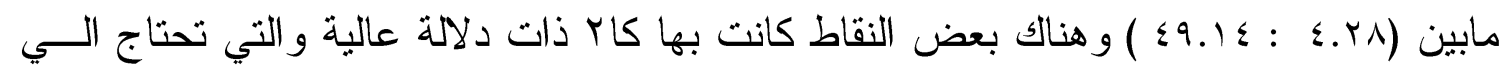

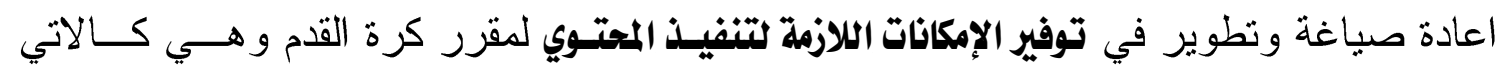

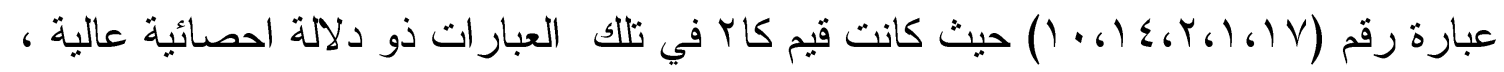

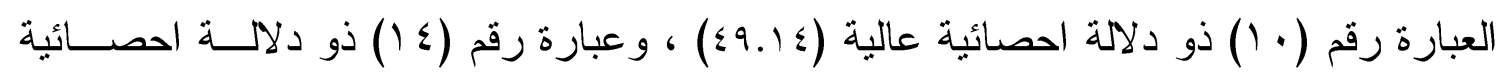

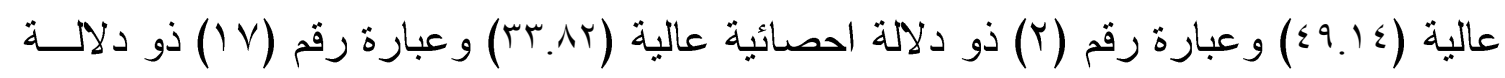

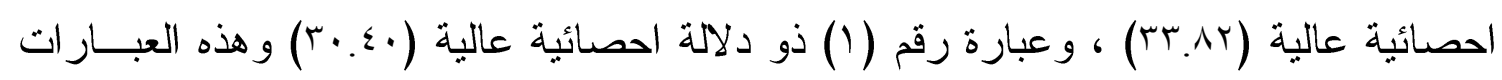

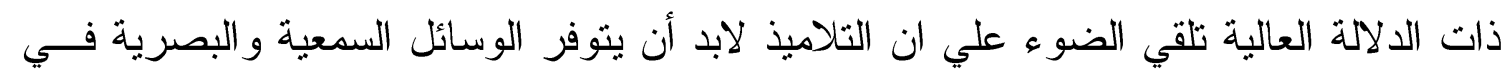

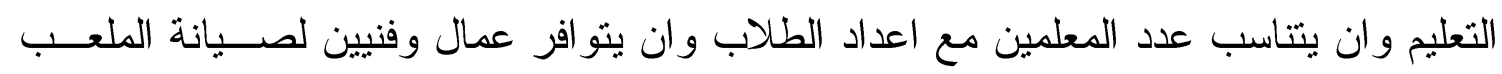

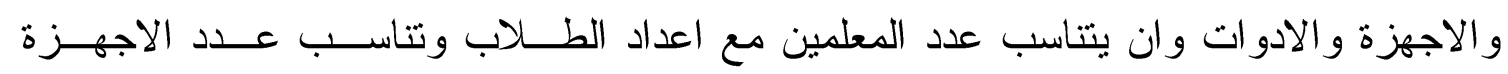

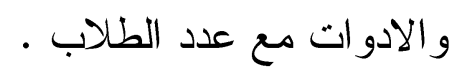

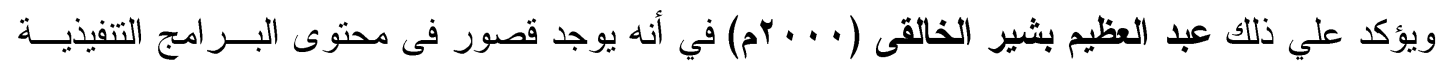

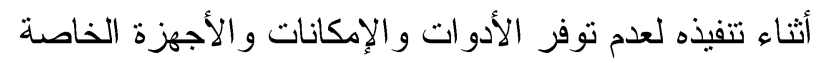

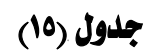

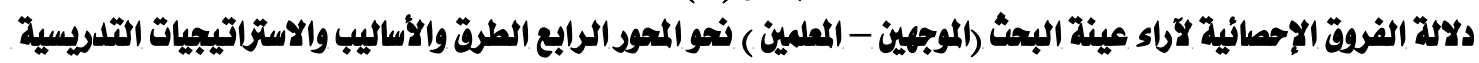

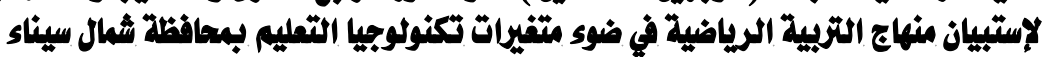

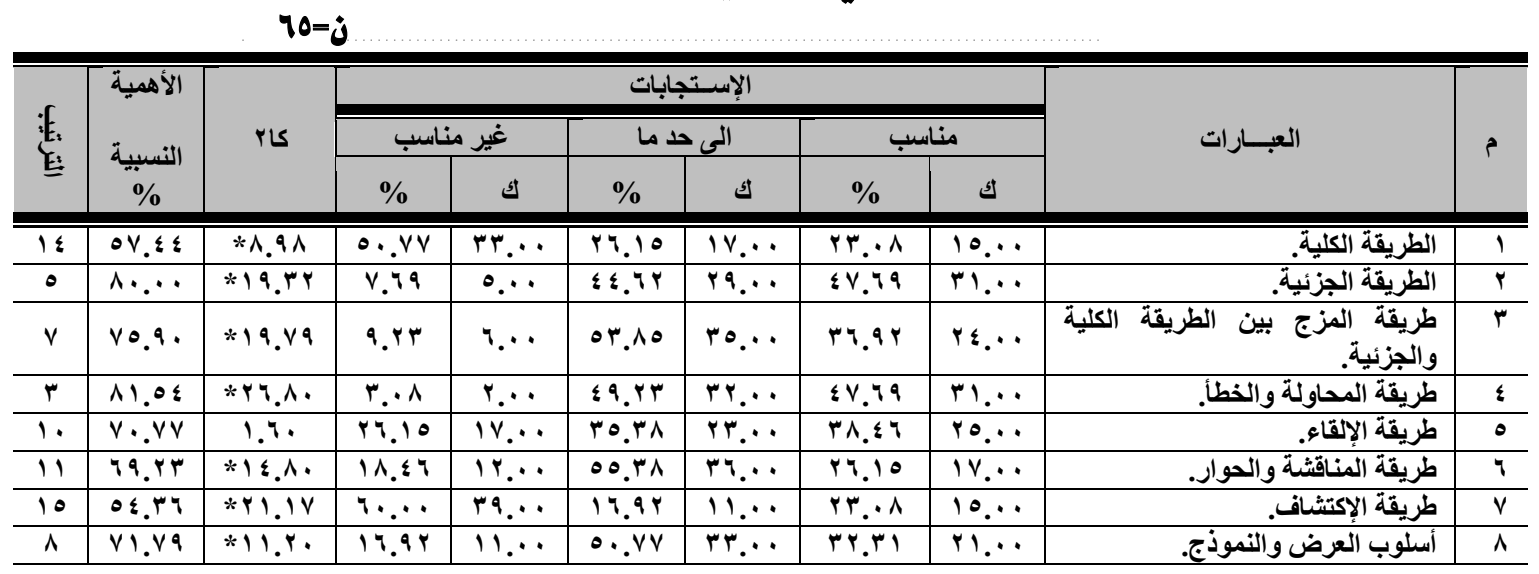




\begin{tabular}{|c|c|c|c|c|c|c|c|c|c|c|}
\hline$\varepsilon$ & $11 . \cdot r$ & $* 11 . \wedge 4$ & $9 . r 4$ & $7 . \cdots$ & $r \Lambda . \leqslant 4$ & ro... & OY.rI & $r \varepsilon . .$. & الرسوم والأشكال التوضيحية. & 9 \\
\hline r & $\Lambda \varepsilon .1$. & *Yq.V० & TY.rI & $\Lambda_{.} \cdot \cdot$ & $r T . \cdot \Lambda$ & $10 .$. & $7 \varepsilon .7 Y$ & $\left\{Y_{.} . \cdots\right.$ & التعليم من خلال مواقف اللعب. & 1. \\
\hline ir & $7 \Lambda . Y 1$ & $* 1 \wedge .71$ & $11 . \leqslant 7$ & IY... & $0 \wedge . \leqslant 7$ & $r \Lambda_{.} \cdot$. & $r r . \cdot \Lambda$ & $10 . \cdots$ & التتريس المصغز. & 11 \\
\hline 17 & $\leqslant v .79$ & $*$ * I.va & $74 . \cdot 1$ & $\leqslant 1 . \cdots$ & $r \cdot . V V$ & $r \cdot \ldots$ & 7.10 & £.. & أسلوب توجيه الأقرّان. & ir \\
\hline $\mathrm{v}$ & Vo.9. & *rr.ro & \&.Tr & r... & $4 \pi .+1$ & $\$ 1 .$. & ru.r. & r1... & أسلوب التّريس بالأهداف. & it \\
\hline 7 & $V 7.94$ & $* 11 . r$. & $1 \% . \wedge 0$ & $9 . \cdots$ & $\leqslant 1.0 \leqslant$ & rV... & $\varepsilon \leqslant .7 Y$ & rq... & التعليم المبرمج. & $1 \leqslant$ \\
\hline 1 & 14.10 & $* \leqslant 1.4$. & IY.MI & ^... & 17.94 & $11 .$. & $V \cdot . V V$ & $\varepsilon 7 . \cdots$ & أسلوب التعليم التعاوني. & 10 \\
\hline 14 & $9 \cdot \ldots$ & \&.Ar & $\$ 7.10$ & $r \cdot \ldots$ & rV.79 & $1 \Lambda_{0} \cdots$ & $r 7.10$ & IV... & أسلوب التعلم الذاتي. & 17 \\
\hline
\end{tabular}

يتضح من جدول (0) وجود فروق ذات دالة إحصائيا بين إستجابات عينة البحث نحو الطرق

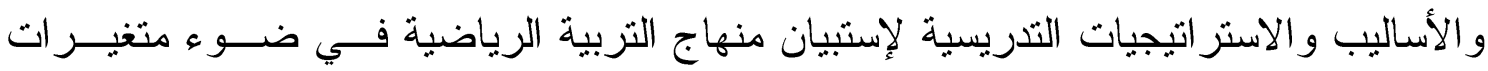

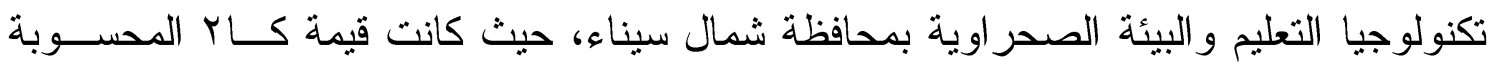

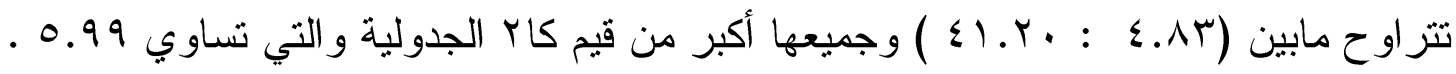
يتضح من جدول (0 1) ان قيمة كاr المحسوبة ثتراوح في المحور الثالث لمقرركرة القـدم

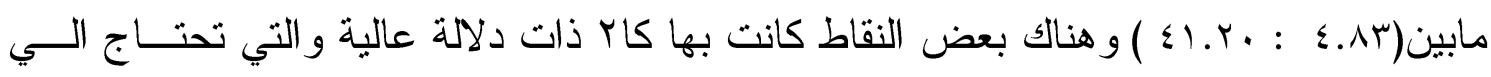
اعادة صياغة وتطوير في اختبارالطرق والأساليب والاستراتيجيات التدريسية لتسريس مقرر كرة القدم

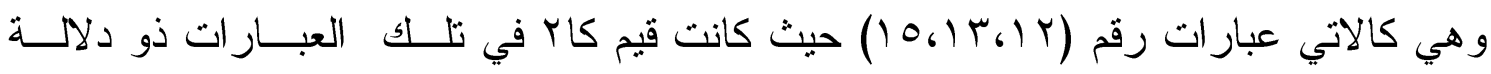

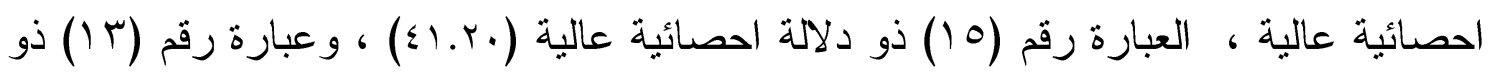

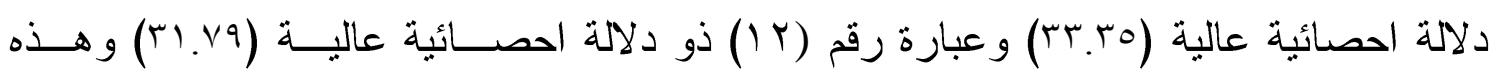

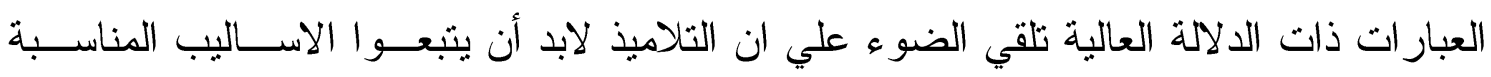
لتدريس مقرر كرة القدم التي يتبعها المعلم لمساعدة التلاميذ علي تحقيق الهدف ونجد ان اتبــاع

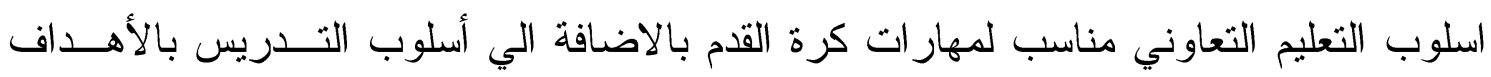
و اسلوب توجية الاقران فانها تعطي الفرصة للتلاميذ للوصول الي الاهداف في تعليم مهـار ات كرة القدم وكل هذه الطرق تعمل علي اتقان وتثبيث الشكل النهائي للمهار ات حتي نصـلـل الـي لـي الاهداف المقررة .

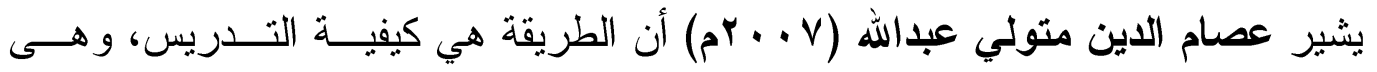
مختلفة بإختلاف المادة التعليمية، و الموقف التعليمي، و لا شك أن فعالية ما ندرسه و أثره يتوقفان إلى حد كبير على الطريقة أو الكيفية التي ندرس بها وفى نفس الوقت فإن نوع الخبــرة التـي ولتي نقدمها تفرض على المدرس اختيار طر ائق وأساليب تدريسية معينة، فلكل نــوع مــن التعلــيم

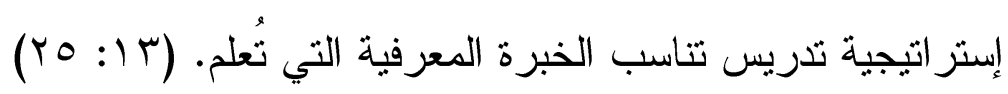

وتشير سامية فرغلي ونادية محمد عبد القادر(r . . r م)أن طر ائق التدريس هى الخطة المسبقة التى يضعها المعلم وهى أسلوبه فى معالجة النشاط التعليمى مع تلاميذه لتحقيق أكبر قدر 


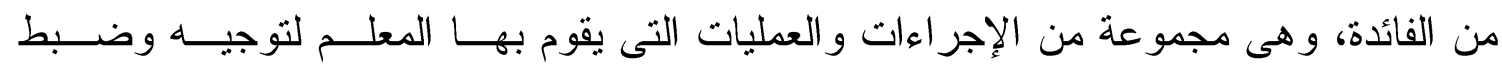

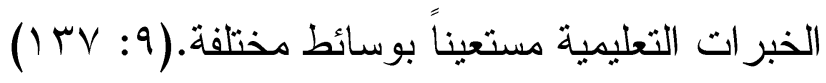

\section{جدول (17)}

\section{دلالة الفروق الإمصائية لآراء عينة البهث (الموجمين - الاملمين ) نهو المهورالثامس أساليب التقويم لإستييان منهاج التربية الرياضية في

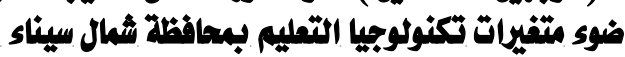

$10=\dot{j}$

\begin{tabular}{|c|c|c|c|c|c|c|c|c|c|c|}
\hline \multirow{3}{*}{ 证 } & \multirow{3}{*}{ الأهمية } & \multirow{3}{*}{ SL } & \multicolumn{6}{|c|}{ الإســتجابات } & \multirow{3}{*}{ العبــارات } & \multirow{3}{*}{ b } \\
\hline & & & \multicolumn{2}{|c|}{ غير مناسب } & \multicolumn{2}{|c|}{ الى حـ ما } & \multicolumn{2}{|c|}{ مناسب } & & \\
\hline & & & $\%$ & ك & $\%$ & ك & $\%$ & s & & \\
\hline$r$ & $\Lambda \varepsilon .7 Y$ & $* Y \wedge .10$ & \&.7r & r... & rq.9r & $r \varepsilon . .$. & $0 \wedge . \leqslant 7$ & $r \Lambda_{.} .$. & ملاحظة سلوك الطالب و أداءة العملي. & 1 \\
\hline$\wedge$ & 79.84 & $* 19.0$ & 17.94 & $11 . \cdots$ & $0 \wedge . \leqslant 4$ & rı... & $r \leqslant .7 r$ & $17 . \cdots$ & الإلبنتبارات البدنية لقياس الصفات & $r$ \\
\hline ir & $0 v .90$ & $* 4 . \wedge 4$ & $\varepsilon v .79$ & $r . .$. & $r \cdot . v V$ & $r \cdot \cdots$ & T1.0 & $1 \leq \ldots$ & الأشتبطة. المهارات الحركية لمختلف & $r$ \\
\hline $\mathrm{v}$ & $v \cdot . v V$ & $* 1 \vee . \vee 0$ & $10 . r \Lambda$ & $1 \cdot \ldots$ & 04.94 & $r v .$. & YV.79 & $11 . \cdots$ & 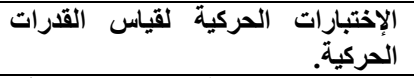 & $\varepsilon$ \\
\hline 1 & A9.Y & $* \leftleftarrows १ . \wedge \wedge$ & 7.10 & $\varepsilon . \cdots$ & $r \cdot \ldots$ & 1r... & $\vee r . \wedge 0$ & $\varepsilon \Lambda_{.}$. & 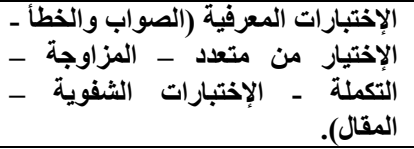 & 0 \\
\hline 1 & $\vee 1 . \vee q$ & r.rs & r..10 & $1 v_{.} \cdots$ & TY.M & $r 1 . \cdots$ & $\leqslant 1.0 \leqslant$ & $r v .$. & 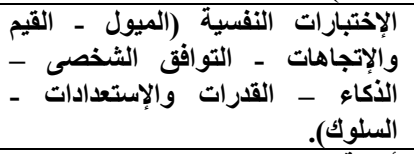 & 1 \\
\hline 17 & $\leq \vee .79$ & $* \mu \Lambda_{.} \cdot 1$ & 79.54 & $\leqslant 0 .$. & $11 . \leqslant 4$ & IY... & IY.M & ^... & أسئلة المشكلات. & $\mathrm{v}$ \\
\hline 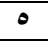 & $v 0.9$. & *Yr.VO & 8.79 & $0 . \cdots$ & 09.94 & $r v . .$. & ro.rn & rr... & التقويم القبلي. & $\Lambda$ \\
\hline 10 & $0 . . \mathrm{VV}$ & *YY.OD & $00 . r \Lambda$ & r... & r..9r & $r \varepsilon .$. & 8.79 & $0 . \cdots$ & التقويم البنائى والتكويني. & 9 \\
\hline 11 & 94.09 & $* 1 V .11$ & $r 7.10$ & IV... & 09.94 & rv... & 17.94 & $11 .$. & التقويم الختامى النهائي. & 1. \\
\hline $1 \varepsilon$ & 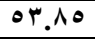 & $* Y \cdot . \wedge q$ & $7 \cdot \cdots$ & rq... & $11 . \leqslant 7$ & IY... & r1.0\& & $1 \varepsilon .$. & تقويم الأقران. & 11 \\
\hline 9 & $7 \varepsilon .74$ & $\varepsilon .9$ & $r \cdot . v V$ & $r \cdot \cdots$ & $\varepsilon \varepsilon .7 r$ & rq... & $r \varepsilon .7 r$ & $17 . \cdots$ & التقاريز الشخصية. & ir \\
\hline 1. & $7 \leqslant .1$ & *Yq.Y. & Y1.0 & $1 \leq .$. & $7 \varepsilon .74$ & $\varepsilon Y_{.} \ldots$ & $11 . \wedge 0$ & $9 . \cdots$ & ينفذ التقويم فى نهاية الدرس. & 14 \\
\hline 11 & 94.09 & $* 14.1 \leq$ & rV.79 & $11 . \cdots$ & or.Ao & ro... & 11.87 & IY... & ينفذ التقويم فى نهاية كل وحدة. & $1 \varepsilon$ \\
\hline$r$ & $\Lambda r . \cdot \Lambda$ & $*$ * 0.7. & $\varepsilon .7 r$ & r... & $\leqslant 1.0 \leqslant$ & $r v . .$. & or.Ao & ro... & ينفذ التقويم فى نهاية الفصل الدراسي. & 10 \\
\hline$\varepsilon$ & $\vee \wedge . \leqslant 4$ & $* 1 \leqslant .99$ & $1 \cdot . \mathrm{VV}$ & $v_{.} . \cdot$ & $\varepsilon r . \cdot \Lambda$ & $r \Lambda_{.} \cdot \cdot$ & $\leqslant 7.10$ & $r \cdot . . \cdot$ & ينفذ التقويم فى نهاية العام الاراسي . & 17 \\
\hline
\end{tabular}

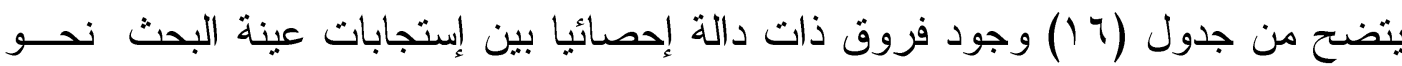

أساليب التقويم لإستبيان منهاج التربية الرياضية في ضوء متغير ات تكنولوجيا التعلــيم و البيأسـة

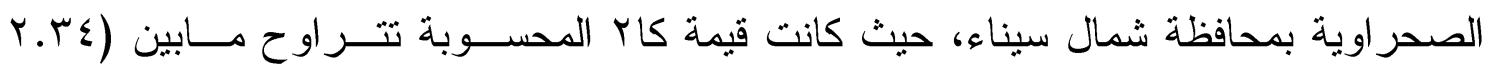

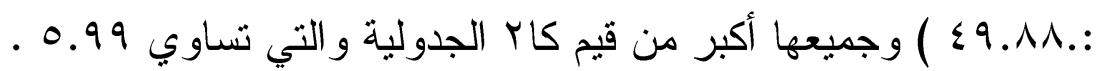

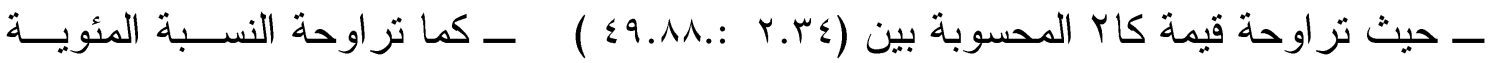

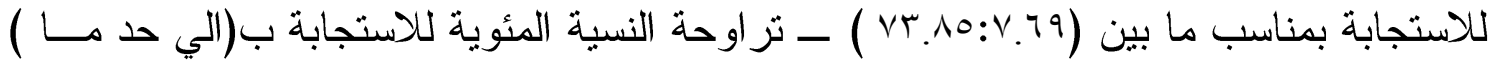

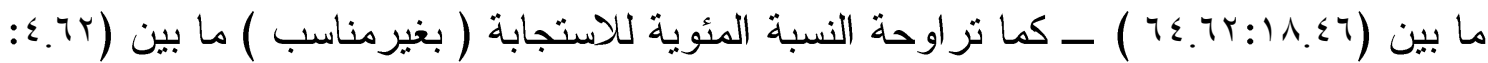


ــ كما تراوحة الاهمية النسبية لار اء عينة البحث من خبراء المناهج وخبراء كرة القـلم في عبارات

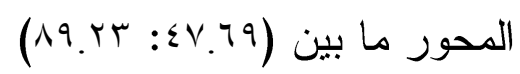

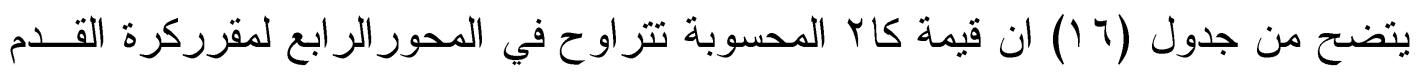

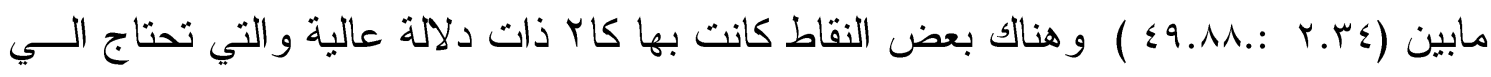

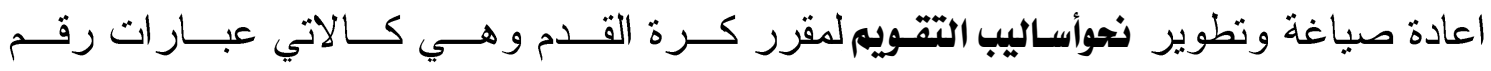

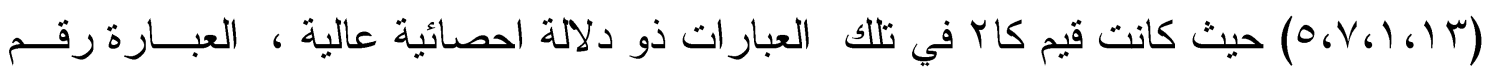

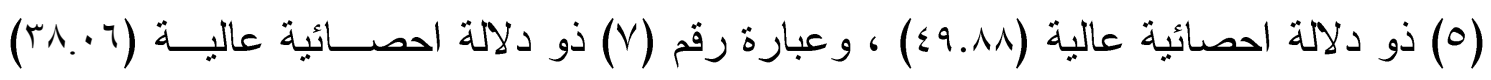

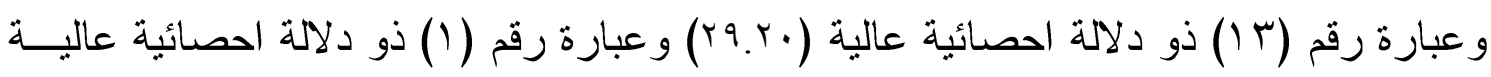

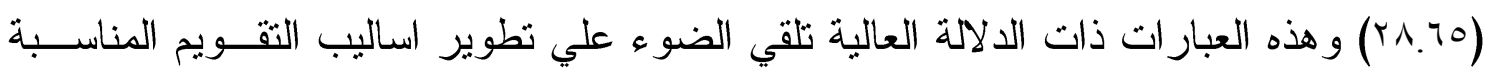

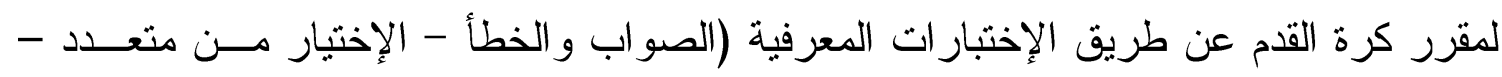

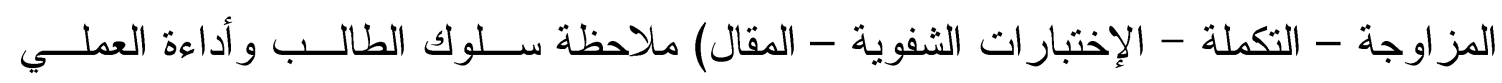
وتقويمة في نهاية الفصل الدراسى بصورة دورية حيث يساعد كلا من مخططي ومنفذي المنهج علي اتخاذ قرارات موضوعية نحو تعديل وتطوير المنهج او المقرر الحالي .

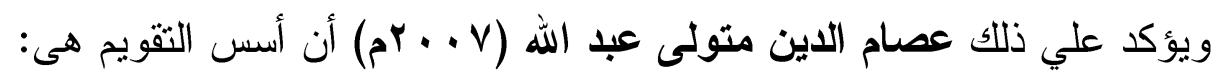

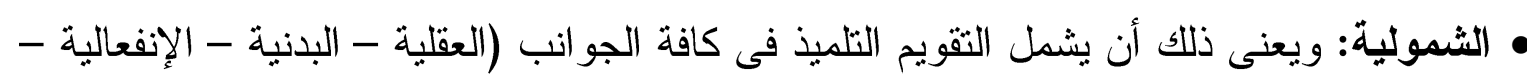

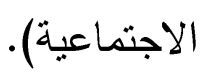
• الاستمرارية: حيث يجب أن يسير مع العملية التعليمية من البداية إلى النهاية وهى من الأسـس المدعمة للثبات و الثمول و التعاون. ه التكامل: حيث يجب أن يتم التكامل بين الوسائل المختلفة فى التقويم وعملية التنريس وبين النظم

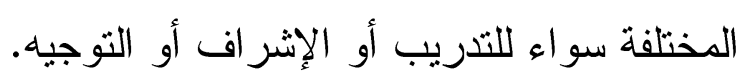

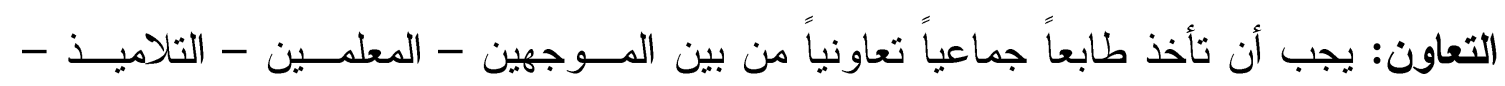

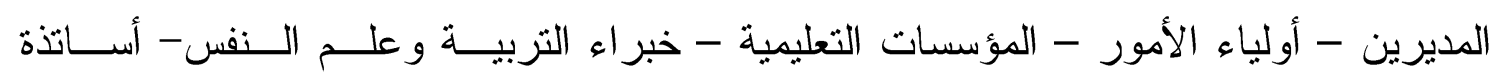
الجامعات. • التناسق والأهداف: من الواجب أن يكون هناك تتاسق بين مفهوم المنهاج و أهدافه و عملية التقويم

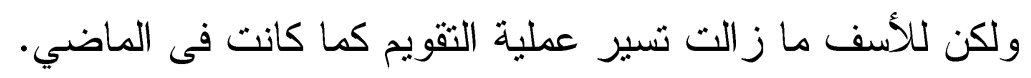

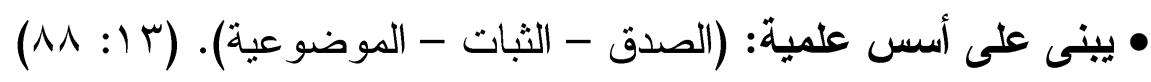




\section{الإستخلاصات والتوصيات: الإسات \\ أوالاً: الإستخلاصات: الماتوصيات}

• • المنهاج المقتر ح مناسب للمرحلة الاعدادية.

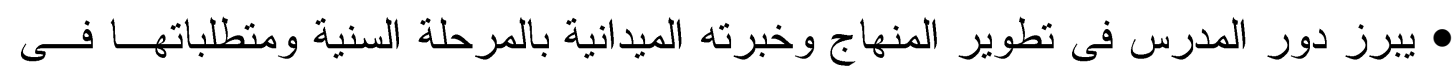
تطوير المنهاج.

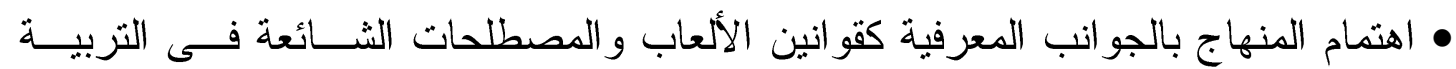

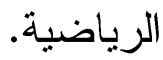
المحور الأول: الأهداف: - الف:

• شمول الأهداف العامة على ما ينطلبه تلاميذ المرحلة الاعدادية و إرتباطها بتعاليم المنهج . • الإهتمام بالجو انب الوجدانية و المعرفية و النفس حركية. المحور الثاني: المحتوى: - المان

• المحتوى مثتوع ومناسب لكافة الإمكانات المتاحسـة و اســـتخدام أدوات بديلـــة ومســاحات متنو عة.

• الإهتمام بالثقافة الرياضية و اللباقة البدنبة وبر امج الإنحر افات القو امية و الأنشطة المتنوعــة

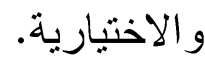

• وضع بر امج لذوى الإحتياجات الخاصة تتاسبهم ومشاركتهر مع الأسوياء كلما أمكن ذلك. المحور الثالث: طر ائق و أساليب التدريس:

• طر ائق و أساليب التدريس مناسبة لتنو عها و المنهاج يقبل الأساليب الحديثة فى التعليم. • للمعلم حرية اختيار طريقة التدريس المناسبة للتعليم. المحور الر ابع: أساليب التقويم:

• أساليب الثقويم مناسبة للأنشطة المختارة وتتميز بتنوعها و اعطائها نتائج أكثر دقة وتكثف نقاط القوة و الضعف وذللك لنطوير الأداء. ثُانياً: التوصييات:

1- نشر وتطبيق المنهاج المقترح على تلاميذ المرحلة الاعدادية. r- زيادة حصص التربية الرياضية بالجدول الدراسى ودعم ميز انية التربية الرياضية.

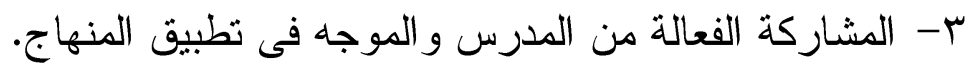
ع- تفعيل الدورات التدريبية للمعلمين والموجهين حتى يواكبوا كل جديد ومنطور للتربية

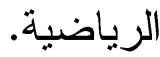


0- في الوحدة الإختيارية يتم فيها اختيار أى لعبة مناسبة لإمكانيات المدرسة المتاحة، ورغبات و استعدادات التلاميذ.

צ- تقويم المنهاج بعد مرور ثلاث سنوات من تطبيقة لمعرفة نواحى القصور ومعالجنها. V- إعطاء المعلومات الرياضية والصحية فى طابور الصباح و التوعية على أهية التربية الرياضية لزيادة الوعى الثقافى للتناميذ و المجتمع المحيط بالمدرسة.

\section{المراجع:}

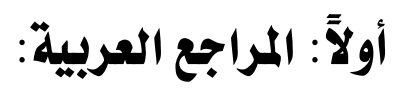

ا. أبو النجا أحمد عز الدين (. . . rم): الإتجاهات الحديثة فى طرق تدريس التربية الرياضية، مكتبة شجرة الدر، المنصورة.

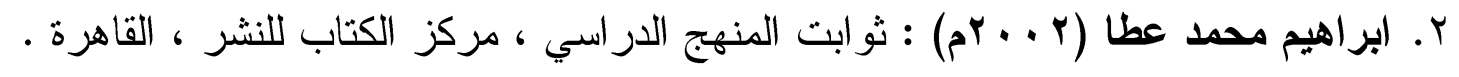

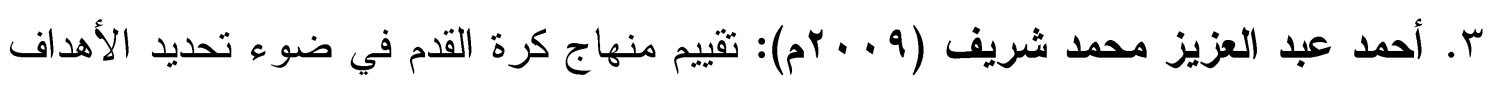

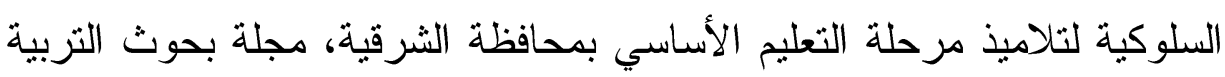

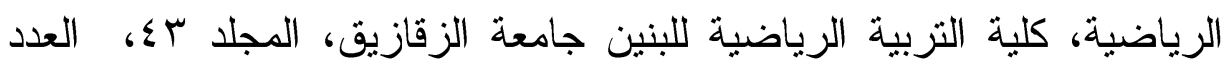

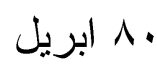

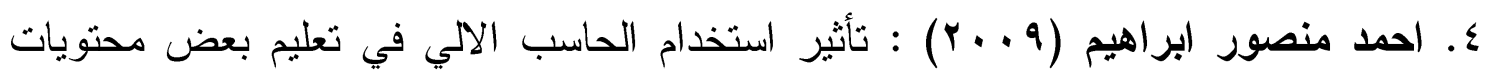

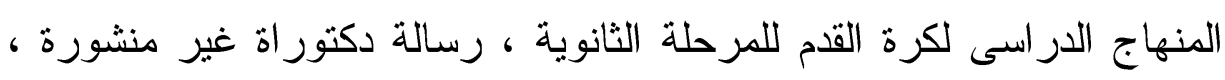
كلية التربية الرياضية بنين ، جامعة الزقازيق ل ه. أسامة كامل راتب وإبراهيم عبدربة خليفة (ه . . بم): النمو و الدافعية، دار الفكر العربي، القاهرة.

T. أثرف محمد رأفت عبدالله (11 • بم): تطوير منهاج التربية الرياضية لمرحلة الإعدادي

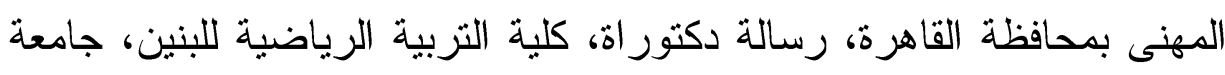

$$
\text { بنها. }
$$

V. الدليل التعليمي لمنهج التربية البلنية فى مراحل التعليم العام (1 + .rم): وزارة المعارف، مركز التطوير التربوي، الرياض.

^. أمين أنور الخولى وجمال الدين الثافعي ( ... . . م): مناهج التربية البدنية المعاصرة، دار

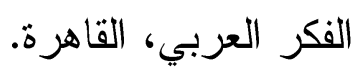


9. أمين أنور الخولى وجمال الاين الثافعي (ه . . rم): مناهج التربية البدنية المعاصرة، الطبعة الثانية، دار الفكر العربي، القاهرة.

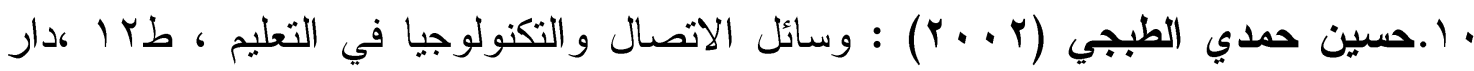
القلم ، الكويت .

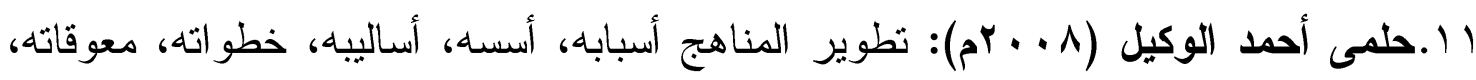
دار الفكر العربي، القاهزة.

r ا.حلمى أحمد الوكيل (999 ام): تطوير المناهج ، دار الفكر العربي ، القاهرة .

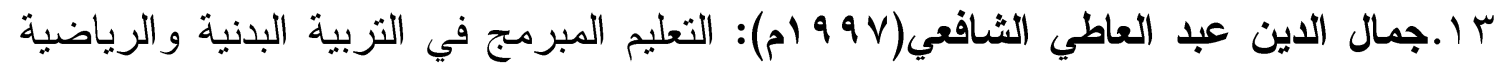
كار الفكر العربي ، القاهرة .

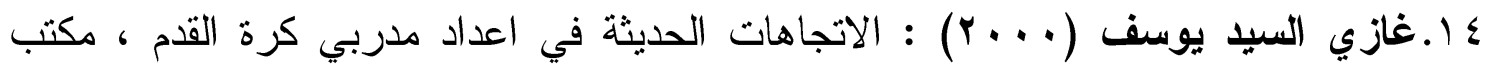

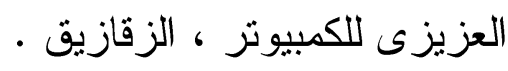

10.فؤادة سليمان قلادة (ه . . rم) : اسس تخطيط المنهاج وبناء سلوك الانسان في التعليم

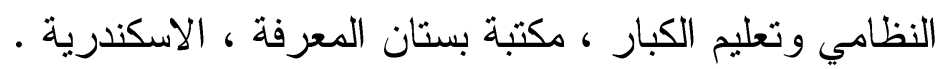

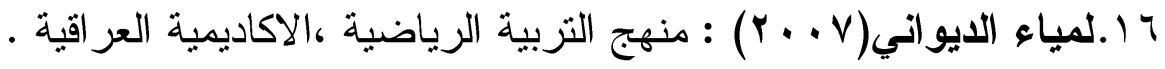

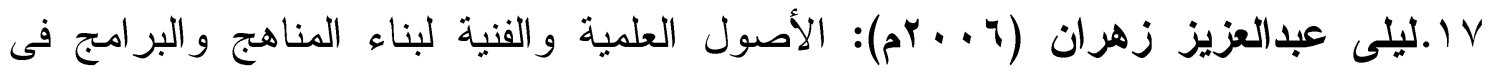
التربية الرياضية، دار زهران للنشر و التوزيع، القاهرة.

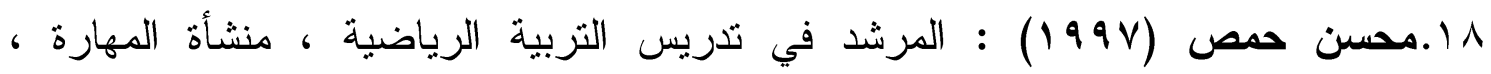
بالاسكندرية

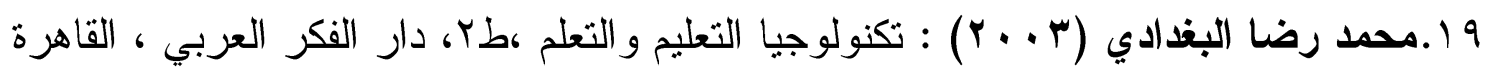
•.r.r.

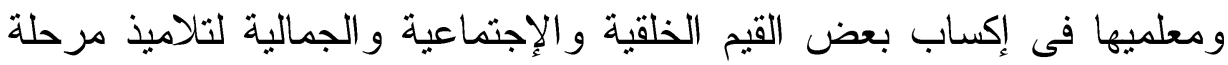
الثانوى العام بجمهورية مصر العربية، رسالة ماجستير، كلية التربية الرياضية،

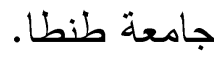




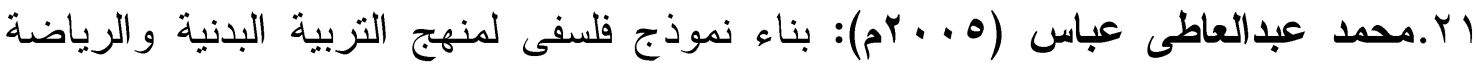

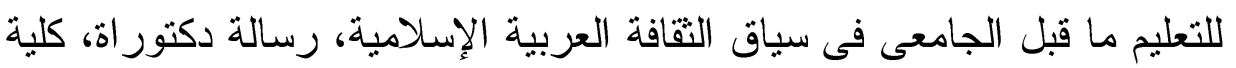
التربية الرياضية للبنين بالهرم، جامعة حلوان.

r Y.محمد محمود محمد أحمد (r I • Yم): دراسة تحليلية لمنهاج التربية الرياضية لطلبة المرحلة

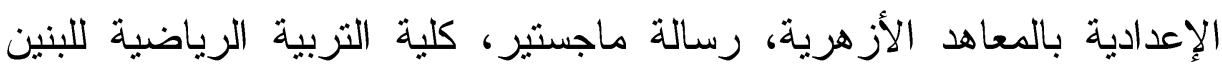

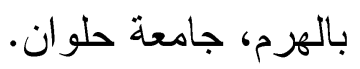

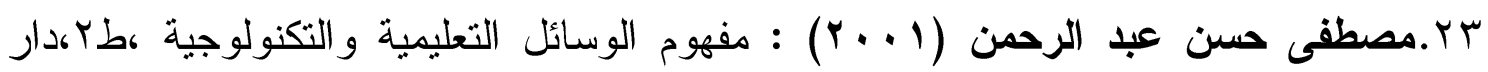

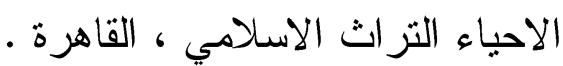

؟Y.مصطفي عبد السميع محمد (999 (م) : تكنولوجيا التعليم ـ دراسات عربية ، مركز

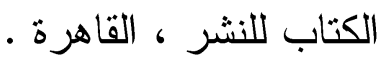

0Y.مصطفى محمد جمعة (؟ . rم): دور البيئة في تتفيذ مناهج التربية الرياضية بالحلقة الثانية من التعليم الأساسي بمحافظة أسوان، رسالة ماجستير، كلية التربية الرياضية

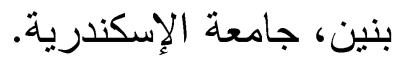

بr.مكارم حلمي ابو هرجة (. . . rم) :مشكلات مناهج التربية الرياضية ، مركز الكتاب للنشر

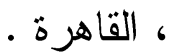

\section{ثَانياً: المراجع الأجنيبة:}

rv. Johns. Davide: Chaning the Hong Kong Physical Education curriculum: A post - strural case $(\varepsilon)$ december $\varepsilon$ p $r \varepsilon 0$ -

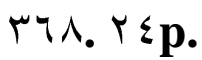

ץ^. Tittel, K Watcher, H. (1990): Analyzing Study for Curriculum Physical Education in Elementary School, Stuuttgrat, leipzing. 